\title{
Templated Synthesis of Interlocked Molecules
}

Fabio Aricó · Jovica D. Badjic · Stuart J. Cantrill • Amar H. Flood · Ken C.-F. Leung $\cdot$ Yi Liu $\cdot$ J. Fraser Stoddart $(\bowtie)$

California NanoSystems Institute and Department of Chemistry and Biochemistry, University of California, Los Angeles, 405 Hilgard Avenue, Los Angeles, CA 90095, USA fabio@chem.ucla.edu, jovica@chem.ucla.edu, cantrill@chem.ucla.edu, amarf@chem.ucla.edu, cfleung@chem.ucla.edu,yliu@chem.ucla.edu, stoddart@chem.ucla.edu

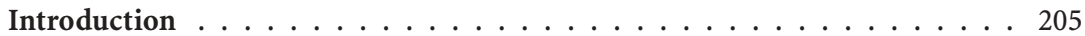

2 Kinetic Approaches to the Synthesis of Interlocked Molecules . . . . . . . . . 209

2.1 Transition Metal Templates . . . . . . . . . . . . . . . . . . . . . . . 209

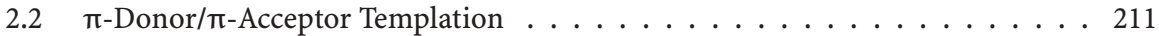

2.2 .1 Charged Templates . . . . . . . . . . . . . . . . . . 211

2.2 .2 Neutral Templates . . . . . . . . . . . . . . . . . . . . . . 213

2.3 Hydrogen Bond Templation . . . . . . . . . . . . . . . . . . 214

2.3 .1 Amide Templates . . . . . . . . . . . . . . . . . . . . . . . . 214

2.3 .2 Ammonium Ion Templates . . . . . . . . . . . . . . . . . 216

2.3 .3 Anion Templates . . . . . . . . . . . . . . . . . . . . . 218

2.3.4 Dipyridiniumethane Templates . . . . . . . . . . . . . . . . 218

2.4 Summary . . . . . . . . . . . . . . . . . . . 218

3 Thermodynamic Approaches to the Synthesis of Interlocked Molecules _ . . 221

3.1 Introduction . . . . . . . . . . . . . . . . . . 221

3.2 Synthesis of Interlocked Molecules by Slippage . . . . . . . . . . . . . . . . 221

3.3 Ring-Closing Metathesis Mediated Syntheses . . . . . . . . . . . . . . 223

3.4 Ammonium Ion Templated Syntheses . . . . . . . . . . . . . . . . . 225

3.5 Disulfide-Based Systems ． . . . . . . . . . . . . . . . . . . . 233

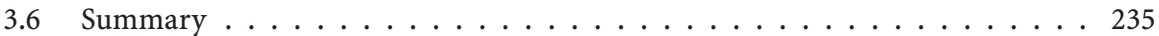

4 Multivalency and Interlocked Molecules . . . . . . . . . . . . . 236

5 Templating the Future of Technology f . . . . . . . . . . . . . . . . . . 243

5.1 Molecular Switching . . . . . . . . . . . . . . . . . . . . . . 243

5.2 Surface Switching . . . . . . . . . . . . . . . . . . . . . 246

5.3 Molecular Electronics . . . . . . . . . . . . . . . . . . . . . . . . 248

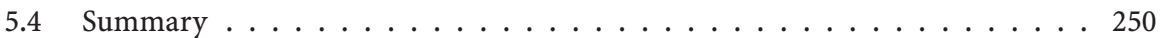

6 Conclusions and Perspectives . . . . . . . . . . . . . . . 251

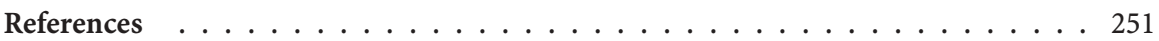


Abstract Mechanically interlocked molecular compounds can be synthesized in high yields by using template-directed assistance to covalent synthesis. Catenanes and rotaxanes are two classes of mechanically interlocked molecules that have been prepared using a variety of methods such as "clipping", "slipping", and "threading-followed-by-stoppering", under both kinetic and thermodynamic regimes. These different methods have utilized a range of templates such as transistion metals, $\pi$-donor/ $\pi$-acceptors, and hydrogen-bonding motifs. Multivalency has emerged as another tool to aid and abet the supramolecularly assisted synthesis of mechanically interlocked molecules. Recent advances in our understanding of the nature of the mechanical bond has led to the construction of molecular machines with controllable motions that have, in one instance, been introduced into molecular electronic devices.

Keywords Catenanes - Dynamic chemistry · Molecular machines · Multivalency · Rotaxanes

$\begin{array}{ll}\text { Abbreviations and Symbols } \\ \text { B24C8 } & \text { Benzo[24]crown-8 } \\ \text { BIPY }{ }^{+} & \text {4,4'-Bipyridinium } \\ \text { BN24C8 } & \text { Benzo-2,3-naphtho[24]crown-8 } \\ \text { Bu } & \text { Butyl } \\ \text { 24C8 } & \text { [24]Crown-8 } \\ \text { CBPQT }^{4+} & \text { Cyclobis(paraquat-p-phenylene) } \\ \text { CT } & \text { Charge-transfer } \\ \text { CV } & \text { Cyclic voltammetry } \\ \text { Cy } & \text { Cyclohexyl } \\ \text { DB24C8 } & \text { Dibenzo[24]crown-8 } \\ \text { DEAD } & \text { Diethyl azodicarboxylate } \\ \text { DMF } & \text { Dimethylformamide } \\ \text { DMSO } & \text { Dimethyl sulfoxide } \\ \text { DN24C8 } & \text { 2,3-Dinaphtho[24]crown-8 } \\ \text { DN38C10 } & \text { 1,5-Dinaphtho[38]crown-10 } \\ \text { DNP } & \text { 1,5-Dioxynaphthalene } \\ \text { Et } & \text { Ethyl } \\ \text { Grubbs I } & \text { First generation Grubbs catalyst } \\ \text { Grubbs II } & \text { Second generation Grubbs catalyst } \\ \text { HMPT } & \text { Hexamethylphosphoric triamide } \\ \text { LB } & \text { Langmuir-Blodgett } \\ \text { Me } & \text { Methyl } \\ \text { MPTTF } & \text { Monopyrrolotetrathiafulvalene } \\ \text { N24C8 } & \text { 2,3-Naphtho[24]crown-8 } \\ \text { NMR } & \text { Nuclear magnetic resonance } \\ \text { RCM } & \text { Ring-closing metathesis } \\ \text { RORCM } & \text { Ring-opening ring-closing metathesis } \\ \text { SAM } & \text { Self-assembled monolayer } \\ \text { tert } & \text { Tertiary } \\ \text { TFAA } & \text { Trifluoroacetic anhydride } \\ \text { THF } & \text { Tetrahydrofuran } \\ \text { Tr } & \text { Triphenylmethyl (Trityl) } \\ \text { TTF } & \text { Tetrathiafulvalene } \\ & \\ & \end{array}$


1

\section{Introduction}

Interlocked molecules [1-5] consist of two or more components that are held together as a consequence of mechanical linking rather than by covalent bonds. The interest of the scientific community was initially piqued by the challenges inherent in their efficient syntheses, as well as by their relatively unconventional architectures - a fascinating aspect of their structure that marries topology [6] with chemistry. Catenanes [7-14] and rotaxanes [15-26] are the archetypal examples of such mechanically interlocked compounds. They merely represent the forerunners, however, of an ever-expanding family of more intricate assemblies [27]. Catenanes (from the Latin catena, meaning "chain") are comprised of two or more mechanically interlocked macrocycles, whereas simple rotaxanes (from the Latin rota and axis, meaning "wheel" and "axle", respectively) contain a linear dumbbell-shaped component - bearing bulky endgroups or "stoppers" - around which one or more macrocycles are trapped. No longer esoteric curiosities, catenanes and rotaxanes are now being explored [28-29] as prototypical molecular machines - an intriguing application that arises from the ability to control the relative translations of interlocked components within any given molecular assembly. Molecular devices such as logic gates, switches, and shuttles are now a reality [28-29].

A common retrosynthetic disconnection shared by generic [2] rotaxane and [2]catenane structures invokes (Fig. 1) a [2]pseudorotaxane precursor, in which a linear molecule is threaded through a macrocyclic one. Post-assembly modification of the threaded [2] pseudorotaxane superstructure can proceed in two ways: (i) macrocyclization of the linear component affords a [2]catenane (Fig. 1a), whereas (ii) end-capping of the linear component with sufficiently large groups - a process often referred to as "stoppering" (Fig. 1b) - results in the formation of a [2] rotaxane. A complementary "clipping" strategy (Fig. 1c), in which an acyclic precursor is cyclized around a linear dumbbell-shaped template, has also been developed for the synthesis of rotaxanes. An alternative approach to prepare rotaxanes, called "slippage" (Fig. 1d), proceeds by heating the preformed macrocycle and dumbbell together in order to slip the macrocycle past the bulky stoppers to produce the thermodynamically favored rotaxane.

Each of these strategies requires the precise geometrical positioning of two or more molecules prior to the formation of the final covalent bond, i.e., the one that defines the ultimate molecular entity. When left to chance, the fragments are highly unlikely to be oriented in the arrangement necessary for the creation of an interlocked molecule - the statistics are not kind! Consequently, early "statistical" approaches $[7,15]$ were poor yielding, relying upon tedious repetition and arduous purification protocols to generate even the smallest quantities of catenanes and rotaxanes. Covalent-directed approaches followed [1] but they fared little better since they required complex multi-step syntheses. Paradigms, however, have a habit of shifting; the chemical landscape was about 


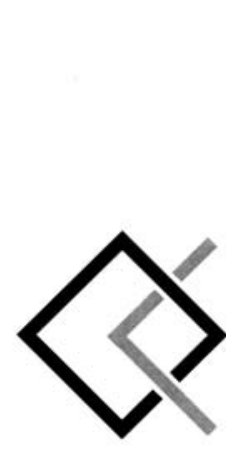

[2]Pseudorotaxane

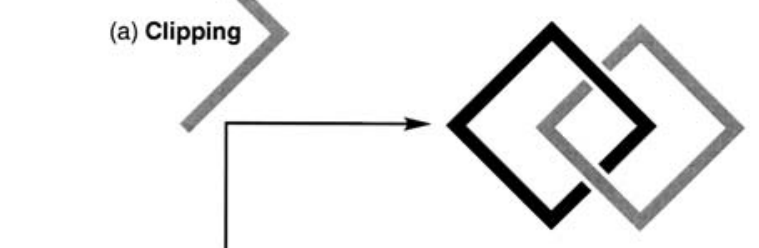

[2]Catenane

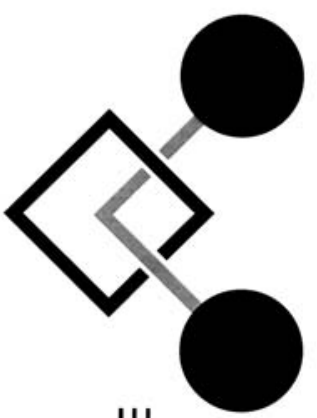

(c) Clipping

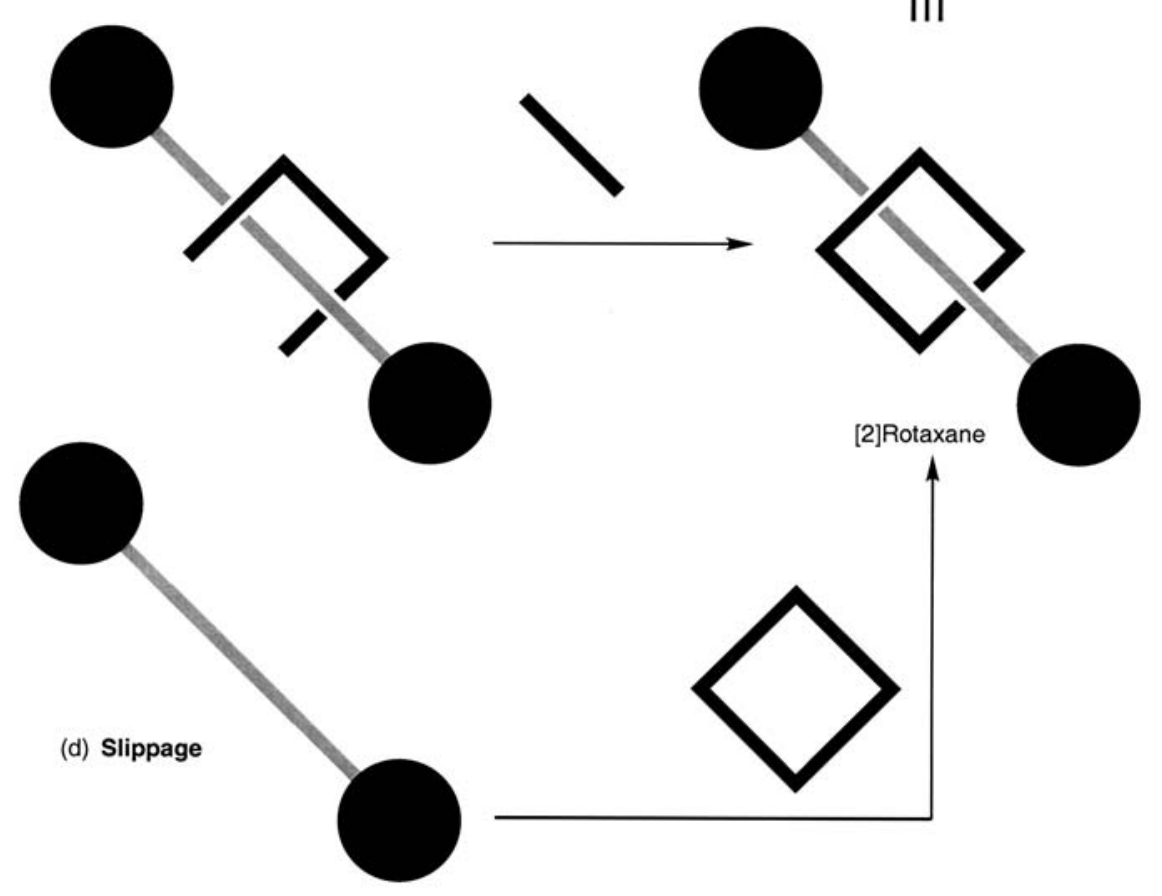

Fig. 1 Schematic representation of the synthesis of a [2] catenane by $a$ clipping, and of a [2] rotaxane by $b$ stoppering, $c$ clipping, and $d$ slippage 
to change. The field of host-guest chemistry [30] gained momentum (and, in some circles, changed its name [31]) as the latter half of the twentieth century wore on, and it was only a matter of time before the principles and practices of supramolecular chemistry were applied to the formation of interlocked molecules. The template-directed strategies that we continue to develop and hone up to this day were born $[8,32-41]$. Whether hydrogen-bonding [42-48] or metalligand interactions, [49-53] $\pi-\pi$ stacking [54-60] or hydrophobic binding, [61-65] molecular recognition and the intermolecular forces - that we are now beginning to comprehend and exploit - are the foundations upon which the field of mechanically interlocked molecules are built.

To date, the final bond-forming reaction employed in the majority of mechanically interlocked molecule syntheses have been performed under kinetic control. Such protocols can result in the irreversible formation of undesired (non-interlocked) side-products, potentially reducing the efficiency of the interlocking processes. By contrast, however, a reversible thermodynamically controlled approach allows for a "proof-reading" step in which "incorrect" structures are consumed and their component parts recycled back into an equilibrating mixture [66-71]. For example, in a stoppering reaction performed (Fig. 2a) under reversible conditions, the formation of a dumbbell-shaped component does not represent a dead end, as it would if this reaction was performed under kinetic control (vide supra). In this case, such an undesired structure can simply re-equilibrate and its components can go on to form the desired dynamic [2]rotaxane product. Furthermore, thermodynamic approaches for the syntheses of mechanically interlocked compounds are not limited to stoppering reactions. The thermodynamically controlled clipping (Fig. 2b) of a macrocyclic component around a preformed dumbbell-shaped molecule can also be envisaged. In fact, there are many ways by which dynamic [2]catenanes and [2] rotaxanes can be assembled, depending upon whether just one or both of the components possess, within their framework, bonds that can be made and broken reversibly. Additionally, the possibility exists for mechanically interlocked molecules to be assembled (Fig. 2c) directly from their constituent components. For example, by mixing two preformed macrocycles with one another - at least one of which contains a reversibly formed bond - it is possible, under the appropriate conditions, to reproduce the conjurer's "magic rings" trick, wherein two apparently "closed" rings can be linked together, one through the other, to form a [2]catenane.

This article surveys, in an appropriate historical context, the state-of-the-art when it comes to the formation of mechanically interlocked molecules - under both kinetic and thermodynamic regimes - and concludes with a vision of what the future may hold, especially if we choose the right templates! 
(a)
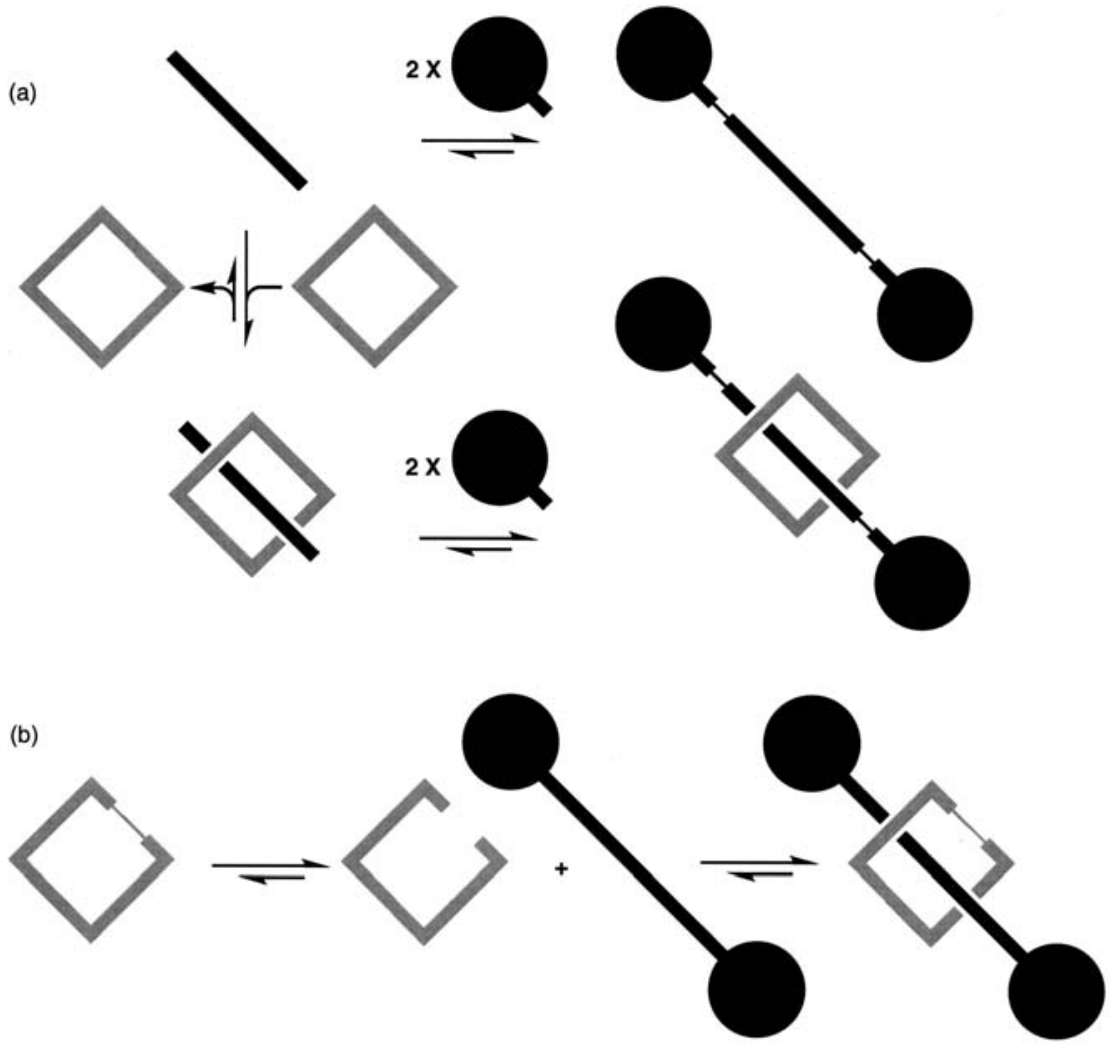

(c)
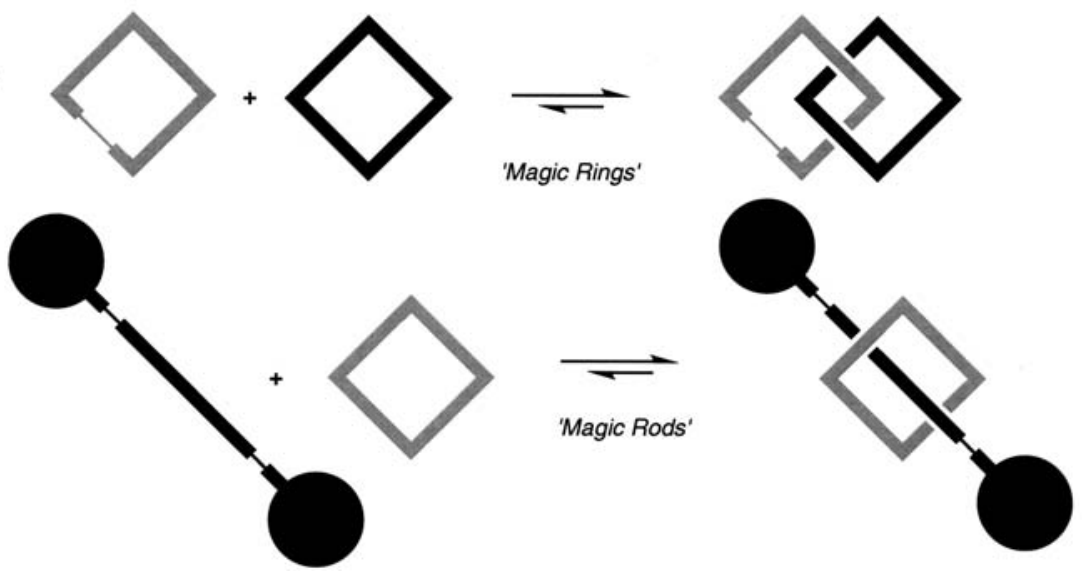

Fig. 2 Schematic representations depicting the thermodynamically controlled synthesis of a [2] rotaxane using $a$ the stoppering methodology and $b$ the clipping methodology. $c$ Represents the magic interlocked molecules. The thinner lines represent the reversibly formed covalent bonds 


\section{2}

\section{Kinetic Approaches to the Synthesis of Interlocked Molecules}

\section{1}

\section{Transition Metal Templates}

Kinetic templates, such as transition metals, have been used for over two decades in the synthesis of catenanes and rotaxanes on account of their ability to gather and coordinate organic ligands in a geometrically precise fashion. In 1983, Sauvage [8] reported the first metal-templated protocols for the synthesis of catenanes and outlined a general procedure for using various transition metals as synthetic templates. Since then, the synthesis of a string of exotic catenanes and rotaxanes [72-73] has been demonstrated. Recently, Sauvage has reported [74-75] the synthesis of metal-templated [2]catenanes, for which an alkene terminated $2,2^{\prime}$-bipyridine derivative $\mathbf{2}$ (Scheme $1 \mathrm{a}$ ) is chelated with a pre-formed bisphenanthroline macrocycle 1 in the presence of a $\mathrm{Ru}(\mathrm{II})$ or a $\mathrm{Rh}$ (III) metal center to afford stable, octahedral coordination complexes, which correspond to the pseudorotaxanes $3 \mathrm{a} \cdot 2 \mathrm{Cl}$ or $3 \mathbf{b} \cdot 3 \mathrm{Cl}$, respectively. These pseudorotaxanes can be transformed into the corresponding olefin-linked [2] catenates $5 \mathbf{a} \cdot 2 \mathrm{Cl}$ or $\mathbf{5 b} \cdot 3 \mathrm{Cl}$, respectively, by using a ring-closing metathesis (RCM) methodology on the two terminal alkenes with the catalyst 4 (Grubbs I) in $68 \%$ or $34 \%$ yield, respectively. Conversely, a $\mathrm{Cu}(\mathrm{I})$-templated [2] rotaxane 9. $\mathrm{BF}_{4}[76]$ can be prepared (Scheme $1 \mathrm{~b}$ ) by means of a threading-followedby-stoppering approach. In this case, a 2,2'-bipyridine derivative 7 is treated with a phenanthroline-terpyridine-containing macrocycle 6 in the presence of $\mathrm{Cu}(\mathrm{I})$ ions, resulting in the formation of a tetrahedral coordination complex namely a semirotaxane $[\mathrm{Cu}(6 \supset 7)] \cdot \mathrm{BF}_{4}$. Subsequently, alkylation of the complex $[\mathrm{Cu}(6 \supset 7)] \cdot \mathrm{BF}_{4}$ with the stoppering reagent 8 gives the desired $\mathrm{Cu}(\mathrm{I})$-templated rotaxane $9 \cdot \mathrm{BF}_{4}$ in a yield of $20 \%$ for the final two steps. The X-ray crystal structure of the rotaxane $9 \cdot \mathrm{BF}_{4}$ confirmed that the $\mathrm{Cu}(\mathrm{I})$ complex adopts a tetrahedral structure with the coordination of the two different bidentate ligands, $2,2^{\prime}$-bipyridine and phenanthroline with the $\mathrm{Cu}(\mathrm{I})$ metal center. It was demonstrated [76] that the $\mathrm{Cu}(\mathrm{I})$-templated [2] rotaxane $\mathbf{9} \cdot \mathrm{BF}_{4}$ undergoes controllable rotary motion (pirouetting) of the macrocycle around the dumbbell's axis following the oxidation and reduction of the $\mathrm{Cu}$ metal center. Specifically, the $\mathrm{Cu}(\mathrm{I})$ ion favors a four-coordinate ligand set in a tetrahedral geometry, a requirement satisfied by the $2,2^{\prime}$-bipyridine and phenanthroline ligands, whereas $\mathrm{Cu}$ (II) ion favors a five-coordinate geometry with $2,2^{\prime}$-bipyridine and terpyridine ligands.

These recent examples demonstrate the ability of metal-ion templates to facilitate the construction of interlocked molecules - and represent only the tip of the iceberg. Over the past two decades, Sauvage and others have employed a wide range of metal-ligand interactions to facilitate the efficient synthesis of both catenanes and rotaxanes, in addition to other complex intertwined molecular architectures, e.g., molecular knots. 

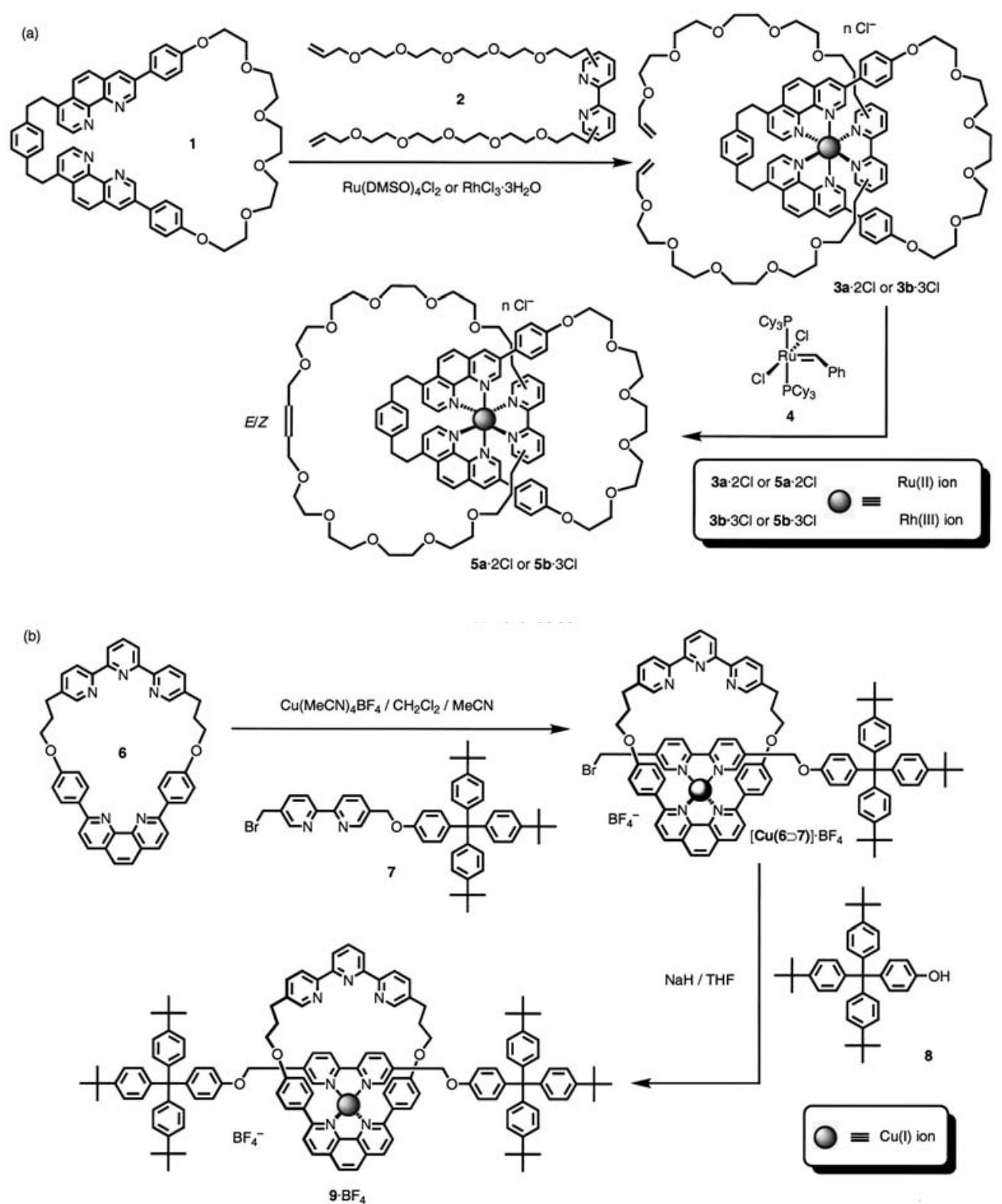

Scheme 1 Syntheses of the metal-templated [2] catenanes $5 \mathrm{a} \cdot 2 \mathrm{Cl} / \mathbf{5 b} \cdot 3 \mathrm{Cl}$ and the [2] rotaxane $\mathbf{9} \cdot \mathrm{BF}_{4}$ by a ring-closing metathesis and an alkylation, respectively 


\section{2}

\section{$\pi$-Donor $/ \pi$-Acceptor Templation}

\subsection{1 \\ Charged Templates}

The first synthesis of a [2]catenane utilizing the templating effects of charged $\pi$-donor/ $\pi$-acceptor noncovalent bonding interactions was reported [77] in 1989 . Since then, charged $\pi$-donor/ $\pi$-acceptor templates have continued to play an important role in the syntheses of catenanes and rotaxanes on account of their high self-assembling efficiency [78]. Thus far, the preparation of catenanes and rotaxanes [61,79-80] has taken advantage of strong binding affinities $\left(K_{a}>3,000 \mathrm{M}^{-1}\right.$ in $\mathrm{MeCN}$ at $298 \mathrm{~K}$ ) between (Fig. 3 ) the charged $\pi$-electron-deficient tetracationic cyclophane, cyclobis(paraquat-p-phenylene) $\left(\mathrm{CBPQT}^{4+}\right)$ $10 \cdot 4 \mathrm{PF}_{6}$ and $\pi$-electron-rich compounds, such as aromatic ethers 11 and 12. This complexation is driven by $\pi-\pi$ stacking and charge-transfer (CT) interactions [81-82], as well as by [C-H...O] hydrogen bonding [83-84]. By far the most effective $\pi$-donors for the preparation of charged catenanes and rotaxanes are those [85] based on tetrathiafulvalene (TTF) 13 and their mutual recognition by the $\pi$-electron-deficient cyclophane $10 \cdot 4 \mathrm{PF}_{6}$. The binding constant between TTF (13) and $\mathbf{1 0} \cdot 4 \mathrm{PF}_{6}$ to form a 1:1 inclusion complex (i.e., a [2]pseudorotaxane) was determined to be ca. $10,000 \mathrm{M}^{-1}$ in $\mathrm{MeCN}$ at $298 \mathrm{~K}$. Even higher binding constants have been obtained [86] for some pyrrole-fused TTF derivatives. The pioneering work in the development of charged $\pi$-donor/ $\pi$-acceptor recognition motifs led to the preparation of a myriad of novel catenanes [87-92], including the [5] catenane "Olympiadane" [87] and other functional rotaxanes [26, 93-96].

In 1998, the Stoddart group [90] reported that the bistable [2]catenanes $17 \mathrm{a} \cdot 4 \mathrm{PF}_{6}$ and $17 \mathrm{~b} \cdot 4 \mathrm{PF}_{6}$ can be prepared (Scheme $2 \mathrm{a}$ ) by template-directed synthesis that utilizes the appropriate preformed macrocyclic polyether $14 \mathrm{a} / \mathrm{b}$. The reaction of the horseshoe-like dicationic salt $15 \cdot 2 \mathrm{PF}_{6}$, under high dilution with the dibromide 16 in the presence of the macrocyclic template $14 \mathrm{a} / \mathrm{b}$, affords either the 1,4-dioxybenzene-containing [2] catenane $17 \mathrm{a} \cdot 4 \mathrm{PF}_{6}$ or the

Acceptor (A)

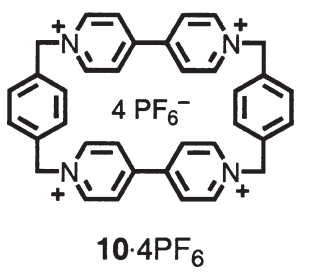

Donors (D)

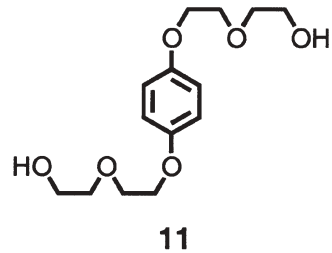

11

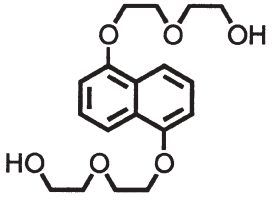

12

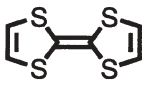

13

Fig. 3 Some examples of a $\pi$-electron acceptor $(A)$ and some donors $(D)$ 
(a)

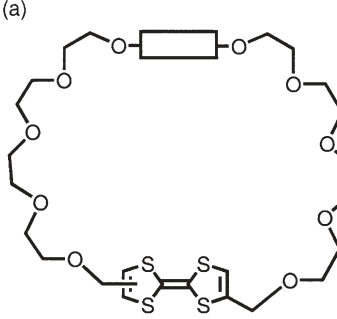

(i) DMF / High Dilution

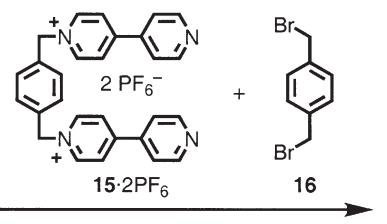

(ii) $\mathrm{NH}_{4} \mathrm{PF}_{6} / \mathrm{H}_{2} \mathrm{O}$
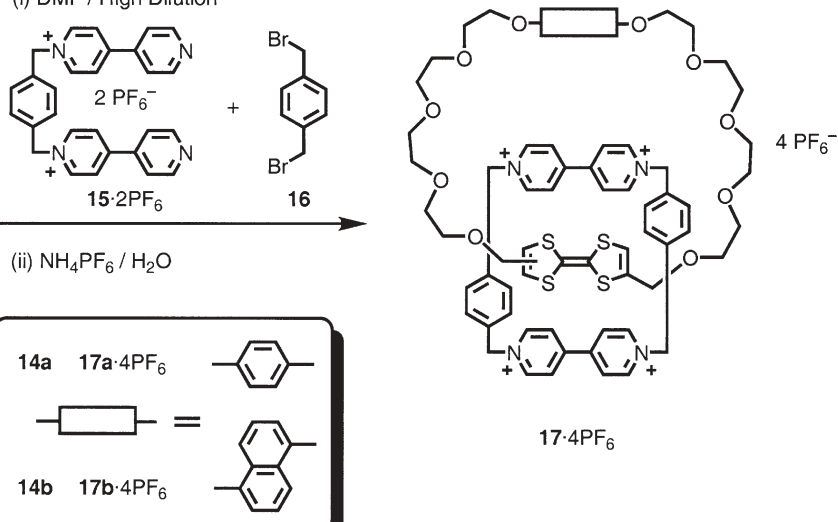

(b)

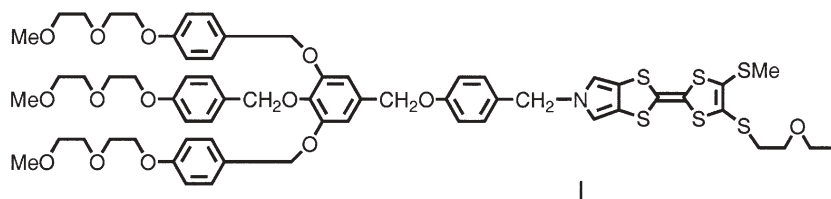

(i) DMF / High Dilution

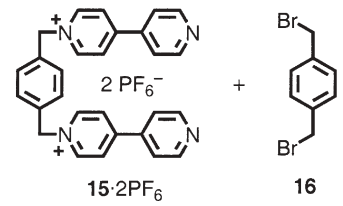

(ii) $\mathrm{NH}_{4} \mathrm{PF}_{6} / \mathrm{H}_{2} \mathrm{O}$

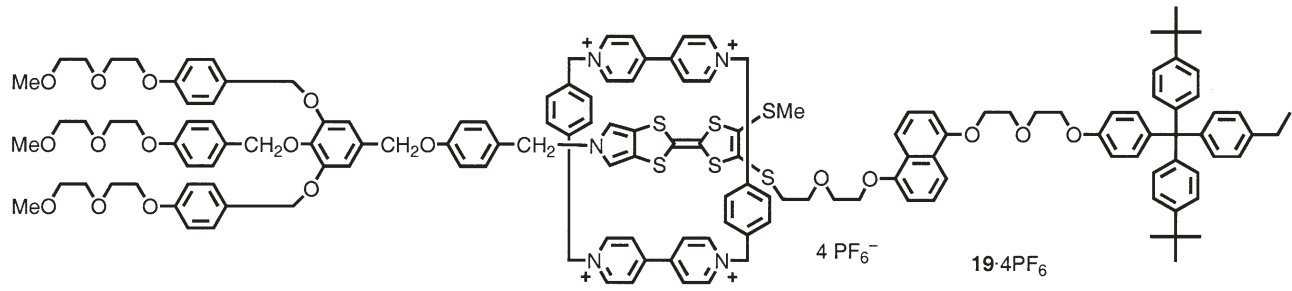

Scheme 2 Template-directed syntheses of the charged $\pi$-donor/ $\pi$-acceptor [2] catenanes $17 \mathrm{a} \cdot 4 \mathrm{PF}_{6} / 17 \mathrm{~b} \cdot 4 \mathrm{PF}_{6}$ and the [2] rotaxane $19 \cdot 4 \mathrm{PF}_{6}$ by clipping reactions around TTF units

1,5-dioxynaphthalene (DNP)-containing [2] catenane $\mathbf{1 7 b} \cdot 4 \mathrm{PF}_{6}$. The [2] catenanes were obtained in yields of 23 and 43\%, respectively, following counterion exchange with ammonium hexafluorophosphate. The X-ray crystal structure of the [2] catenane $\mathbf{1 7 b} \cdot 4 \mathrm{PF}_{6}$ revealed that the tetracationic $\mathrm{CBPQT}^{4+}$ cyclophane encircles the TTF unit, leaving the DNP ring system to interact with the outer face of one of the bipyridinium rings of the cyclophane. Interestingly, the [2] catenanes $17 \mathrm{a} \cdot 4 \mathrm{PF}_{6}$ and $\mathbf{1 7 b} \cdot 4 \mathrm{PF}_{6}$ exhibit controllable, reversible circumro- 
tary movements that exchange the TTF unit for the other aromatic ring system within the cavity of the tetracationic cyclophane. This switching behavior occurs in both solution [91] and in the semi-solid state [92]. By further elaborating this synthetic method, a bistable, electrochemically switchable, [2] rotaxane $19 \cdot 4 \mathrm{PF}_{6}$ [95] was synthesized (Scheme $2 \mathrm{~b}$ ) in $23 \%$ yield by employing the same template-directed clipping process with the dicationic salt $15 \cdot 2 \mathrm{PF}_{6}$ and the dibromide 16 around the dumbbell compound 18 containing the two donors, monopyrrolo-TTF (MPTTF) and DNP. Furthermore, when the clipping reaction is performed under high pressure (10 kbar), the yield of the [2] rotaxane can be increased dramatically, i.e., up to as much as $50 \%$ !

\subsection{2}

\section{Neutral Templates}

In addition to these charged $\pi$-stacking systems, Sanders [97] has more recently reported that neutral $\pi$-stacking motifs can be utilized for the construction of [2] catenanes with high efficiencies. The neutral $\pi$-stacking motifs that involve $\pi$-electron-deficient diimides, such as pyromellitimide 23 (Scheme 3) and $\pi$-electron-rich aromatic ethers, such as the previously mentioned DNP derivative 12, self-assemble to give charge-transfer complexes with intense colors [98]. By employing this type of neutral recognition motif (Scheme 3a) when a

(a)
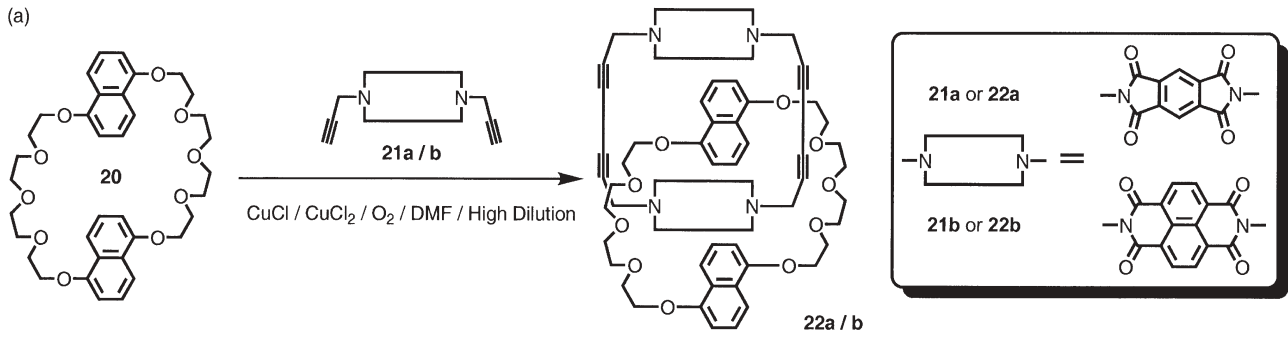

$2 a / b$
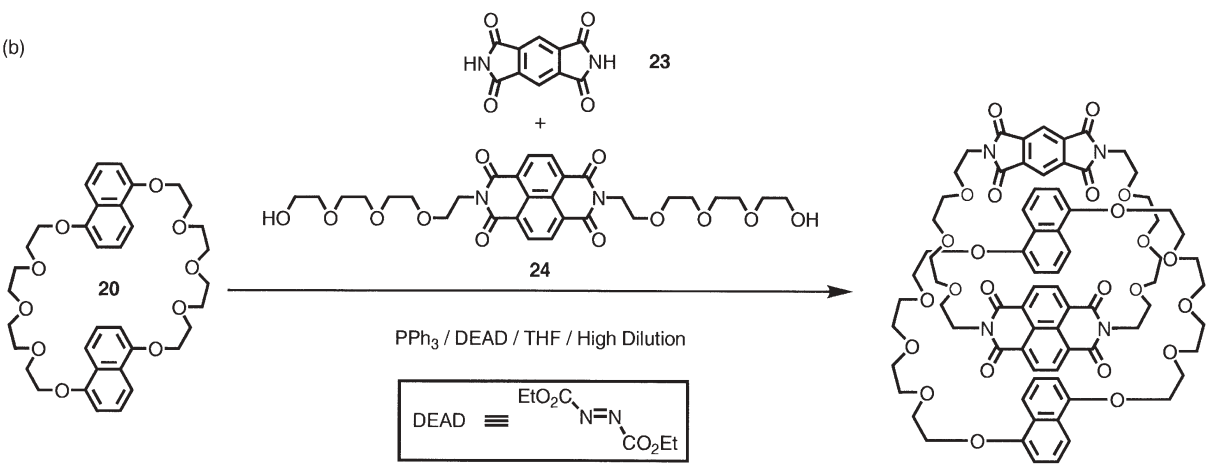

25

Scheme 3 Template-directed syntheses of neutral $\pi$-donor/ $\pi$-acceptor [2]catenanes $22 \mathrm{a} / \mathbf{2 2 b}$ and 25 
DNP-based macrocycle 20 (DN38C10) is treated separately with the bisacetylene 21a or $21 \mathrm{~b}$ utilizing the Glaser-Hay oxidative homo-coupling reaction, the [2]catenane 22a is produced as an orange-red solid in $38 \%$ yield and the [2] catenane $22 \mathrm{~b}$ as a purple solid in $52 \%$ yield, respectively [99-100]. From the $\mathrm{X}$-ray crystal structural analysis of the [2] catenane 22a, both the $3.5 \AA \pi-\pi$ interaction and the weak, intramolecular $[\mathrm{N}-\mathrm{C}-\mathrm{H} \cdots \mathrm{O}]$ hydrogen bonds are observed and are believed to be essential for maintaining the self-assembled structures. Moreover, an acetylene-free [2]catenane 25 (Scheme $3 \mathrm{~b}$ ) can be constructed from the same starting macrocycle 20 with pyromellitimide 23 and diol 24 under Mitsunobu dehydrating reaction conditions to give the product 25 as a deep-red solid in 17\% yield [101]. In the synthetic studies of other similar neutral [2] catenanes, the authors [97] conclude that the acidic methylene protons adjacent to the diimide unit facilitate the formation of the [2]catenanes from the macrocycle 20 by additional [ $\mathrm{N}-\mathrm{C}-\mathrm{H} \cdots \mathrm{O}$ ] hydrogen bonding.

\section{3 \\ Hydrogen Bond Templation}

\subsection{1 \\ Amide Templates}

In 1992, Hunter [102] and Vögtle [103] reported separately that amide-based [2]catenanes can be prepared in reasonable yields by amide-forming reactions such that the intermediates are held in place by strong $[\mathrm{C}=\mathrm{O} \cdots \mathrm{H}-\mathrm{N}]$ hydrogenbonds [104]. Subsequently, in 1995, Leigh [9] published a convenient one-step preparation (Scheme 4) of an amide-based [2] catenane 28 . The synthesis involves simply mixing isophthaloyl chloride 26 and $p$-xylylenediamine 27 in the presence of triethylamine to furnish the [2] catenane 28 in a $20 \%$ yield by a double $[2+2]$ macrocyclization. The catenane formation is facilitated by two types of interactions - the $[\mathrm{C}=\mathrm{O} \cdots \mathrm{H}-\mathrm{N}]$ hydrogen-bonds as well as $\pi-\pi$ interactions between phenylene rings - in a minimally spaced system. Based on this landmark research, Leigh [105] has recently reported the synthesis (Scheme 5a) of a "three-station" amide-based [2]catenane 30, which serves as the basis for a unidirectional photochemically driven molecular motor. To

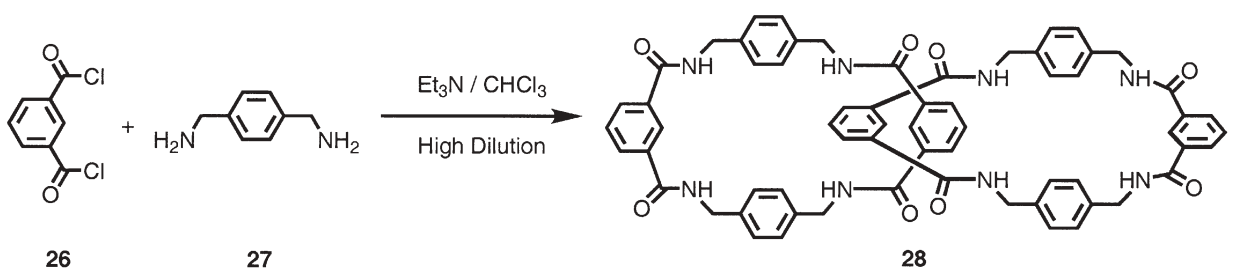

Scheme 4 One-pot hydrogen bonding-assisted synthesis of the amide-based [2] catenane 28 from the acyclic starting materials $\mathbf{2 6}$ and $\mathbf{2 7}$ 


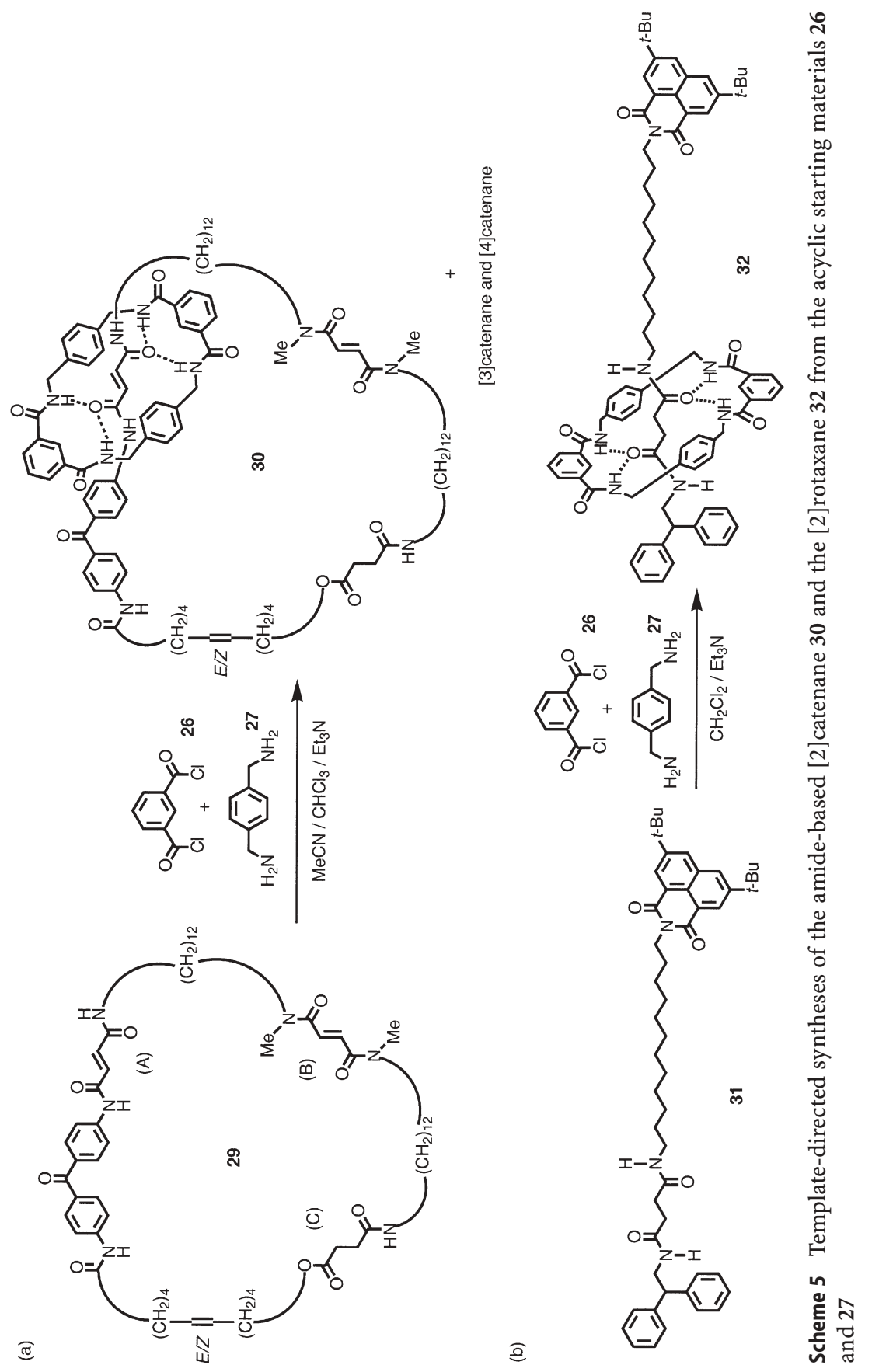


begin with, a large amide-based macrocycle 29 , which consists of (a) a secondary amide fumaramide group, (b) a tertiary amide fumaramide group, and (c) a succinic amide ester group, is treated with isophthaloyl chloride $\mathbf{2 6}$ and $p$-xylylenediamine 27 to yield, following a [2+2] macrocyclization, the [2]catenane 30 as the major product in 50\% yield. ${ }^{1} \mathrm{H}$-NMR spectroscopy confirmed that the newly formed macrocyclic lactam was situated at the secondary amide fumarmide moiety by forming a close-to-ideal hydrogen-bonding geometry. And, as expected, [3]- and [4]catenanes were obtained as bonuses from the one-pot reaction as minor products.

Employing a similar hydrogen bonding-induced macrocyclization strategy, various amide-based [2] rotaxanes can be constructed [106-112]. One example [110] is that of a [2] rotaxane 32 (Scheme 5b) that can be synthesized in a $59 \%$ yield from a succinamide and naphthalimide-containing compound 31 with a standard one-pot formation of the macrocyclic lactam from compounds 26 and 27. Upon electrochemical stimulation, the [2] rotaxane 32 displays bistable switching behavior in which the macrocyclic lactam ring moves from the succinamide station to the naphthalimide station. Furthermore, by using similar synthetic strategies described above, other amide-based [2] catenanes [113-116] and amide-based [2] rotaxanes [117] have also been reported.

\subsection{2}

\section{Ammonium lon Templates}

It is well known [16, 118-119] that crown ethers, such as [18]crown-6 and [24]crown-8 are ideal hosts for binding both with primary alkyl- and secondary dialkyl-ammonium ions as a result of strong $\left[\mathrm{N}^{+}-\mathrm{H} \cdots \mathrm{O}\right]$ hydrogen-bonding interactions. The Stoddart group [17, 120-121] has recently reported that ammonium-containing [2] rotaxanes $35-\mathrm{H} \cdot 2 \mathrm{PF}_{6}, 36-\mathrm{H} \cdot 3 \mathrm{PF}_{6}, 38-\mathrm{H} \cdot \mathrm{PF}_{6}$ and $39-\mathrm{H} \cdot \mathrm{PF}_{6}$ (Scheme 6) can be synthesized by templation between dibenzo[24]crown-8 (DB24C8) and dialkylammonium salts $33-\mathrm{H} \cdot \mathrm{PF}_{6}$ or $34-\mathrm{H} \cdot \mathrm{PF}_{6}$. The synthesis [122-123] involves a threading-followed-by-stoppering approach. In all these cases, one-end-capped dialkylammonium salt $33-\mathrm{H} \cdot \mathrm{PF}_{6}$ (Scheme $6 \mathrm{a}$ ) or the nonend-capped ammonium salt $34-\mathrm{H} \cdot \mathrm{PF}_{6}$ (Scheme 6b) is threaded into DB24C8, followed by stoppering with triphenylphosphine to afford [2] rotaxanes $35-\mathrm{H} \cdot 2 \mathrm{PF}_{6}$ in $80 \%$ or $36-\mathrm{H} \cdot 3 \mathrm{PF}_{6}$ in $55 \%$ yield, respectively. Subsequently, the triphenylphosphonium stoppers can be modified to become aryl stoppers by Wittig reactions with, for example, the aldehyde 37 . Such reactions, followed by catalytic hydrogenation, yield new [2] rotaxanes $38-\mathrm{H} \cdot \mathrm{PF}_{6}$ or $39-\mathrm{H} \cdot \mathrm{PF}_{6}$, respectively, both in about $50 \%$ yield. During the post-modification reactions, there is no evidence for the escaping of the crown ether from the dumbbell component. The X-ray crystal structures of the [2] rotaxane $38-\mathrm{H} \cdot \mathrm{PF}_{6}$ and $39-\mathrm{H} \cdot \mathrm{PF}_{6}$ reveal that both the ammonium protons and the $\alpha$-methylene protons adjacent to the nitrogen atom contribute to the hydrogen bonding with the DB24C8 component. 

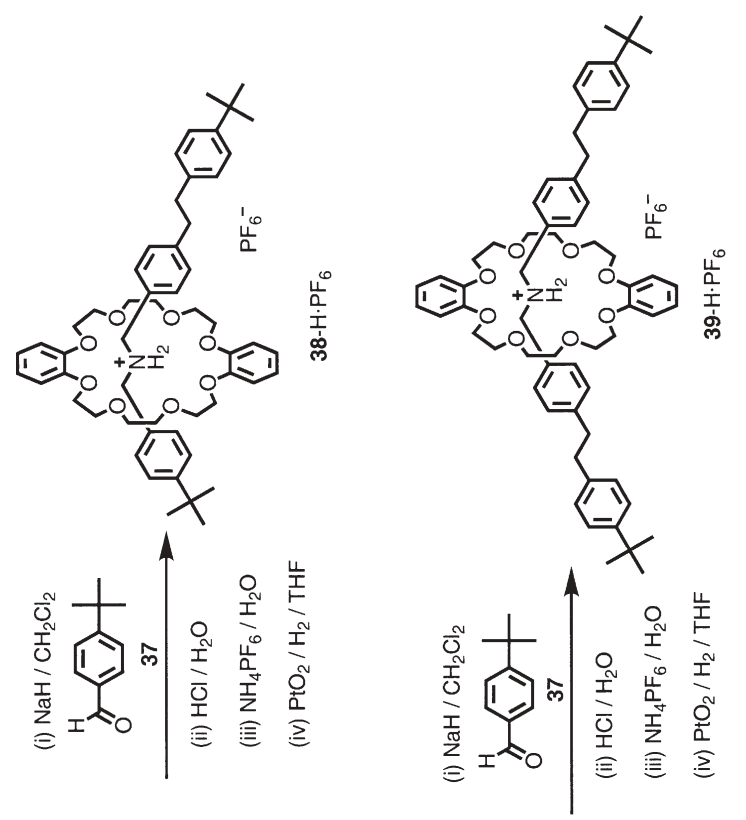

足
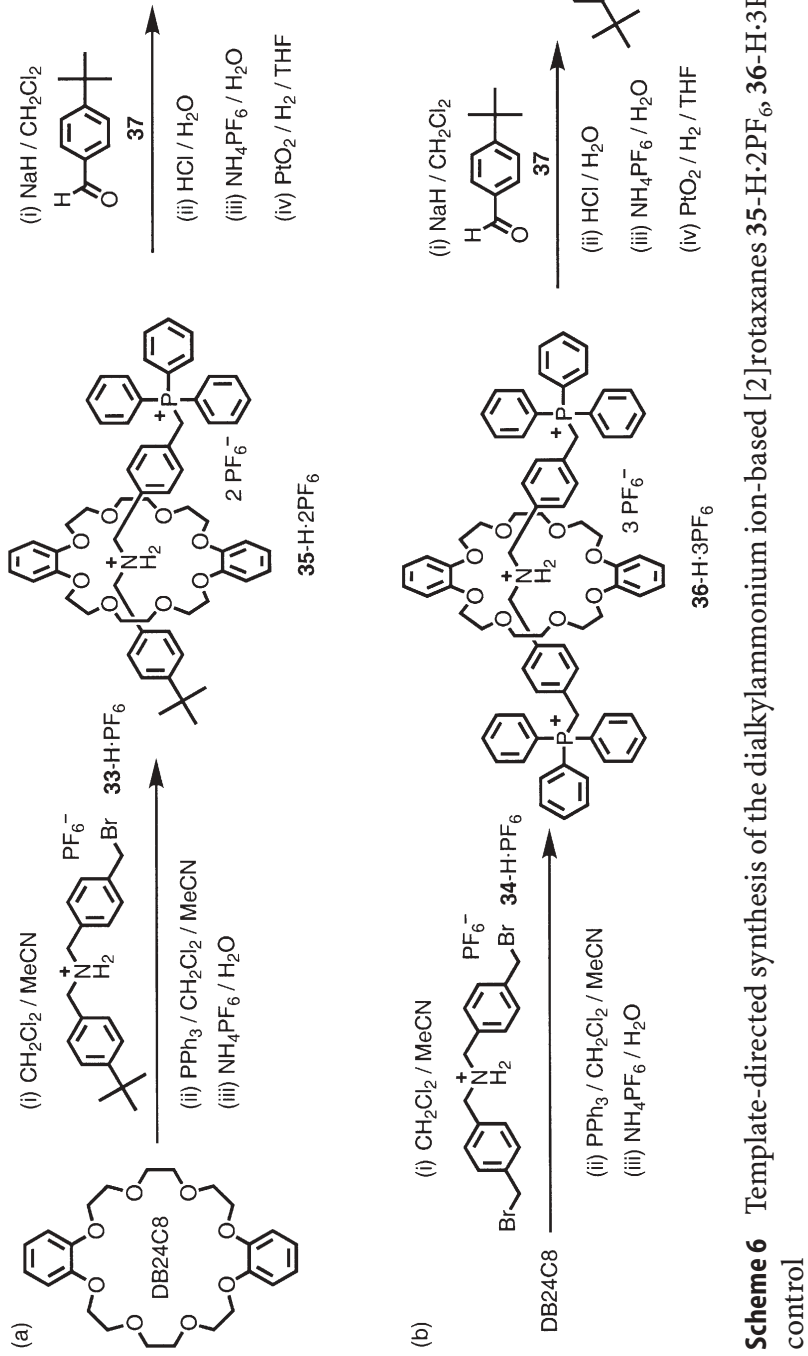


\subsection{3 \\ Anion Templates}

In the presence of appropriate macrocycles, the use of phenoxy anion templates directs the synthesis of [2] rotaxanes [124-129] in high yielding reactions. In 1999, Vögtle [124] reported that a macrocyclic lactam 40 (Scheme 7a) is a good acceptor for a $p$-tritylphenoxy anion as a result of forming $\left[\mathrm{N}-\mathrm{H} \cdots \mathrm{O}^{-}\right]$hydrogen bonds. In this case, an intermediate complex [40 $\supset 41]^{-}$is subsequently reacted with a trityl end-stoppered alkylbromide 42 , affording an amide-containing [2] rotaxane $\mathbf{4 3}$ in $95 \%$ yield. By using a similar synthetic protocol, Schalley [128] reported the synthesis (Scheme $7 \mathrm{~b}$ ) of the amide-containing [2] rotaxane 46 . Initially, the diamine $\mathbf{4 4}$ is treated with a mild base, prompting it to thread onto the same starting macrocycle 40 to give a [2]pseudorotaxane $[40 \supset 44]^{-}$. The threading is followed by end-capping reactions with triphenylacetic acid chloride 45 at both ends, generating the resulting [2] rotaxane 46. Use of esterification to add two stoppers in a one-pot reaction leads to a significantly lower yield 20-30\%, compared with that for the mono-alkylation $(95 \%)$ of a single stopper in the former example.

\subsection{4 \\ Dipyridiniumethane Templates}

In 1998, Loeb and Wisner $[19,130]$ reported that 1,2-bis(pyridinium)ethane and DB24C8 self-assemble to form [2]pseudorotaxanes $\left(K_{a}=1,200 \mathrm{M}^{-1}\right.$ in $\mathrm{MeCN}$ at $298 \mathrm{~K}$ ). The complex is held together by two modes of attractive interactions, namely $\left[\mathrm{N}^{+} \mathrm{CH}_{2} \cdots \mathrm{O}\right]$ hydrogen-bonding and $\left[\mathrm{N}^{+} \ldots \mathrm{O}\right]$ ion-dipole interactions. This finding led these researchers to prepare new rotaxane [131-132] and catenane [133] derivatives. For example, the [3] rotaxanes $50 \cdot 5 \mathrm{BF}_{4}$ and $51 \cdot 6 \mathrm{CF}_{3} \mathrm{SO}_{3}$ (Scheme $8 \mathrm{a}$ ) were made by the monoalkylation of the pyridinium salt $47 \cdot 4 \mathrm{BF}_{4}$ or dialkylation of the pyridinium salt $48 \cdot 4 \mathrm{CF}_{3} \mathrm{SO}_{3}$ [131] with 4-tert-butylbenzyl bromide 49, respectively, in the presence of an excess of DB24C8, to afford the [3] rotaxanes, both in about $18 \%$ yield. In each series, however, the [2] rotaxanes can also be prepared by using a limiting amount of the crown ether [132].

Alternatively, Loeb [133] has demonstrated (Scheme 8b) that, when various crown ethers, such as $24 \mathrm{C} 8, \mathrm{~B} 24 \mathrm{C} 8, \mathrm{~N} 24 \mathrm{C} 8, \mathrm{BN} 24 \mathrm{C} 8, \mathrm{DN} 24 \mathrm{C} 8$, and DB24C8, are treated separately with the pyridinium salt $52 \cdot 2 \mathrm{Br}$ and the dibromide 53 , then a large number of [3] catenanes $54 \cdot 8 \mathrm{CF}_{3} \mathrm{SO}_{3}$ can be produced. According to the nature of the crown ether, the percentage yields vary from $17 \%$ to $66 \%$, with DB24C8 giving the best result.

\section{4}

\section{Summary}

Mechanically interlocked molecules, such as catenanes and rotaxanes, can be synthesized in high efficiencies by utilizing organic or inorganic templates un- 

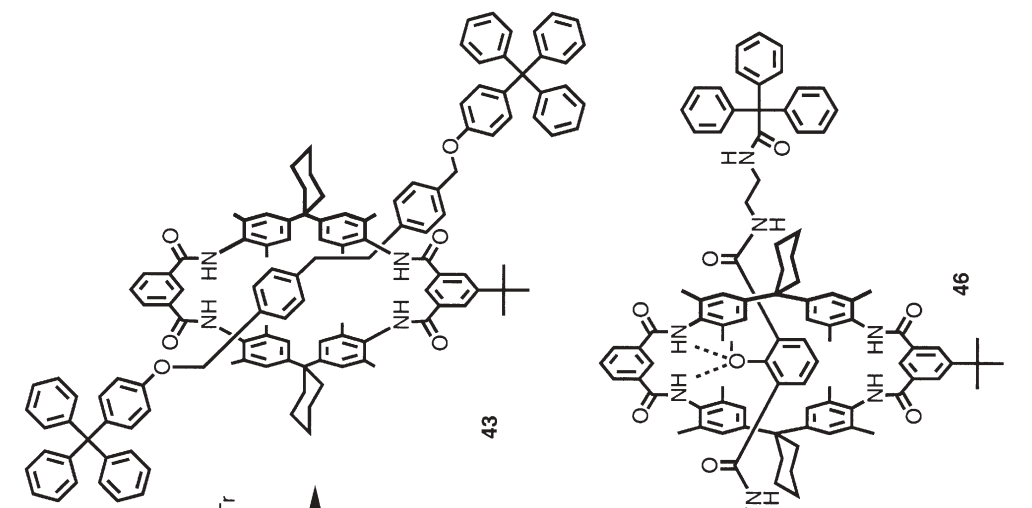

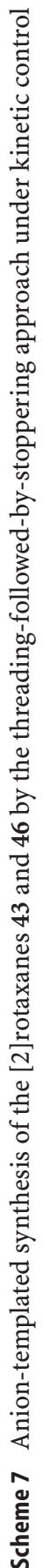
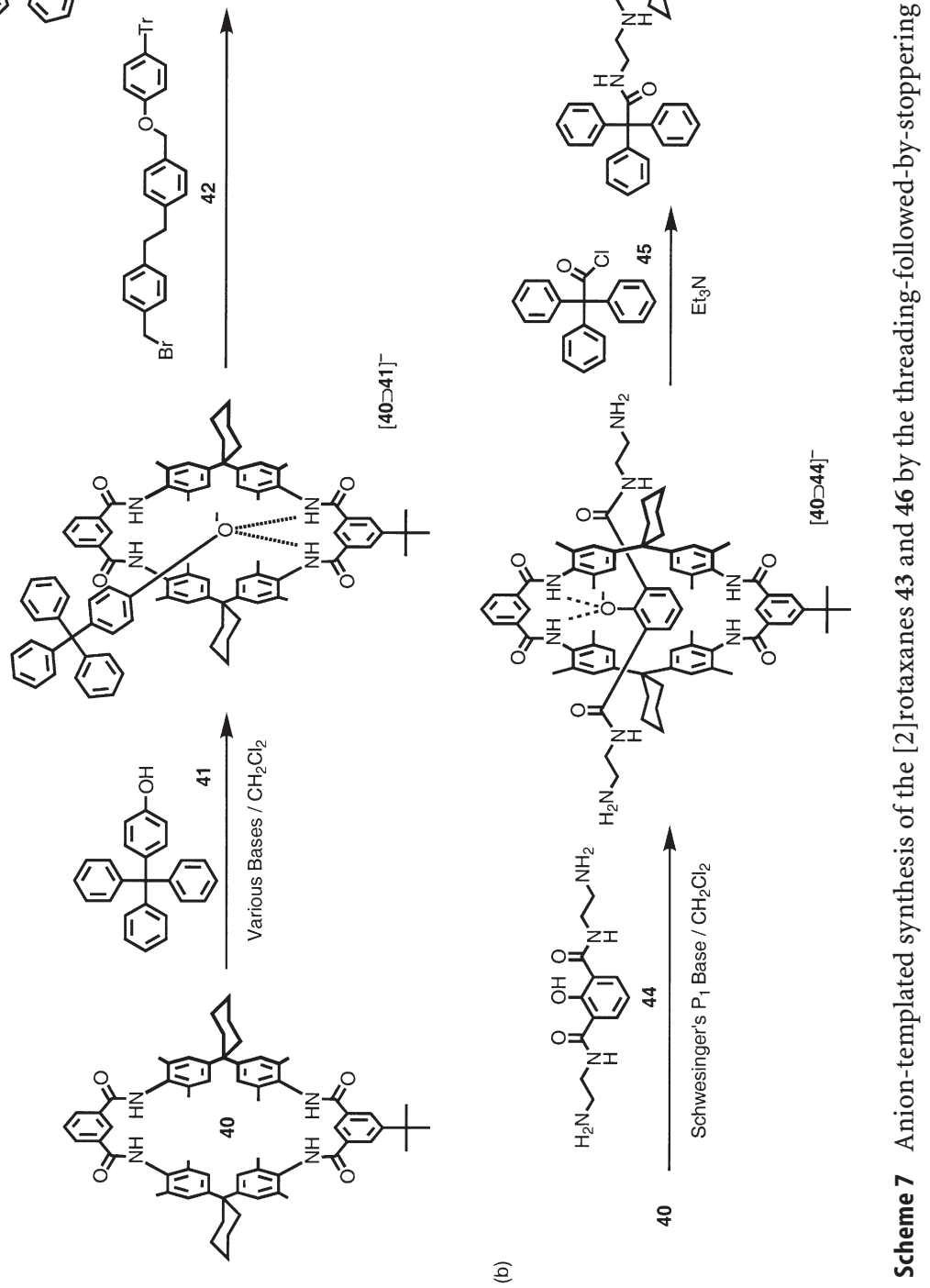

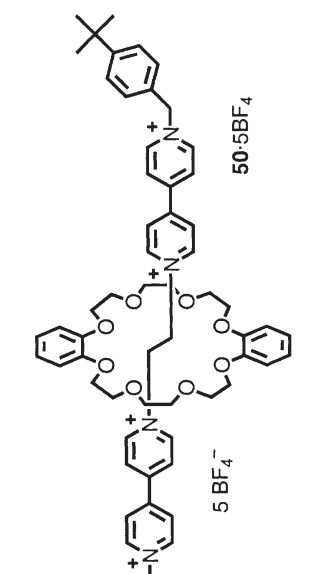

1.
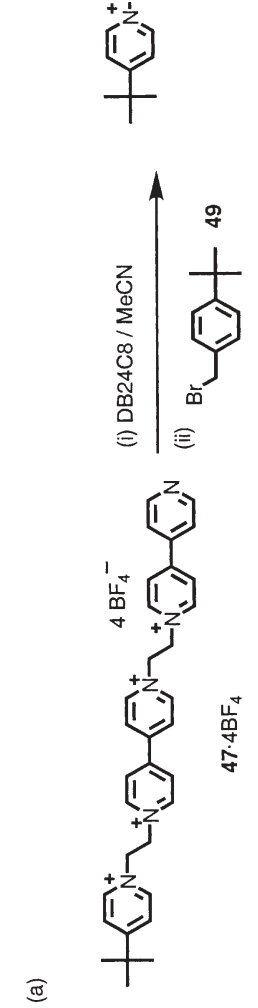
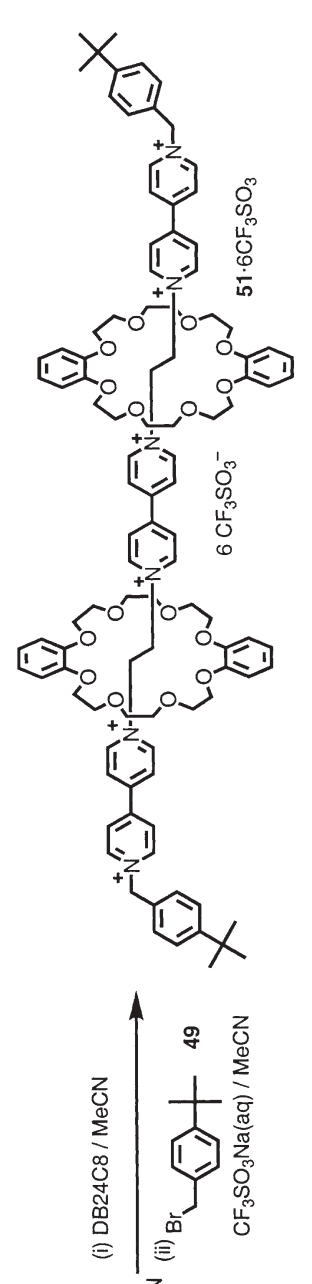

(1)

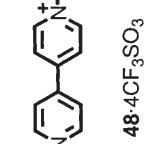

a

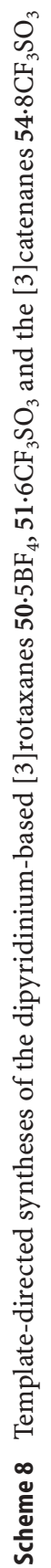


der kinetic control. The efficiency of these template-directed syntheses relies upon a supramolecular approach that utilizes a combination of cooperative noncovalent bonding interactions such as, metal-ligand interactions, $\pi-\pi$ stacking and hydrogen bonding to form intermediates, leading to the irreversible formation of mechanically interlocked molecules by the formation of a final covalent bond under kinetic control.

\section{3}

\section{Thermodynamic Approaches to the Synthesis of Interlocked Molecules}

\section{1}

\section{Introduction}

During the past 30 years, the synthesis of mechanically interlocked molecular compounds such as rotaxanes and catenanes has relied, for the most part, upon kinetically controlled reactions. However, as a result of the irreversible nature of this synthetic approach, non-interlocked by-products(free dumbbell components and free macrocycles) that are formed during the final post-assembly step, invariably reduce the yield of the mechanically interlocked compounds. So, in recent years, dynamic chemistry [134] has become the focus of some interest, leading to molecular assemblies that are formed in a thermodynamically controlled manner. In contrast with the kinetic process, the reversible thermodynamic regime allows the undesired or competitive by-products to be recycled to afford the most energetically favored mechanically interlocked compound.

\section{2}

\section{Synthesis of Interlocked Molecules by Slippage}

The so-called slippage approach has been employed successfully, in the past three decades to self-assemble a series of linear [135-139] and branched [n] rotaxanes [140-142] under thermodynamic control. In this strategy, the macrocycle and the dumbbell, which are synthesized independently prior to self-assembly, are usually heated together in an appropriate solvent until the macrocycle slips over the dumbbell's stopper by overcoming the associated free energy of activation. The resulting pseudorotaxane is stabilized by noncovalent bonding interactions. The rotaxane comes into being when the solution is cooled down to ambient temperature, at which point the free energy barrier to its dissociation back into its components becomes insurmountable.

In 1972, Harrison [143] reported the synthesis of a rotaxane using a thermodynamically controlled slippage process. This interlocked molecular compound was obtained by heating a solution containing macrocyclic hydrocarbons with ring sizes between $\mathrm{C}_{14}$ and $\mathrm{C}_{42}$ and a dumbbell-shaped compound, namely 1,10-bis(triphenylmethoxy)decane, up to $120^{\circ} \mathrm{C}$. After cooling the solution down to room temperature, Harrison was able to isolate chromatographically 
a [2] rotaxane comprised of the thread and the $\mathrm{C}_{29}$-macrocycle. It transpires that at high temperatures, the $\mathrm{C}_{29}$ macrocycle has sufficient energy to stretch out and pass over the triarylmethane stoppers to afford, after cooling, a [2] rotaxane.

Macrocycles with a ring size of $\mathrm{C}_{30}$ are instead free to pass freely over the end groups of the dumbbell and hence assemblies containing these rings are simply [2]pseudorotaxanes (1:1 complexes) at room temperature and dissociate into their components when chromatographic purification is attempted. When this type of slippage experiment was repeated in the presence of a small amount of trichloroacetic acid, a number of [2] rotaxanes containing cyclics ranging from $\mathrm{C}_{25}-\mathrm{C}_{29}$ could be separated chromatographically. Thus, Harrison postulated that, as a result of the acid-catalyzed reversible cleavage of the triaryl group, the species that threads through the $\mathrm{C}_{25}-\mathrm{C}_{29}$ rings, is now only the monotriphenylmethyl ether (i.e., the half dumbbell) prior to reformation of the ether linkage. In 1986, Schill [144] reported a similar synthesis of interlocked molecular compounds obtained by the reversible covalent bond approach but using thioethers instead of ethers.

Recently, the Stoddart group has demonstrated [135-136] the efficiency of the slippage approach by self-assembling a number of linear and branched [2]-, [3]-, and [4]rotaxanes, incorporating $\pi$-electron-rich hydroquinone-based macrocyclic polyethers and $\pi$-electron-deficient bipyridinium-based dumbbellshaped compounds. A kinetic investigation of the slippage process revealed [138, 145] that the free energies of activation associated with the slipping-on and slipping-off processes are correlated with the size of the cavity of the macrocyclic component, as well as with the size of the stoppers attached to the dumbbellshaped component. The free energy of activation was observed to increase upon reducing the size of the cavity of the macrocycle and/or enlarging the bulk of the stoppers. Rotaxanes have also been synthesized [146-148] by slippage using other well-known recognition motifs. For example [146], the interaction of secondary dialkylammonium ions with commercially available dibenzo[24]crown8. In 1997, Vögtle [148] reported the synthesis of the first amide-type rotaxane using the slippage approach. The rotaxane-like structure was achieved by briefly melting the macrocycle and dumbbell components together in order to overcome the high energy of activation for the slippage process. The reported examples demonstrate the efficiency of the thermodynamically controlled slippage approach to achieve a range of rotaxanes using a wide variety of noncovalent interactions by tuning the size between the stoppers and the macrocycle.

The slippage approach leads to rotaxanes that are only stable under certain conditions. In fact an increase in temperature, solvent polarity or acidity can drastically affect [146] the stability of rotaxanes obtained by slippage. Thus, in the last decade, more and more attention has become focussed on dynamic covalent chemistry. In this case, by utilizing reversible bond formation, in conjuction with supramolecular assistance, it is possible to make mechanically interlocked compounds by thermodynamically controlled stoppering or clipping reactions that can, in principle, produce rotaxanes that are stable under a broader range of conditions. 


\section{3 \\ Ring-Closing Metathesis Mediated Syntheses}

In 1998, the Sanders group [149] explored the use of dynamic covalent bond formation for synthesizing neutral $\pi$-associated [2] catenanes by ring-closing metathesis (RCM) [150-160]. The mechanically interlocked structure was achieved using the electronic complementarity of $\pi$-electron-deficient aromatic diimides substituted with olefin terminated alkyl chains and the $\pi$-electron-rich dinaphtho[38]crown-10 (DN38C10) in the presence of the catalyst 4. The Cambridge group proved that, in the absence of the RCM catalyst, the main product formed is a white precipitate containing presumably only a mixture of oligomeric species. However, upon treatment of this product with the catalyst 4 , the mixture of linear and cyclic oligomers re-equilibrates to afford isomeric [2]catenanes. Some competition experiments were performed using an alternative diimide derivative to confirm the reversibility of these reactions. The slow reaction kinetics, however, prevents the system from reaching the ultimate equilibrium. Despite these difficulties, the Sanders group was able to demonstrate that a reversible thermodynamic process, such as olefin metathesis, can lead to the formation of an interlocked structure. Once again, the use of noncovalent bonding interactions to direct the synthesis of the [2]catenane led to greatly improved yields compared to the previous statistical methods.

A similar approach was employed by the Leigh group [161] in the synthesis of a [2] catenane wholly stablized by hydrogen bonds. The combination of ring-closing olefin metathesis and hydrogen bond-mediated assembly of self complementary macrocycles, under appropriate condition leads to the formation (Scheme 9) of [2]catenanes in $>95 \%$ yield. A mixture of benzylic amide macrocycles ( $E$ - and $Z$-diastereoisomers) 55a (or 55b) was used in

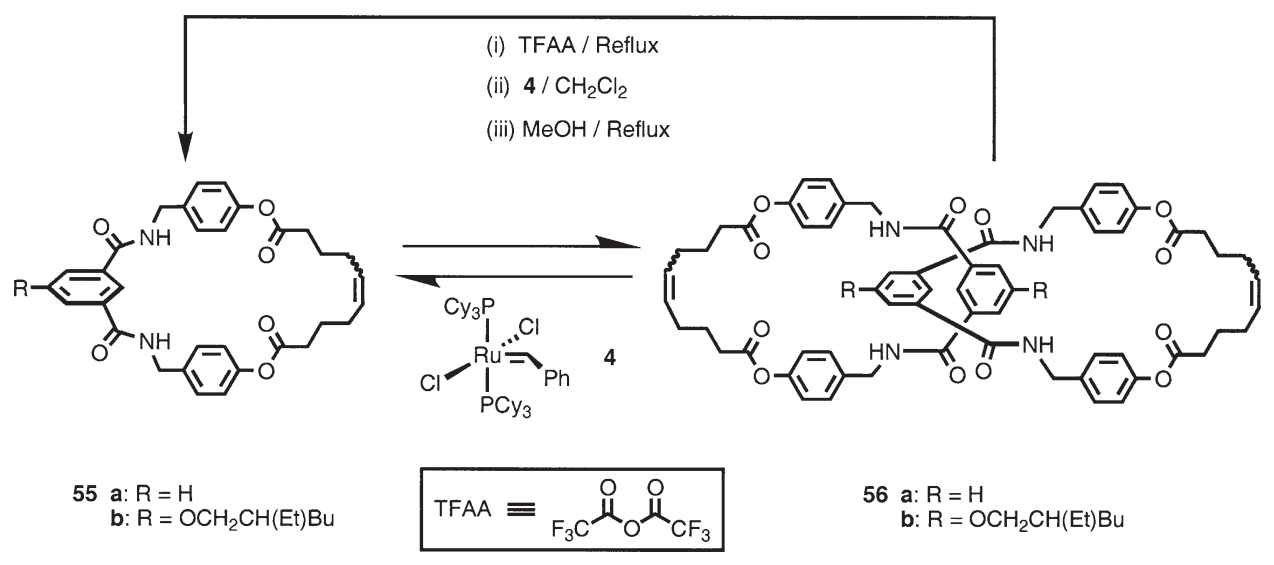

Scheme 9 Reversible olefin metathesis is employed for the synthesis of [2]catenanes 56a and 56b under thermodynamic control. Their complete disassembly is achieved upon protection of the amide groups, followed by treatment with Grubbs I catalyst 4, and subsequent deprotection 
the metathesis experiments. Reversible ring-opening ring-closing metathesis (RORCM) reactions were carried out in a noncompeting solvent (typically $\mathrm{CH}_{2} \mathrm{Cl}_{2}$ ) to maximize the strength of the inter-ring hydrogen bonding interactions in the presence of the catalyst 4 .

Under these conditions, the formation of the [2] catenane is readily detected in high yields (>95\%) reminiscent of the "magic" interlocking rings trick. In the RORCM experiment, the product distribution is, as expected, strongly dependent on the concentrations of the monomers. Thus, at low concentrations $(0.2 \mathrm{mM})$, only the macrocycles can be detected. By increasing the reaction concentrations progressively, however, more and more of the [2]catenane is produced until, at $0.2 \mathrm{M}$, more than $95 \%$ of a mixture of the three diolefin isomers $(E E, E Z, Z Z)$ is produced. The isolated mixture of these isomers can subsequently be converted into a single kinetically stable product by simply hydrogenating the double bonds catalytically.

As further proof that the metathesis reaction proceeds under thermodynamic control, the product mixture from one particular reaction was re-exposed at a different concentration to the catalyst 4 . The product distribution readjusted to that obtained if only the macrocycle (or catenane) was subjected to metathesis originally at that same concentration of the solution. Finally, to complete the magic ring-trick, the [2]catenane was disassembled into the macrocyclic components by trifluoroacetylation of the amide group in 56a and 56b. This protection procedure provides a mild and efficient method for switching "off" the inter-macrocycle hydrogen bonding interactions. Although these chemically modified macrocycles are stable in the interlocked structure, when the Grubbs I catalyst 4 is added to the mixture, the dynamic nature of the [2] catenane shifts the equilibrium towards the formation of the free macrocycles 55. Subsequently, cleavage of the trifluoroacetyl groups by refluxing in $\mathrm{MeOH}$, prior to removal of the metathesis catalyst, affords the starting parent macrocyclic compound 55.

Recently, in an extension of this work, the Leigh group [162] reported the synthesis of a rotaxane based on hydrogen bonding under thermodynamic control. In this research, a benzylic amide macrocycle, a rod containing two bulky stoppers, peptide-based template sites, and an olefinic bond are exposed to the Grubbs I catalyst 4. In a manner similar to that observed for the magic rings, the rod is broken and the macrocycle binds to the template through fourpoint hydrogen bonding. Upon reformation of the carbon-carbon double bond and removal of the metathesis catalyst, the macrocycle is then trapped on the dumbbell component of the now kinetically stable [2] rotaxane. Since the dumbbell contains two templation sites, the interlocked structure obtained can be easily converted into a [3] rotaxane by another round of metathesis. The reversibility of the magic rod systems can be convincingly demonstrated either by concentration or disassembly experiments.

In summary, the Leigh group has demonstrated with the magic ring and dumbbell experiments that the combination of the olefin metathesis reaction with hydrogen bonding interactions represents a powerful method for inte- 
grating thermodynamically controlled "error-checking" with a kinetically robust final product in the shape of mechanically interlocked compounds.

\section{4}

\section{Ammonium Ion Templated Syntheses}

Even although the introduction of supramolecular assistance to covalent synthesis leads to a tremendous improvement in reaction yields compared with the early statistical methods, the thermodynamic approach to the synthesis of wholly organic interlocked structures remained largely unexplored prior to the exploitation of the reversible imine bond [163]. Recently, the Stoddart group [164] reported a simple and effective dynamic procedure for the synthesis of a [2] rotaxane combining the reversible formation of the imine bond with the widely investigated secondary ammonium ion/crown recognition motif [119, 165-176]. Mixing a bis(4-formylbenzyl)ammonium salt with two equivalents of 3,5-di-tert-butylaniline, as a stoppering precursor, in the presence of one equivalent of DB24C8 afforded, after five days, the expected diimine [2] rotaxane as the major species (47\%) present in solution. This reaction was demonstrated to proceed under thermodynamic control by the observation that the equilibrium composition was independent of the order of the addition of components. Finally, the dynamic system can be readily converted into the kinetically stable product by addition of benzeneselenol [177], leading to the isolation of the "fixed" diamine [2] rotaxane in $18 \%$ yield.

Further investigations into the reversibility of the imine bond were conducted by Rowan and Stoddart [178] in the dynamic synthesis of [2] rotaxanes based upon $\pi$-electron-rich/ $\pi$-electron-deficient recognition expressed by diaryl ethers and bipyridinium cations [66, 179-181]. This study not only explored the reversible behavior of imine bond formation but also illustrated its ability to undergo exchange reactions with competiting amines to form new imines.

All the thermodynamically controlled syntheses of interlocked molecular compounds discussed so far in this Section have, as a common feature, the location of the reversible covalent linkage in the dumbbell component. This approach has led to the preparation of rotaxanes by either threading-followedby-stoppering [152,182-184] or slippage [135-148] protocols. However, in 2001, the Stoddart group [185] reported a simple and highly effective dynamic procedure (Scheme 10) for the formation of a [2] rotaxane by the clipping of a diamine with a dialdehyde, as the precursor components of a [24]crown-8-like macrocycle, around a dialkylammonium center that also acts as a template.

When an equimolar mixture of 2,6-diformylpyridine $\mathbf{5 7}$ and the diamine $\mathbf{5 8}$ are mixed together in acetonitrile- $d_{3}$, the ${ }^{1} \mathrm{H}-\mathrm{NMR}$ spectrum revealed broad peaks that clearly arise from a complex mixture of many different cyclic and acyclic oligomeric species. However, addition of bis(3,5-dimethoxybenzyl)ammonium hexafluorophosphate $60-\mathrm{H} \cdot \mathrm{PF}_{6}$ to this equilibrating mixture has an immediate and dramatic effect. After only a few minutes, a new equilibrium state is established in which the main component is the [2] rotaxane $61-\mathrm{H} \cdot \mathrm{PF}_{6}$. 

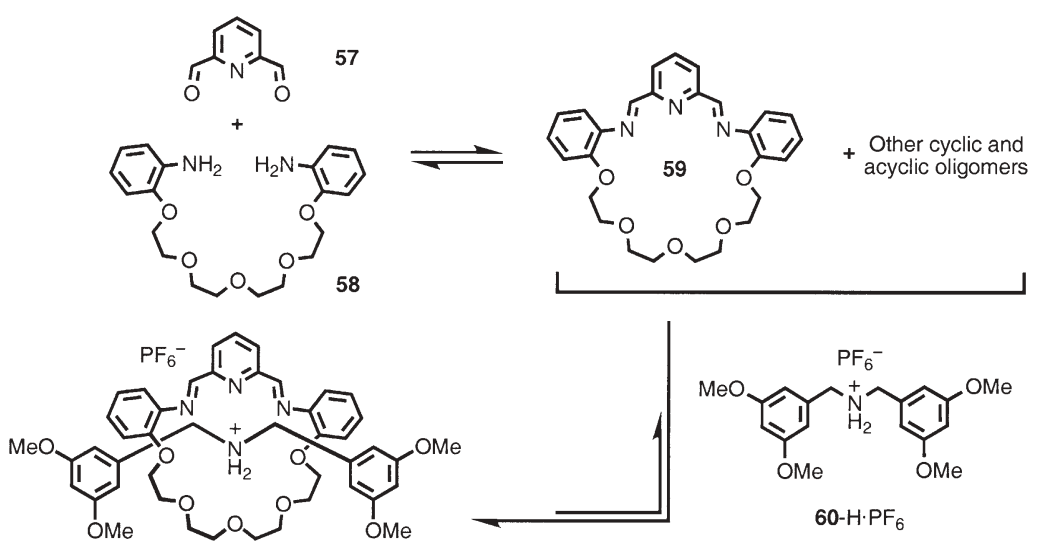

$61-\mathrm{H} \cdot \mathrm{PF}_{6}$

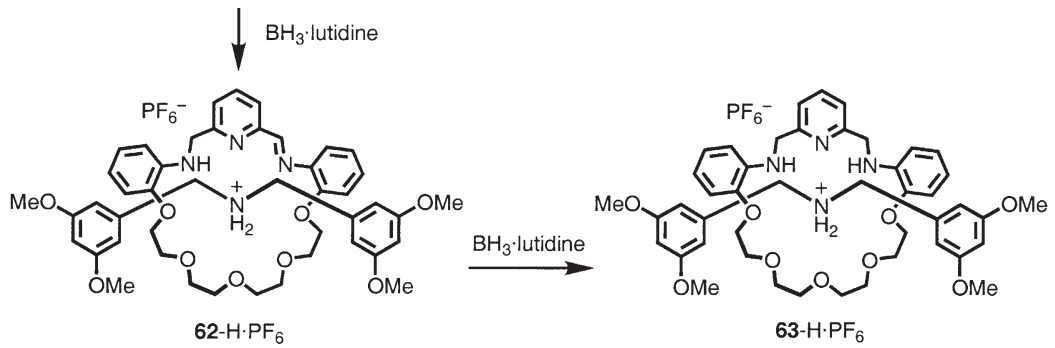

Scheme 10 Reaction of the pyridine-containing macrocycle with $60-\mathrm{H} \cdot \mathrm{PF}_{6}$ leads to the equilibrium being shifted to form almost exclusively the [2] rotaxane $61-\mathrm{H} \cdot \mathrm{PF}$. Subsequent reduction affords the kinetically stable [2] rotaxane $63-\mathrm{H} \cdot \mathrm{PF}_{6}$ in essentially quantitative yield

This result indicates that the dibenzylammonium ion templates the formation of the [24]crown-8-like macrocycle, thus generating the mechanically interlocked compound.

The [2] rotaxane obtained in this manner is thermodynamically stable, even although it interconverts slowly with its free components as a result of the presence of easily hydrolyzable imino groups. These groups can be subsequently reduced to the corresponding kinetically stable amino functions using the borane-2,6-lutidine complex [178].

The reaction between the equilibrium mixture set up by the dialdehyde 57 , the diamine 58 , and the dialkylammonium salt $60-\mathrm{H} \cdot \mathrm{PF}_{6}$, in the presence of a slight excess of the $\mathrm{BH}_{3}$.lutidine complex in $\mathrm{CD}_{3} \mathrm{CN}$, was monitored by ${ }^{1} \mathrm{H}-\mathrm{NMR}$ spectroscopy. The [2] rotaxane $61-\mathrm{H} \cdot \mathrm{PF}_{6}$ is consumed gradually with the initial appearance and subsequent disappearance of the monoreduced rotaxane $62-\mathrm{H} \cdot \mathrm{PF}_{6}$ being detected until, ultimately, the fully reduced rotaxane $63-\mathrm{H} \cdot \mathrm{PF}_{6}$ is produced.

Interestingly, the free dibenzylammonium ion signals also disappear while the reduction of the imine bonds takes place. This result indicates that the reduction of the imine bonds in the interlocked structures occurs at a rate faster 
than those of the imine bonds in the free macrocycles or acyclic oligomers. Therefore, as more of the kinetically stable $63-\mathrm{H} \cdot \mathrm{PF}_{6}$ is formed, its removal from the equilibrium mixture is compensated by a shifting of the equilibrium between threaded and free macrocycles to form more of $61-\mathrm{H} \cdot \mathrm{PF}_{6}$. Although the imino groups of the interlocked structures are not as accessible sterically as those in free macrocycles or acyclic species, the presence of the $\mathrm{NH}_{2}^{+}$center in the rotaxanes provides a mildly acidic environment for the addition of the B-H bond to these particular imines, thereby catalyzing their reduction. The whole process, namely, thermodynamic formation of the diimine [2] rotaxane followed by kinetically controlled borane reduction, is somewhat reminiscent of enzyme catalysis [186] and also catalysis employing synthetic enzyme mimics (for an example of a synthetic receptor with enzyme-like activity, see [187]), wherein an initial recognition process results in a substrate pre-organization and hence access to a conformation that lowers the activation barrier for the final reaction.

The clipping approach based on the reversible imine bond [188] was investigated further by the preparation of a library of [2] rotaxanes (Scheme 11). This study describes the influence that the constitutions of two of the three precursor components have on the kinetic and thermodynamic stabilities of these

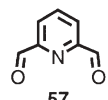

57

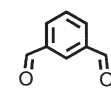

64<smiles>O=Cc1ccc(C=O)o1</smiles>

65
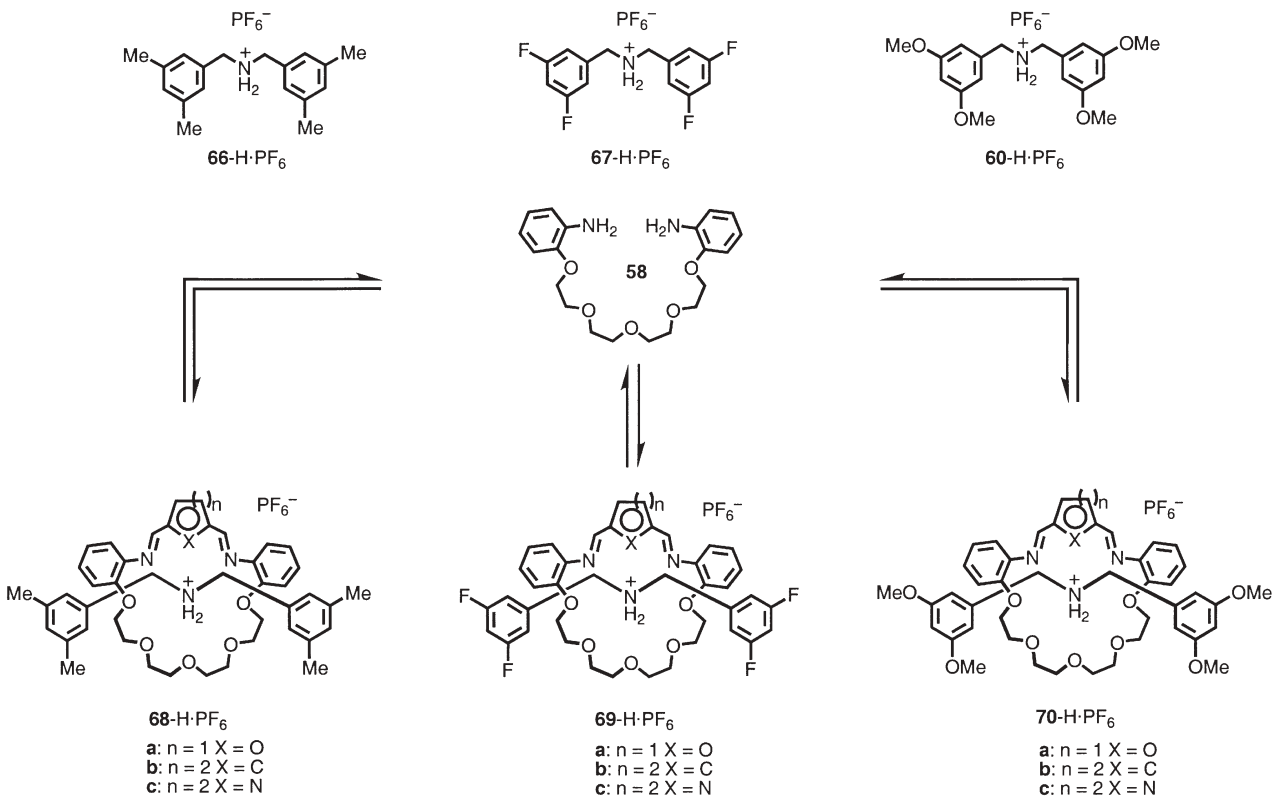

Scheme 11 Dynamic covalent syntheses of the imine [2]rotaxanes by clipping of the dialdehydes $(57,64$ and 65$)$ and the diamine 58 around the dialkylammonium ions $\left(60-\mathrm{H} \cdot \mathrm{PF}_{6}\right.$, $\left.66-\mathrm{H} \cdot \mathrm{PF}_{6}, 67-\mathrm{H} \cdot \mathrm{PF}_{6}\right)$ 
dynamically interlocked compounds. In particular, the donor-acceptor nature of the terminal benzyl stoppering groups of the dumbbell-shaped dialkylammonium ions is varied from the $\pi$-electron-rich $60-\mathrm{H} \cdot \mathrm{PF}_{6}[189]$ through the $\pi$-electron-neutral $66-\mathrm{H} \cdot \mathrm{PF}_{6}$ to the $\pi$-electron-deficient $67-\mathrm{H} \cdot \mathrm{PF}_{6}$. The dialdehyde is varied between 2,6-diformylpyridine 57 [190], isophthalaldehyde 64 and 2,5-diformylfuran 65 [191]. The tetraethylene glycol bis(2-aminophenyl)ether 58 is used as the diamine monomer in all the cases. On combining these dumbbell-shaped ions and the three dialdehydes with the diamine monomer, a library of nine dynamic [2] rotaxanes is obtained. The stabilities and stoichiometry of the dynamic [2] rotaxanes are established by mass spectrometry and ${ }^{1} \mathrm{H}-\mathrm{NMR}$ spectroscopy. The non-existence of higher-order assemblies, such as doublestranded [3]pseudorotaxanes, in this dynamic equilibrating system confirms that the [2] rotaxanes are by far the most stable entities.

The rates of rotaxane formation vary drastically, however, depending on the components used in the assembly. In general, the 2,6-diformylpyridine $\mathbf{5 7}$ is associated with the fastest clipping reactions with all of the three dumbbells, and the 2,5-diformylfuran 65 results in the slowest. Clipping of isophthalaldehyde 64 occurs at an intermediate rate. This reactivity scale is consistent [183-195] with the electrophilicities of the different formyl groups. As expected, the dialdehyde 57 exhibits the most electrophilic behavior, while 65 exhibits the least. The donor-acceptor nature of the dumbbell-shaped dialkylammonium ion also affects the rates of clipping. In particular, the $67-\mathrm{H} \cdot \mathrm{PF}_{6}$ dumbbell establishes the fastest reaction equilibria with all of the three dialdehydes. This result can be attributed to the higher acidity of the $\mathrm{NH}_{2}^{+}$center relative to those of the other dumbbells and so increases the rate of imine bond formation. Additionally, during the clipping process, there are likely to be significant aromatic-aromatic interactions occurring between the stoppers on the dumbbell and the aryl units ( $\pi$-electron-rich units in the diamine 58 and $\pi$-electron-deficient ones in 64 and 65) of the forming macrocycle.

Some predictions on the rate of clipping can be made by considering the $\pi$-electron density alone, based on the simple model of charge distribution in $\pi$-systems proposed by Hunter and Sanders [81]. This model indicates that fast clipping reactions would occur for the most $\pi$-electron-rich dumbbell with the most $\pi$-electron-deficient dialdehyde (i.e., $60-\mathrm{H} \cdot \mathrm{PF}_{6}$ with 57 ) and the most $\pi$-electron-deficient dumbbell with the most $\pi$-electron-rich dialdehyde (i.e., $67-\mathrm{H} \cdot \mathrm{PF}_{6}$ with 65 ), as well as for pairs of $\pi$-electron-deficient dumbbells and dialdehydes (i.e., $67-\mathrm{H} \cdot \mathrm{PF}_{6}$ with 57 ). Based on the same idea, the slowest clipping reactions should occur for the interaction of the most $\pi$-electron-rich dumbbell with the most $\pi$-electron-rich dialdehyde (i.e., $60-\mathrm{H} \cdot \mathrm{PF}_{6}$ with 65 ). The Hunter-Sanders model turns out to be a good one for explaining the rates of the dynamic reactions obtained by ${ }^{1} \mathrm{H}-\mathrm{NMR}$ spectroscopic studies. Another factor that influences the rate of reaction is the number of hydrogen bond acceptors in the nascent macrocycles. Thus, macrocycles containing either pyridine or furan units bind to all of the dialkylammonium-ions more strongly than the one derived from the isophthalaldehyde. 
Estimations of the effective association constants $\left(K_{\text {eff }}\right)^{1}$ between the macrocycles and dumbbells are available for all nine systems. The $K_{\text {eff }}$ values support the fact that [2] rotaxanes $68 \mathrm{a}, \mathrm{c}-\mathrm{H} \cdot \mathrm{PF}_{6}, 69 \mathrm{a}, \mathrm{c}-\mathrm{H} \cdot \mathrm{PF}_{6}$ and $70 \mathrm{a}, \mathrm{c}-\mathrm{H} \cdot \mathrm{PF}_{6}$ are more thermodynamically stable (i.e., they have high values of $K_{\text {eff }}$ ) on account of the incorporation of eight heteroatoms into their macrocycles. By contrast, low values of $K_{\text {eff }}$ are estimated for the remaining three [2] rotaxanes $68 \mathrm{~b}-\mathrm{H} \cdot \mathrm{PF}_{6}$, $69 \mathrm{~b}-\mathrm{H} \cdot \mathrm{PF}_{6}$ and $70 \mathrm{~b}-\mathrm{H} \cdot \mathrm{PF}_{6}$ incorporating the isophthaloyl unit and are related to the absence of the extra heteroatom as well as to the presence of an aryl hydrogen atom, which may interact sterically in an unfavorable manner with the dumbbell.

The [2] rotaxanes $69 \mathrm{a}-\mathrm{c}-\mathrm{H} \cdot \mathrm{PF}_{6}$, which incorporate the most $\pi$-electron-deficient dumbbell, are the most stable thermodynamically; a feature that is probably a consequence of a combination of enhanced $\left[\mathrm{N}^{+}-\mathrm{H} \cdots \mathrm{X}\right]$ hydrogen bonding and significant aromatic $\pi-\pi$ stacking interactions. Finally, $K_{\text {eff }}$ values for [2] rotaxanes containing pyridine or furan units are similar for each dumbbell-shaped ion and are comparable to the strengths of binding in $\mathrm{CD}_{3} \mathrm{CN}$ of disubstituted dibenzylammonium salts with the crown ethers DB24C8 [118, 196-198] and dipyridyl[24]crown-8 [199].

Several competition experiments were also conducted to evaluate the relative stabilities of pairs of [2] rotaxanes formed from a choice of either two dialdehydes or two dumbbell-shaped components. These experiments were carried out in $\mathrm{CD}_{3} \mathrm{CN}$ with equimolar mixtures of four chosen components in which either (a) the four components were mixed together and then equilibrated or (b) the competing dumbbell or dialdehyde was added to a pre-equilibrated mixture of a single [2] rotaxane and the reaction was monitored until re-equilibration occurred. The times (6-30 days) required for these systems to reach equilibrium are generally longer than those found for the formation of a [2] rotaxane on combining the three single components - namely the diamine, the dialdehyde, and the dibenzylammonium salt. This observation suggests that the rates of macrocyclic ring opening of the [2] rotaxanes are relatively slow when compared to the rates of their clipping. Once again, the data showed that the [2] rotaxanes formed by using the fluorine-containing dialkylammonium ion $60-\mathrm{H} \cdot \mathrm{PF}_{6}$ were the most stable. The differences in the stabilities of the [2] rotaxanes, incorporating either methoxy or methyl units in the dumbbell, were found to be negligible. Comparing the $K_{\text {eff }}$ values with the data collected from the competitive experiments, it

\footnotetext{
${ }^{1} K_{\text {eff }}$ values between a macrocycle and a dumbbell in a rotaxanes were obtained using the equation: $K_{\text {eff }}=\frac{\text { Rotaxane }}{\text { Macrocycle }}$ Dumbbell. This equation is based on the assumption that, in an equimolar mixture of dialdehyde, diamine, and dumbbell, all of the diamine and dialdehyde that is not incorporated into a [2] rotaxane is condensed into a free macrocycle whose concentration is equal to that of the uncomplexed dumbbell minus the concentration of the free dialdehyde. The real concentration of each free macrocycle is smaller than that, but, by making this assumption, we reduce the complexity of the system down to a bimolecular self-assembly involving one macrocycle and one dialkylammonium ion.
} 


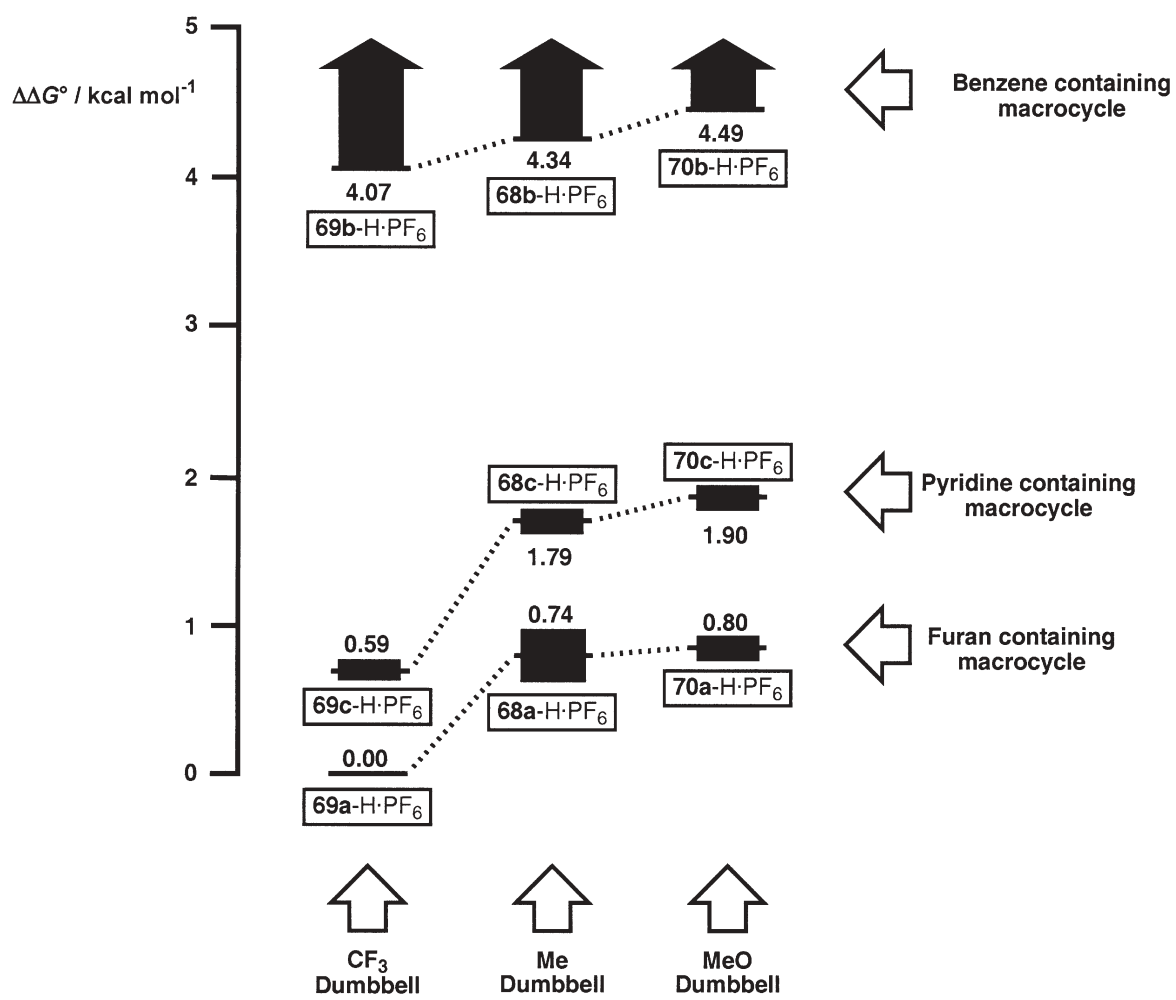

Fig. 4 Stabilities of the nine [2] rotaxanes in a competition experiment relative to the stability of [2] rotaxane $69 \mathrm{a}-\mathrm{H} \cdot \mathrm{PF}_{6}$, which is designated as zero. The thickness of each black bar indicates the error associated with each measurement

is possible to obtain the complete sequence of relative stabilities for the nine [2]rotaxanes studied. These are portrayed graphically in Fig. 4.

The fluorine-containing [2] rotaxanes $69 \mathrm{a}-\mathrm{c}-\mathrm{H} \cdot \mathrm{PF}_{6}$ are found to be the most stable compounds, whereas [2] rotaxanes derived from isophthalaldehyde 64 are the least stable. An unexpected result is the higher stability of furan-containing [2] rotaxanes $68 \mathrm{a}-\mathrm{H} \cdot \mathrm{PF}_{6}, 69 \mathrm{a}-\mathrm{H} \cdot \mathrm{PF}_{6}$ and $70 \mathrm{a}-\mathrm{H} \cdot \mathrm{PF}_{6}$ compared to the interlocked structures incorporating the pyridine ring. One might expect that a pyridine ring, being more basic than the furan one, would form the stronger hydrogen bonds. It is suggested, however, that the relative basicities of the pyridine and furan rings incorporated in the macrocycles is only one of the factors that play a part in determining the relative stabilities of the structure and that the basicities of their imino nitrogen atoms must be considered as well. $^{2}$

${ }^{2}$ The solid-state structure of a reduced form of $61-\mathrm{H} \cdot \mathrm{PF}_{6}$ suggests that the aminophenyl nitrogen atoms are important for hydrogen bonding with the $\mathrm{NH}_{2}^{+}$center. 
In fact, any partial positive charge that these groups receive upon hydrogen bonding to an $\mathrm{NH}_{2}^{+}$center is better stabilized by the furan ring than by a pyridine one, by virtue of the former's greater $\pi$-electron density. The pyridine ring may be expected to also withdraw a significant amount of electron density mesomerically from the phenolic ether oxygen atoms of the macrocycle. Thus, although the furan ring, when compared with the pyridine ring, is not as capable of accepting a hydrogen bond directly, the enhanced basicity of its neighboring imino and phenoxy units results in a more strongly coordinating macrocycle. ${ }^{3}$ To our knowledge, this study represents the most complete piece of work on [2] rotaxanes that are thermodynamically equilibriating with their starting products, based on a dynamic imine clipping. These systems are remarkably sensitive to small changes in the constitutions of the macrocyclic and dumbbell-shaped components, which in turn have dramatic effects on the kinetics and thermodynamics of the assemblies.

Another important investigation on some interlocked molecular compounds synthesized thermodynamically was recently reported by the Grubbs group [200]. In this work, the well established mutual recognition exhibited by secondary dialkylammonium $\left(\mathrm{R}_{2} \mathrm{NH}_{2}^{+}\right)$ions and suitably sized crown ethers is combined, in an elegant fashion, with the versatile reversible RCM reaction. In this manner, a terminal diolefin macrocyclic precursor 71 (Scheme 12) was designed in an effort to mimic the significant $\mathrm{R}_{2} \mathrm{NH}_{2}^{+}$ion-binding capability of DB24C8.

Treatment of this linear oligomer 71 with the Grubbs I catalyst 4 [201] under dilute conditions, gave the 24 -membered olefinic crown ether analog 72 as a mixture of $E$ and $Z$ isomers. The constitution of the macrocycle is strikingly similar in nature to the macrocyclic skeleton of $24 \mathrm{C} 8 .{ }^{1} \mathrm{H}-\mathrm{NMR}$ spectroscopic analyses showed that compound $\mathbf{7 2}$ interacts readily with a dibenzylammonium ion rod to form a 1:1 complex with a threaded geometry, i.e., a [2]pseudorotaxane. Therefore, repeating the same RCM reaction of the terminal diolefin 71 in the presence of a dumbbell-shaped template containing an ammonium ion $60-\mathrm{H} \cdot \mathrm{PF}_{6}$ leads to the isolation of the corresponding [2] rotaxane as a mixture of $E$ and $Z$ isomers in $73 \%$ yield.

The significant templating effect of the $\mathrm{NH}_{2}^{+}$ion center can be appreciated by comparing this reaction with the untemplated macrocyclization of 71 to form the cyclic compound 72. In fact, while the untemplated reaction is carried out at low concentration $(5 \mathrm{mM})$ to avoid oligo/polymerization and yields only $48 \%$ of the desired macrocycle, the templated reaction can be performed at

\footnotetext{
${ }^{3}$ Inspection of molecular models (Chem3D) suggests that the bite angle of a 2,5-diiminofuryl unit $\left(\mathrm{N} \cdots \mathrm{O} \cdots \mathrm{N}\right.$ angle of ca. $\left.144^{\circ}\right)$ is somewhat larger than that of a corresponding pyridyl unit $\left(\mathrm{N} \cdots \mathrm{N} \cdots \mathrm{N}\right.$ angle of ca. $\left.125^{\circ}\right)$. This larger bite angle suggests that any $\mathrm{NH}_{2}^{+}$unit that hydrogen bonds to the two imino nitrogen atoms of these subunits will be positioned about $0.4 \AA$ closer to the furan oxygen atom than to the pyridine nitrogen atom. This small structural effect may result in more favourable electrostatic interactions and help to explain the stability of [2] rotaxanes incorporating the furan unit.
} 


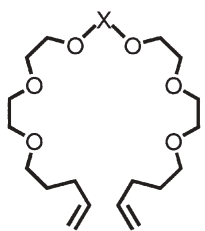

71 a: $\mathrm{X}=\mathrm{CH}_{2} \mathrm{CH}_{2}$ b: $\mathrm{X}=0-\mathrm{C}_{6} \mathrm{H}_{4}$

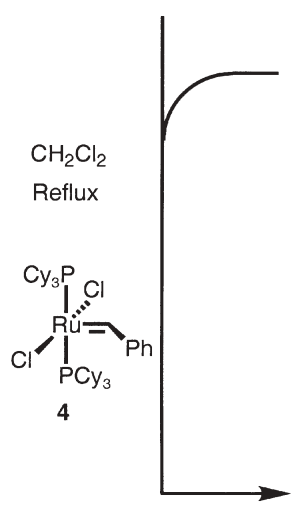

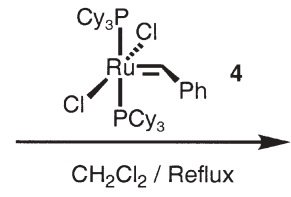
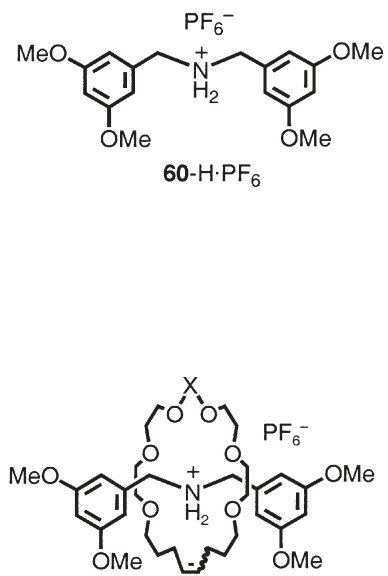

$74 \mathrm{a}-\mathrm{H} \cdot \mathrm{PF}_{6}: \mathrm{X}=\mathrm{CH}_{2} \mathrm{CH}_{2}$ $74 \mathrm{~b}-\mathrm{H} \cdot \mathrm{PF}_{6}: \mathrm{X}=\mathrm{O}-\mathrm{C}_{6} \mathrm{H}_{4}$

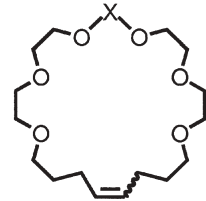

72 a: $\mathrm{X}=\mathrm{CH}_{2} \mathrm{CH}_{2}$ b: $\mathrm{X}=0-\mathrm{C}_{6} \mathrm{H}_{4}$

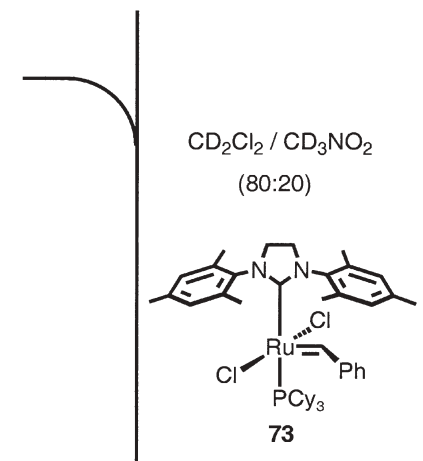

Scheme 12 Synthesis of the olefin macrocycles 72, via their corresponding diolefin precursors 71. Rotaxane synthesis can be achieved through either a ring-closing-metathesis approach, by utilizing 71 as starting material (lower left pathway), or by a magic ring synthesis in which the preformed macrocycles 72 are employed (lower right pathway)

much higher concentrations (ca. $100 \mathrm{mM}$ in this case) to give $73 \%$ of the mechanically interlocked system.

The inherent reversibility of this system was investigated by performing a magic ring experiment. The second generation Grubbs II catalyst 73 was added to a mixture containing equimolar quantities of the dumbbell $60-\mathrm{H} \cdot \mathrm{PF}_{6}$ and the macrocycle 72. ${ }^{1} \mathrm{H}-\mathrm{NMR}$ spectroscopic analysis, prior to the addition of any catalyst, confirmed that the terminally bulky substituted secondary dialkylammonium ion $60-\mathrm{H} \cdot \mathrm{PF}_{6}$ cannot pass through the cavity of the 24 -membered macrocyclic ring. However, upon the addition of the Grubbs II catalyst 73 [202] (10 mol\%), the system re-equilibrates to a new thermodynamic minimum ${ }^{4}$ and results in the formation of the [2] rotaxane $74 a / b$. The equilibrium was achieved after only $45 \mathrm{~min}$ and more than $95 \%$ of the species in solution was identified as the desired interlocked compound.

\footnotetext{
${ }^{4} \mathrm{~A}$ thermodynamic minimum is a process driven by the creation of $\mathrm{N}^{+}-\mathrm{H} \cdots \mathrm{O}$ and $\mathrm{C}-\mathrm{H} \cdots \mathrm{O}$ hydrogen bonds.
} 


\section{5 Disulfide-Based Systems}

A common dynamic covalent bond, widespread in natural systems (i.e., stabilizing protein structures), is the thiol-disulfide redox system. Extensive mechanistic studies on thiols and disulfides by Whitesides [203] has shown that disulfide exchange takes place efficiently under mild conditions in the presence of a catalytic amount of a thiol and that disulfides are stable toward many different functional groups. Although disulfide linkages have been employed in the synthesis of both catenanes [204] and rotaxanes ${ }^{5}$ [205], this potentially reversible covalent bond was employed for the first time to construct an interlocked molecule under thermodynamic control in early 2000 by the Takata group [206-207]. A symmetrical dumbbell-shaped compound $75-\mathrm{H}_{2} \cdot 2 \mathrm{PF}_{6}$ possessing two secondary dialkylammonium ion centers in addition to a centrally located disulfide linkage was synthesized. In the knowledge that DB24C8 can bind secondary dialkylammonium ions within its macroring, two equivalents of this crown ether were added (Scheme 13) to a solution of $75-\mathrm{H}_{2} \cdot 2 \mathrm{PF}_{6}$ in $\mathrm{CD}_{3} \mathrm{CN}$. No crown ether was observed to thread onto the dumbbell containing two $\mathrm{NH}_{2}^{+}$centers since the 3,5-di-tert-butylphenyl end groups are far too large to pass through the cavity of the DB24C8 macrocycle, even when the solution is heated to $100{ }^{\circ} \mathrm{C}$. Upon addition of a catalytic amount of benzenethiol, however, the slow formation (equilibrium is reached after 30 days) of both a [2]- and a [3] rotaxane ( 8 and $58 \%$, respectively) was observed. In the event, the small amount of catalytic thiol acts to "unlock" the disulfide bond in the dumbbell and create two threads containing $\mathrm{NH}_{2}^{+}$centers, both of which are capable of threading through a DB24C8 macrocycle. Subsequent attack of the thiol-terminated [2]pseudorotaxane on any of the disulfides present in solution results in the formation of either a [2]- or a [3] rotaxane, $76-\mathrm{H}_{2} \cdot 2 \mathrm{PF}_{6}$ and $77-\mathrm{H}_{2} \cdot 2 \mathrm{PF}_{6}$, respectively.

Takata [207] also went on to show that increases in both temperature and catalyst loading resulted in the equilibrium being reached more quickly in this dynamic system. In a similar experiment, a small amount of benzenethiol was added to a solution of the dumbbell and DB24C8 (1:2 ratio, respectively) in $\mathrm{CD}_{3} \mathrm{CN}$. The mixture was heated at $50^{\circ} \mathrm{C}$ and the progress of the reaction was monitored by ${ }^{1} \mathrm{H}-\mathrm{NMR}$ spectroscopy. This time, the [2] rotaxane $76-\mathrm{H}_{2} \cdot 2 \mathrm{PF}_{6}$ was formed faster, and its yield gradually increased to reach a maximum value (69\%) after only $4 \mathrm{~h}$. Eventually the signals in the ${ }^{1} \mathrm{H}-\mathrm{NMR}$ spectrum relating to the [3] rotaxane start to appear and they increase rapidly with a concomitant decrease in the amount of the [2] rotaxane in the mixture. Finally, the system reached equilibrium after about $36 \mathrm{~h}$ (instead of 30 days) and the final yields

\footnotetext{
${ }^{5}$ The kinetically controlled crystallization of a dynamic system appears to have been used to advantage in a high yielding preparation of a [3] rotaxane following a reversible oxidative coupling of the thiol groups of two [2] pseudorotaxane supermolecules by a so-called molecular riveting action.
} 


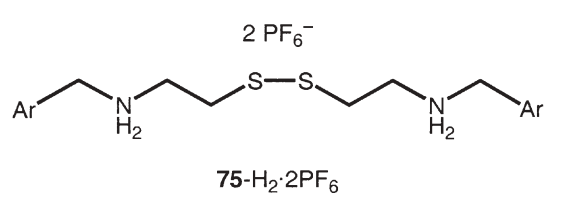

a: $\mathrm{Ar}=3,5-(t-\mathrm{Bu})_{2} \mathrm{C}_{6} \mathrm{H}_{3}$

b: $\mathrm{Ar}=4-t-\mathrm{BuC}_{6} \mathrm{H}_{4}$

c: $\mathrm{Ar}=3,5-(\mathrm{Me})_{2} \mathrm{C}_{6} \mathrm{H}_{3}$

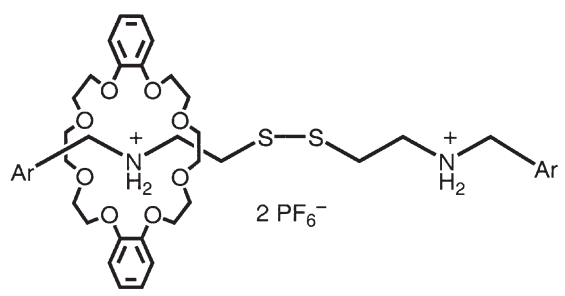

$76-\mathrm{H}_{2} \cdot 2 \mathrm{PF}_{6}$

$$
\begin{aligned}
& \text { a: } \mathrm{Ar}=3,5-(t-\mathrm{Bu})_{2} \mathrm{C}_{6} \mathrm{H}_{3} \\
& \text { b: } \mathrm{Ar}=4-t-\mathrm{BuC} \mathrm{C}_{6} \mathrm{H}_{4} \\
& \text { c: } \mathrm{Ar}=3,5-(\mathrm{Me})_{2} \mathrm{C}_{6} \mathrm{H}_{3}
\end{aligned}
$$
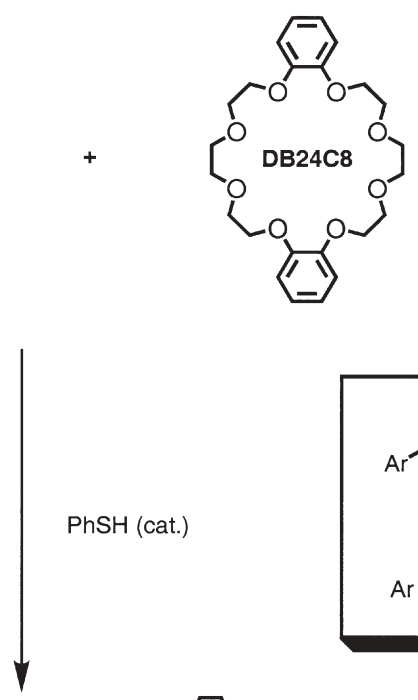

$\downarrow$
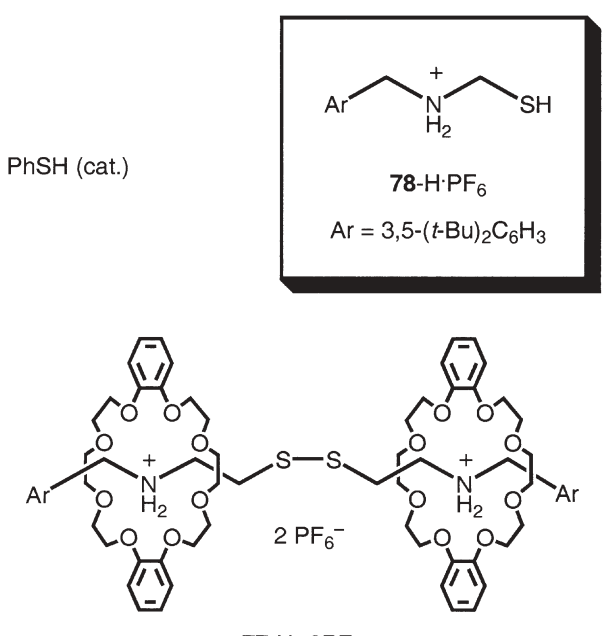

$77-\mathrm{H}_{2} \cdot 2 \mathrm{PF}_{6}$

a: $\mathrm{Ar}=3,5-(t-\mathrm{Bu})_{2} \mathrm{C}_{6} \mathrm{H}_{3}$
b: $\mathrm{Ar}=4-t-\mathrm{BuC}{ }_{6} \mathrm{H}_{4}$
c: $\mathrm{Ar}=3,5-(\mathrm{Me})_{2} \mathrm{C}_{6} \mathrm{H}_{3}$

Scheme 13 Synthesis of the [2]- and [3] rotaxane $76-\mathrm{H}_{2} \cdot 2 \mathrm{PF}_{6}$ and $77-\mathrm{H}_{2} \cdot 2 \mathrm{PF}_{6}$, respectively, by thiol-disulfide bond interchange

of $76-\mathrm{H}_{2} \cdot 2 \mathrm{PF}_{6}$ and $77-\mathrm{H}_{2} \cdot 2 \mathrm{PF}_{6}$ were 29 and $65 \%$, respectively. If the system is cooled down to room temperature for $80 \mathrm{~h}$, the reaction mixture reaches another equilibrium state in which the yields of [2]- and [3] rotaxanes are 15 and $81 \%$, respectively. Since the main driving force for rotaxane formation is the exothermic hydrogen-bonding interaction between the secondary dialkylammonium group and DB24C8, the equilibrium shifts to the [3] rotaxane side on lowering the reaction temperature. And, of course, raising the temperature again to $50{ }^{\circ} \mathrm{C}$ returns the equilibrium to its original state. These observations are wholly consistent with a reversible process where the yields of the rotaxanes can be changed under thermodynamic control.

Changing the solvent polarity also drastically affects the yields of the interlocked species. By using a mixture of $\mathrm{CDCl}_{3} / \mathrm{CD}_{3} \mathrm{OD}(1: 1)$ instead of $\mathrm{CD}_{3} \mathrm{CN}$ as solvent, the equilibrium shifts to give predominately the [2] rotaxane $(37 \%$ at $\left.50^{\circ} \mathrm{C}\right)$. When nitromethane $\left(\mathrm{CD}_{3} \mathrm{NO}_{2}\right)$ was used as the solvent, the highest yield 
(83\%) of [3] rotaxane $77-\mathrm{H}_{2} \cdot 2 \mathrm{PF}_{6}$ was observed, while the use of dimethylformamide (DMF) as solvent resulted in a dramatic decrease in yield (total yield of interlocked compounds $<10 \%)$. Both the experiments were carried out at $50{ }^{\circ} \mathrm{C}$.

As expected, increasing the amount of the $\mathrm{DB} 24 \mathrm{C} 8$ also shifts the equilibrium of the reaction mixture. When equimolar amounts of DB24C8 and $76-\mathrm{H}_{2} \cdot 2 \mathrm{PF}_{6}$ were employed, the [2] rotaxane was obtained preferentially (at $50{ }^{\circ} \mathrm{C}$ ). Increasing the $\mathrm{DB} 24 \mathrm{C} 8$ /dumbbell ratio dramatically shifts the equilibrium to the [3] rotaxane $77-\mathrm{H}_{2} \cdot 2 \mathrm{PF}_{6}[208-209]$.

To evaluate the effect of the thiol catalyst, the monomer $78-\mathrm{H} \cdot \mathrm{PF}_{6}$ and tert$\mathrm{BuSH}$ were used as initiators. The use of $78-\mathrm{H} \cdot \mathrm{PF}_{6}$ retarded the reaction rate and the yield of the [2] rotaxane reached a maximum $33 \mathrm{~h}$ after initiation, indicative of a much slower rate than that obtained with $\mathrm{PhSH}$. The advantage of this slow rate, however, is that it makes it easier to isolate the [2] rotaxanes. When tert-BuSH was employed as an initiator, the reaction rate was much slower than that obtained with $\mathrm{PhSH}$ and $78-\mathrm{H} \cdot \mathrm{PF}_{6}$. The system did not reach equilibrium, even after $300 \mathrm{~h}$. This result can be attributed to the low nucleophilicity of tert-BuSH because of the steric hindrance of tert-Bu group.

In fact, the disulfide linkages can be cleaved by various nucleophiles other than thiols [210], such as 4-nitrophenol, diethylamine, and hexamethylphosphoric triamide (HMPT). Diethylamine was observed to catalyze the rotaxane synthesis, yielding $25 \%$ and $4 \%$, of the [2]- and [3] rotaxane, respectively, at $50{ }^{\circ} \mathrm{C}$ after $67 \mathrm{~h}$, but the reaction rate was as slow as that with tert-BuSH.HMPT also catalyzed the formation of [2]- and [3] rotaxane $76-\mathrm{H}_{2} \cdot 2 \mathrm{PF}_{6}$ and $77-\mathrm{H}_{2} \cdot 2 \mathrm{PF}_{6}$, (the yields were 60 and $25 \%$, respectively, at $50{ }^{\circ} \mathrm{C}$ after $54 \mathrm{~h}$ ). Finally, 4-nitrophenol did not react with $75-\mathrm{H}_{2} \cdot 2 \mathrm{PF}_{6}$ at $50^{\circ} \mathrm{C}$, even after $60 \mathrm{~h}$. Thus, amines and phosphines are potential catalysts for rotaxane synthesis utilizing the reversible nature of disulfide linkages.

\section{6}

\section{Summary}

To the best of our knowledge, four dynamic interlocked architectures have been examined to date (Fig. 5). A dynamic [2] catenane, in which each ring contains one or more reversibly formed covalent bonds (I), can be utilized for the self-assembly of homocircuit [2] catenanes, as demonstrated by Leigh [161].

However, as shown by the Sanders group [149], it is possible to assemble a dynamic [2] catenane (II) that is comprised of one static ring and one reversibly formed ring, thereby affording a heterocircuit [2]catenane. It has been shown that both structures III and IV can be utilized successfully in the self-assembly of dynamic [2] rotaxanes [164, 178, 185, 200, 208-209]. The reversibly formed component can be located in either the dumbbell (III) or the ring (IV) components, thus allowing for threading-followed-by-stoppering and clipping approaches, respectively. It should be noted that structure $\mathbf{V}$, in which both components of the [2] rotaxane contain reversibly formed linkages, is largely 


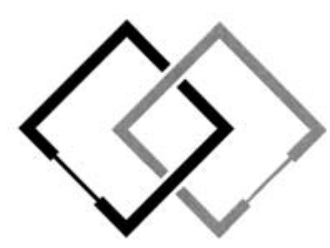

I

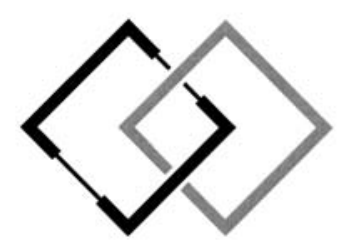

II

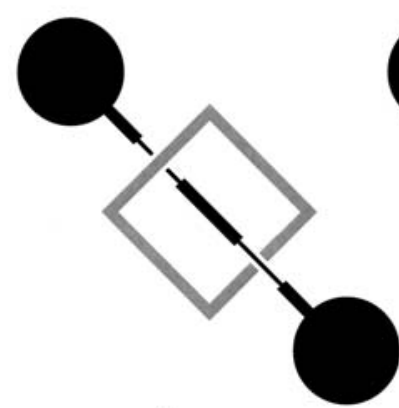

III

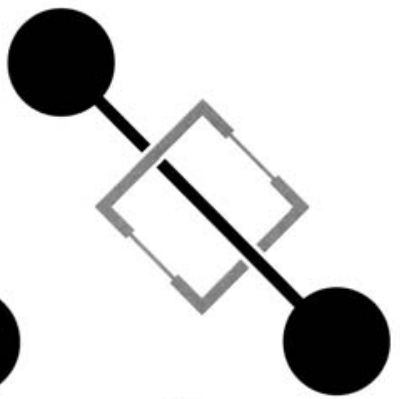

IV

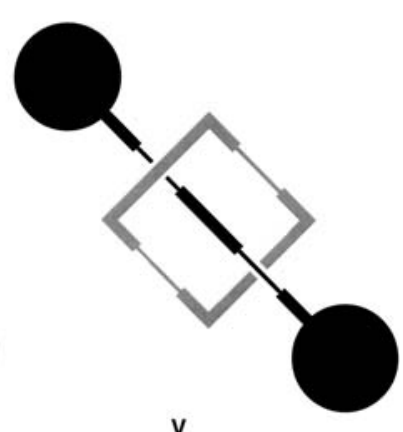

V

Fig. 5 Selected examples of dynamic [2]catenanes (I and II) and dynamic [2] rotaxanes (III-V). The thin lines represent dynamic covalent bonds

redundant as the only advantage of each component in an interlocked assembly having dynamic covalent bonds arises in cases where a homocircuit [2] catenane is desired. A [2] rotaxane comprised of a dynamic ring, as well as of a dynamic dumbbell, requires a certain orthogonality in the choice of the reversible reactions chosen for each component, i.e., the formation of the ring should not interfere with the formation of the dumbbell and vice versa.

In summary, the use of thermodynamically controlled approaches for the synthesis of wholly organic interlocked molecules is slowly growing in popularity. The use of olefin metathesis, imine formation/exchange and disulfide exchange as the reversible covalent step - in addition to the exploitation of different molecular recognition motifs - demonstrates the generality of thermodynamically controlled approaches for the synthesis of mechanically interlocked molecules.

\section{4}

\section{Multivalency and Interlocked Molecules}

The preparation of increasingly complex and functional mechanically interlocked molecules using template-directed methods will depend to a great extent on our understanding of the concept of multivalency [211-215]. The coordi- 
nated binding of multiple ligands on one chemical entity to multiple receptors on another is typically defined as a multivalent interaction and it can be much stronger than the sum of the corresponding monovalent interactions [216-225]. The relative ease of increasing binding affinities by multiplying the number of existing interactions [226-229], rather than addressing the more complicated task of evolving a new and stronger interaction could be an efficient way forward in the design of more effective receptors, drug delivery agents, inhibitors, and catalysts [230-235]. In an effort (i) to enhance noncovalent associations of molecules in unnatural settings, and (ii) to be able to build mechanically interlocked molecules beyond rotaxanes and catenanes, the complexation of multi-ligand with multi-receptor compounds and the construction of multivalent two-component mechanically interlocked bundles [236-240] have been investigated.

The formation of a triply threaded, two-component supramolecular bundle [79 $\left.\supset \mathbf{8 0}-\mathrm{H}_{3}\right] \cdot 3 \mathrm{PF}_{6}$ (Scheme 14) has been demonstrated [241-242], wherein each arm of a trifurcated trication $\mathbf{8 0}-\mathrm{H}_{3} \cdot 3 \mathrm{PF}_{6}$ (in which three dibenzylammonium ions are linked 1,3,5 to a central benzenoid core) is threaded through each macroring of a tritopic receptor 79 , in which three benzo[24]crown-8 macrorings are fused onto a triphenylene core. Spectroscopic, photophysical and electrochemical experiments corroborated the formation of a very stable 1:1 adduct $\left(K_{\mathrm{a}}>10^{7} \mathrm{~mol} \mathrm{~L}^{-1}\right.$ in $\left.\mathrm{CH}_{2} \mathrm{Cl}_{2}\right)$ with the averaged $C_{3 \mathrm{~V}}$ symmetry in solution. The supramolecular bundle [ $\left.79 \supset \mathbf{8 0}-\mathrm{H}_{3}\right] \cdot 3 \mathrm{PF}_{6}$ is both kinetically and thermodynamically stable, lending itself to studies in which template-directed methods could be probed in the syntheses of multivalent interlocked molecules.

[1,3]-Dipolar cycloaddition reactions have been used to pursue the postassembly covalent modification of a multivalent supramolecular assembly, wherein one molecular structure interpenetrates another molecular structure ${ }^{6}$ [243] to yield a mechanically interlocked molecular compound. The triply threaded superbundle $83-\mathrm{H}_{3} \cdot 3 \mathrm{PF}_{6}$ (Scheme 15) containing the tritopic crown ether 79 and the trifurcated trisammonium trication $81-\mathrm{H}_{3} \cdot 3 \mathrm{PF}_{6}$, which carries azidomethyl functions on the para positions of its three benzyl groups, was initially assembled [244] in $\mathrm{CH}_{2} \mathrm{Cl}_{2} / \mathrm{MeCN}$ (3:2) in $40 \%$ yield. Interestingly, neither the singly nor the doubly threaded mechanically interlocked compounds were detected or isolated ${ }^{7}[245]$. The complete mechanical entanglement was

\footnotetext{
${ }^{6}[1,3]$-Dipolar cycloadditions have already been used successfully in the template-directed synthesis of [2]-rotaxanes, using a threading-followed-by-stoppering approach, see [17]. Furthermore, a range of virtually instantaneous reactions, i.e., click chemistry, may be utilized in the place of the cycloaddition.

${ }^{7}$ In the strict self-assembly of a triply threaded two-component superbundle, starting from a tritopic receptor in which three benzo[24]crown-8 macrorings are fused onto a triphenylene core and a trifurcated trication wherein three bipyridinium units are linked $1,3,5$ to a central benzenoid core, it transpires that the rapid formation of a doubly threaded two-component complex is followed by an extremely slow conversion over a week at $253 \mathrm{~K}$ in $\mathrm{CD}_{3} \mathrm{COCD}_{3}$ to reach equilibrium of this kinetically controlled product into a thermodynamically controlled one - namely, a triply threaded two-component superbundle.
} 


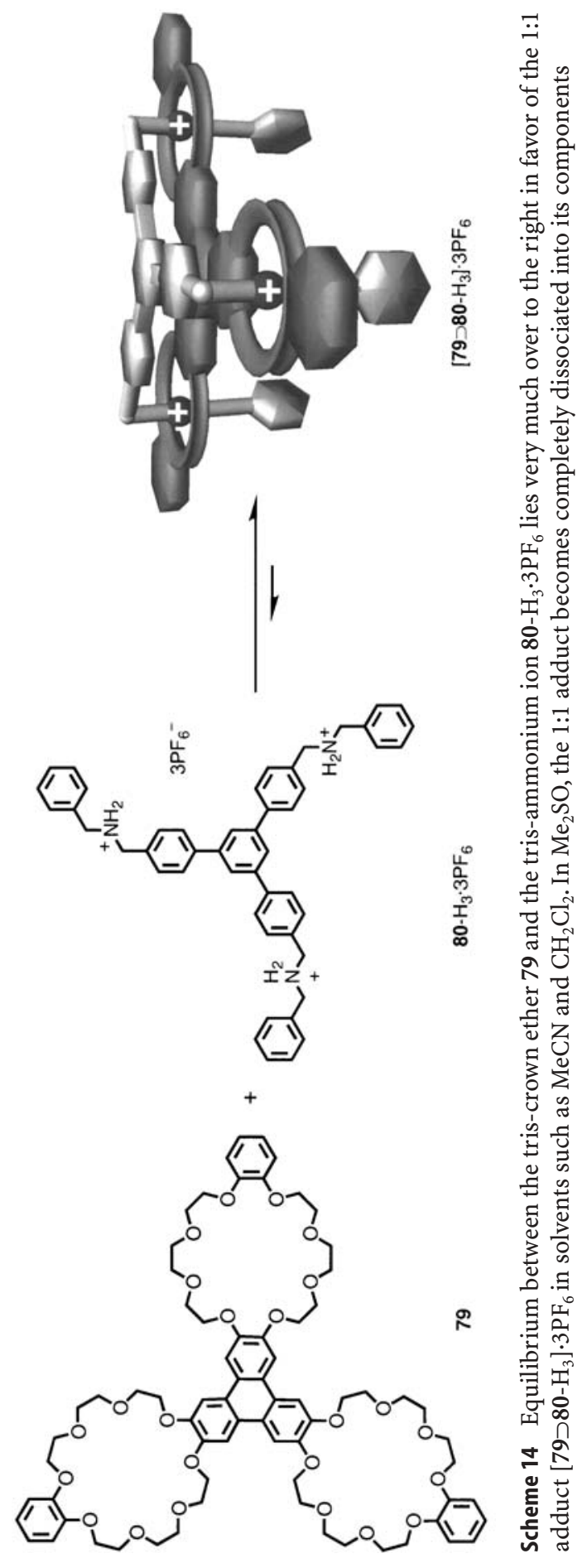


vindicated in experiments where the bundle $83-\mathrm{H}_{3} \cdot 3 \mathrm{PF}_{6}$ was fully deprotonated using a strong base tert-BuOK. Although the deprotonation did loosen the interlocked molecular structure, a result of replacing relatively strong $\left[\mathrm{N}^{+}-\mathrm{H} \cdots \mathrm{O}\right]$

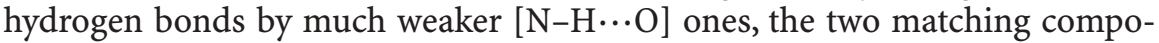
nents stayed mechanically interlocked, as confirmed by ${ }^{1} \mathrm{H}-\mathrm{NMR}$ and fluorescence spectroscopies.

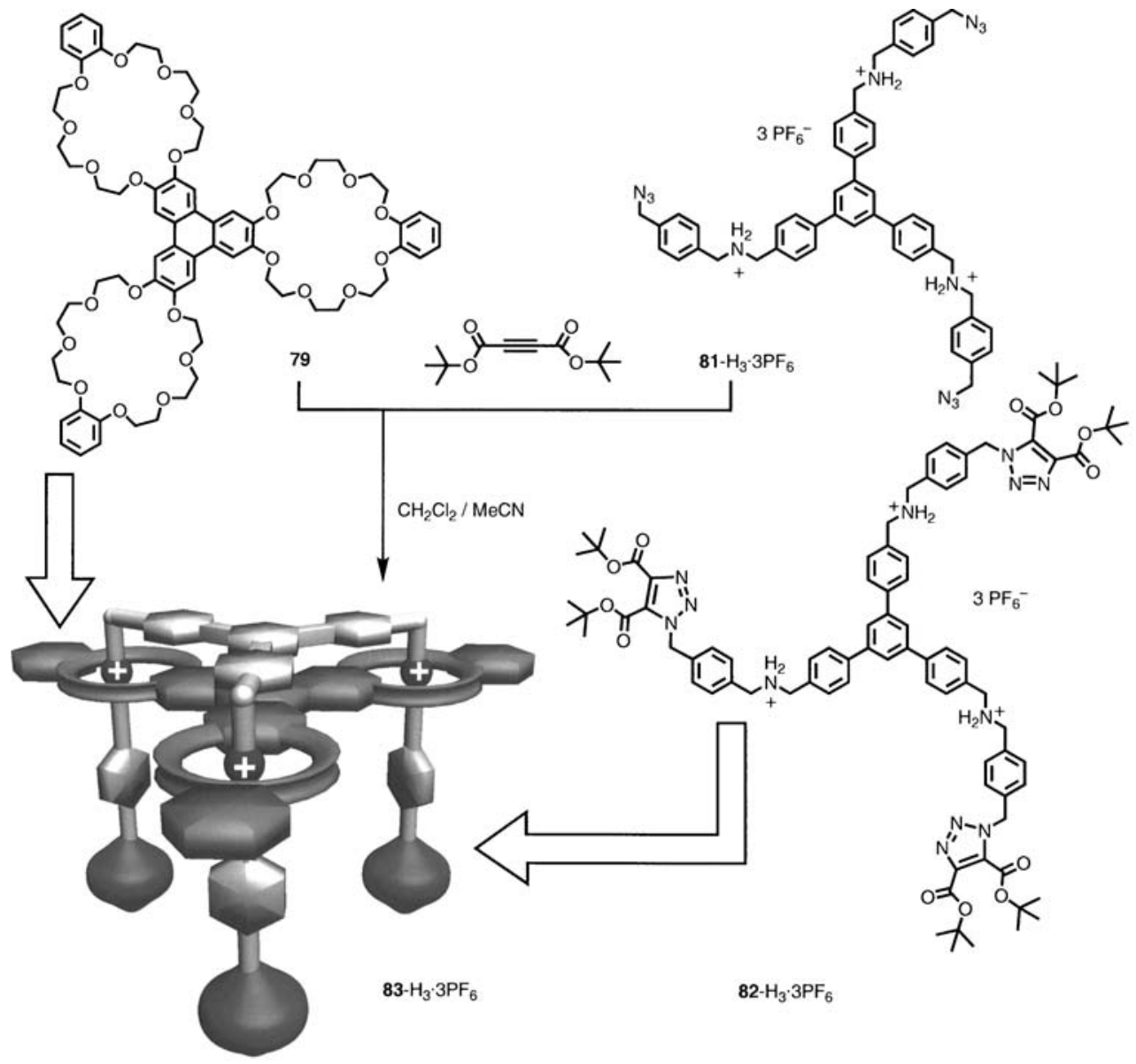

Scheme 15 Template-directed synthesis of the mechanically interlocked bundle $83-\mathrm{H}_{3} \cdot 3 \mathrm{PF}_{6}$ using kinetically controlled, [1,3]-dipolar cycloadditions to trap the superbundle formed in $\mathrm{CH}_{2} \mathrm{Cl}_{2} / \mathrm{MeCN}$ (3:2) at $40{ }^{\circ} \mathrm{C}$ between the tritopic triscrown ether 79 and the trifurcated trisammonium salt $81-\mathrm{H}_{3} \cdot 3 \mathrm{PF}_{6}$

Incorporating the architectural features of the previously designed mechanically interlocked bundle, a two-component molecule $86-\mathrm{H}_{3} \cdot 9 \mathrm{PF}_{6}$ that behaves like a nanometer-scale elevator was synthesized (Scheme 16) efficiently on account of the template-direction, coupled with the multivalency effect [246]. 

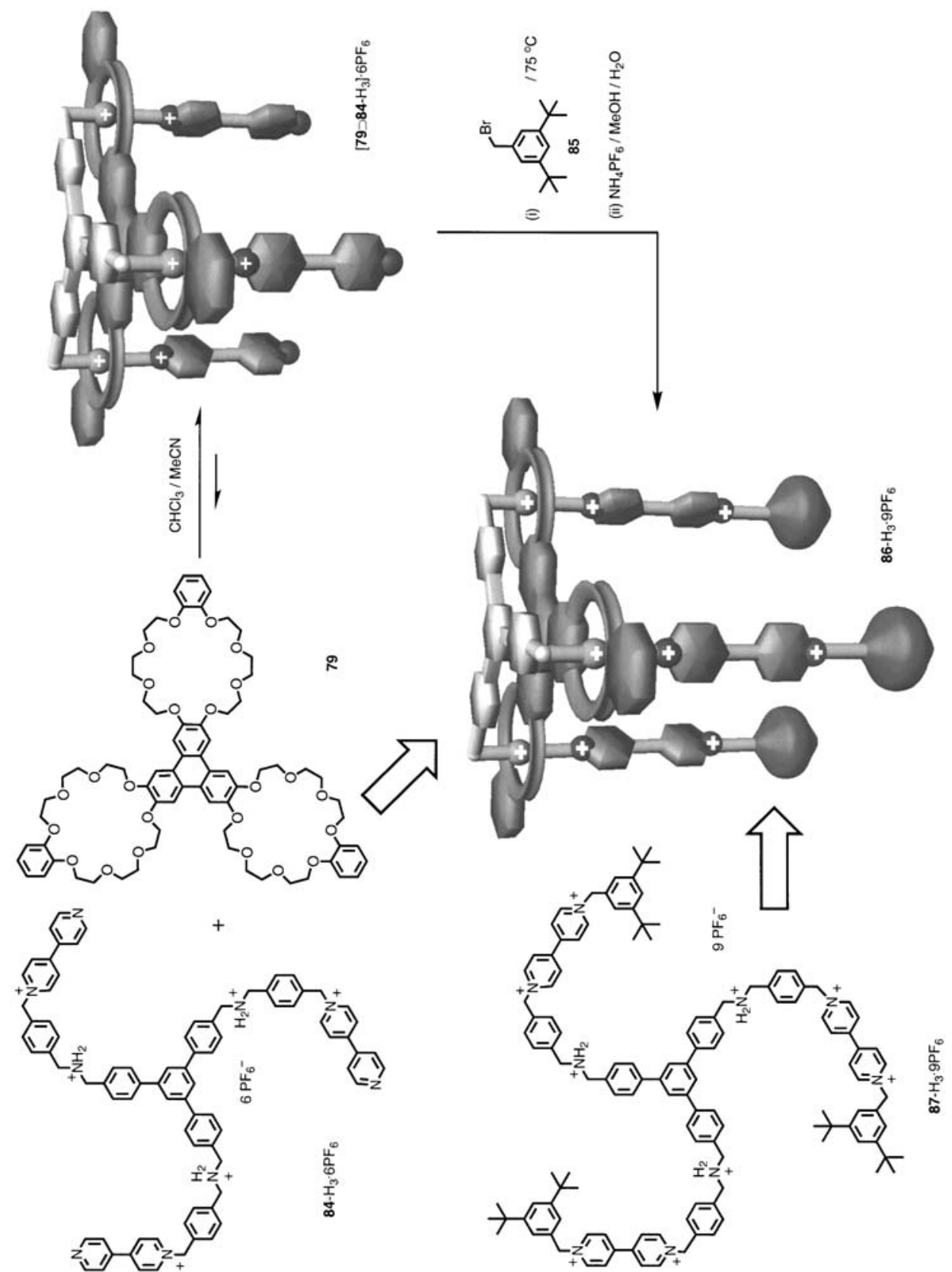

Scheme 16 Trifurcated guest salt $84-\mathrm{H}_{3} \cdot 6 \mathrm{PF}_{6}$ and the tritopic host 79 (each $6.6 \mathrm{mM}$ ) in a $\mathrm{CHCl}_{3} / \mathrm{MeCN}$ solution $(3.0 \mathrm{~mL}, 2: 1)$ form a $1: 1$ adduct (superbundle) that is converted, at elevated temperature $\left(75^{\circ} \mathrm{C}\right)$, to the mechanically interlocked elevator $86-\mathrm{H}_{3} \cdot 9 \mathrm{PF}_{6}$ in a reaction with 3,5-di-tert-butylbenzylbromide $85(200 \mathrm{mM})$, followed by the counterion-exchange $\left(\mathrm{NH}_{4} \mathrm{PF}_{6} / \mathrm{MeOH} / \mathrm{H}_{2} \mathrm{O}\right)$ 
The trifurcated trisammonum hexacation $84-\mathrm{H}_{3} \cdot 6 \mathrm{PF}_{6}$ and the tritopic crown ether 79 forms, in $\mathrm{CH}_{3} \mathrm{CN} / \mathrm{CHCl}_{3}$ solution, an extremely stable 1:1 supramolecular bundle. The trifurcated trisammonium hexacation $\left[79 \supset 84-\mathrm{H}_{3}\right] \cdot 6 \mathrm{PF}_{6}$ containing three terminal pyridyl groups, each threading through one of the three macrocyclic rings associated with the triscrown ether 79 , was reacted with bulky 3,5-di-tert-butylbenzyl bromide 85, affording [247] the mechanically interlocked species $86-\mathrm{H}_{3} \cdot 9 \mathrm{PF}_{6}$ in $33 \%$ yield. ${ }^{1} \mathrm{H}-\mathrm{NMR}$, absorption and fluorescence spectroscopies, in addition to electrochemistry measurements, indicated that $86-\mathrm{H}_{3} \cdot 9 \mathrm{PF}_{6}$ has averaged $C_{3 \mathrm{v}}$ symmetry with the platform's three crown ether loops encircling the three $\mathrm{NH}_{2}^{+}$centers (Scheme 16). Acid/base treatment of the $86-\mathrm{H}_{3} \cdot 9 \mathrm{PF}_{6}$ drives the crown ether platform between the $\mathrm{NH}_{2}^{+}$and $\mathrm{BIPY}^{2+}$ recognition sites, a mechanical motion that resembles the operation of a nanoscale elevator.

The advent of dynamic covalent chemistry has opened up attractive alternative routes to mechanically interlocked molecules, vide supra. It has already been shown that reversible RCM and RORCM reactions, mediated by Grubbs catalysts, can be used in the thermodynamically controlled synthesis of catenanes and rotaxanes [149,157, 161-162, 200, 248-249]. If multivalent sites between two or more components could be created spontaneously in situ by dynamic covalent chemistry [134], it seems reasonable that the multivalency effect, which is primarily a thermodynamic phenomenon, could assist in the formation of elaborate multiply threaded interlocked molecules [250].

When the triphenylene hexa-olefin $\mathbf{8 8}$ (Scheme 17) was subjected to the RCM reaction with and without the monovalent bis-3,5-dimethoxydibenzylammonium ion template and using Grubbs I catalyst 4, neither the desired crown ether analog nor [4] rotaxane, respectively, was observed. When an equimolar mixture of the triphenylene hexa-olefin $\mathbf{8 8}$ and trifurcated trisammonium trication $89-\mathrm{H}_{3} \cdot 3 \mathrm{PF}_{6}$ was subjected to an RCM reaction using Grubbs I catalyst 4, the exclusive product was the mechanically interlocked molecular "bundle" 90- $\mathrm{H}_{3} \cdot 3 \mathrm{PF}_{6}$, containing $\mathrm{C}=\mathrm{C}$ double bonds with both $E$ and $Z$ configurations and with averaged quasi- $C_{3 v}$ symmetry, as confirmed by ${ }^{1} \mathrm{H}-\mathrm{NMR}$ spectroscopy.

The almost quantitative production of $90-\mathrm{H}_{3} \cdot 3 \mathrm{PF}_{6}$ is presumably the result of the build-up of cooperative binding interactions, which result from the three productive RCM reactions assisted by the statistical and cluster effects associated with the multivalency that characterizes the thermodynamically stable product. The assembly of the mechanically interlocked $90-\mathrm{H}_{3} \cdot 3 \mathrm{PF}_{6}$ was also attempted (Scheme 17) using already preformed components $89-\mathrm{H}_{3} \cdot 3 \mathrm{PF}_{6}$ and 91. The two components do not form a supramolecular bundle in solution. However, RORCM reactions do take place upon addition of Grubbs II catalyst 73 , leading to the opening and closing of 91 . The equilibration process led to the exclusive formation of the mechanically interlocked compound $90-\mathrm{H}_{3} \cdot 3 \mathrm{PF}_{6}$, as evidenced by ${ }^{1} \mathrm{H}$-NMR spectroscopy and mass spectrometry. The dynamic interplay between molecular recognition and the reversible formation of covalent and mechanical bonds, using suitable catalysts, in combination with template-directing effects can apparently be used in the efficient production of 

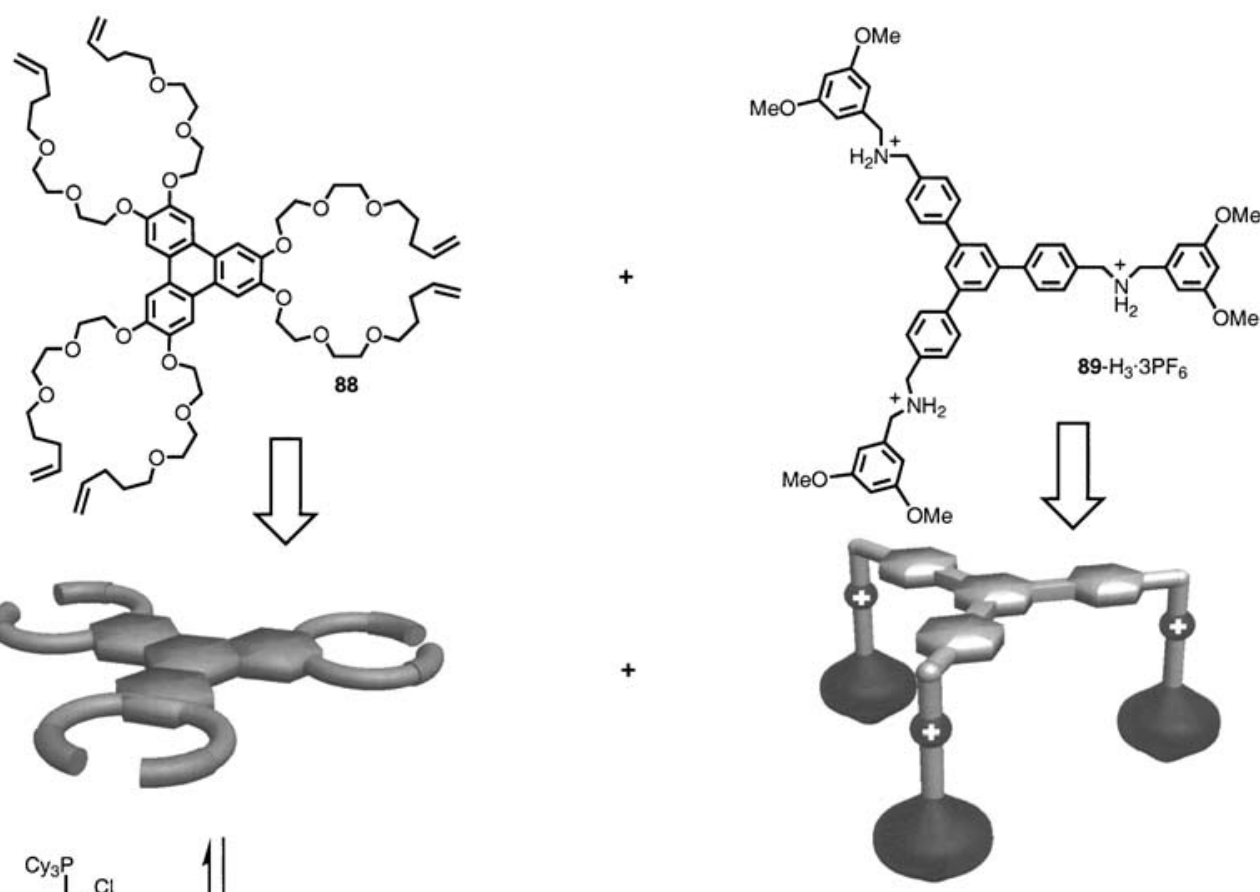

|r

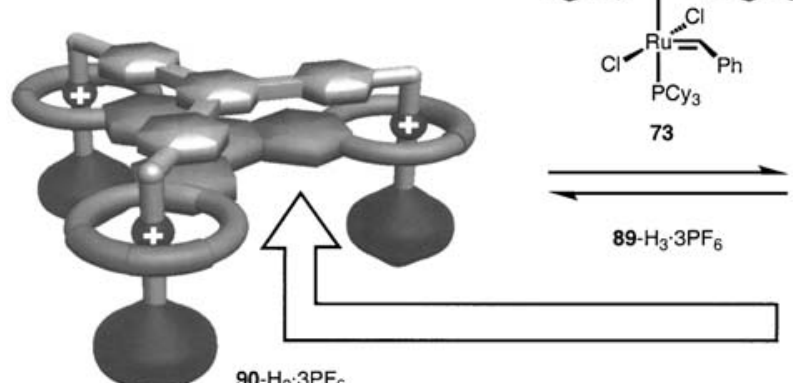

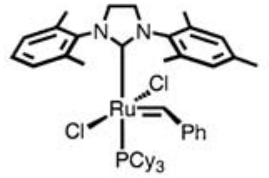

73

90- $\mathrm{H}_{3} \cdot 3 \mathrm{PF}_{6}$

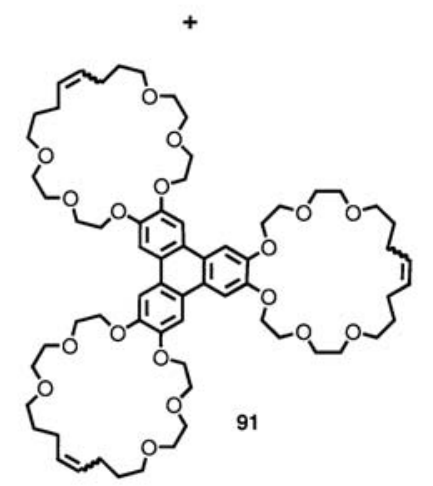

Scheme 17 Efficient preparation of the mechanically interlocked "bundle" $90-\mathrm{H}_{3} \cdot 3 \mathrm{PF}_{6}$ as a mixture of isomers containing $\mathrm{C}=\mathrm{C}$ double bonds with both $(E)$ and $(Z)$ configurations can be achieved through either RCM reaction, starting from an equimolar mixture $\left(\mathrm{CH}_{2} \mathrm{Cl}_{2}\right.$ at $40{ }^{\circ} \mathrm{C}$ ) of the trifurcated trisammonium salt $89-\mathrm{H}_{3} \cdot 3 \mathrm{PF}_{6}$ and hexa-olefin 88 using the functional-group tolerant Grubbs I catalyst 4 or RORCM reaction starting from an equimolar mixture $\left(\mathrm{CH}_{2} \mathrm{Cl}_{2}\right.$ at $\left.25^{\circ} \mathrm{C}\right)$ of the trifurcated trisammonium salt $89-\mathrm{H}_{3} \cdot 3 \mathrm{PF}_{6}$ and tris-crown 91 using the Grubbs II catalyst 73 
intriguing and functional molecular assemblies, and also hopefully of high molecular weight polymers with appealing materials properties. As the need for elaborate functional systems grows, the concept of multivalency is likely to play a significant role in the areas of supramolecular, medicinal, and materials chemistry.

\section{5}

\section{Templating the Future of Technology}

Template-directed synthesis allows for the precise control over the mutual location of the components in mechanically interlocked molecules. This high degree of organization lays the foundations for the production of molecular machinery [251-259]. In particular, with the addition of more than one templating unit, a property of higher order emerges - motion [78, 260]. Specifically, when two different templates are utilized [261-265], mechanically operating switchable molecules can be realized, wherein it is now their movements that can be controlled by an external chemical [266-268], electrochemical [269-271], or photochemical [272-275] stimulus. The stimulants are utilized to turn off and on the recognition motifs, namely the very templates that were employed in the compound's preparation. Additional criteria - organization and integration onto surfaces and ultimately into multi-scale devices [251-252,276-278] - have been recognized and are presently being addressed in order to give molecular machines their rightful place in a technological world. As a first step, some of the molecular machines outlined in this review are being tethered to a variety of surfaces. In one significant instance, bistable [2]catenanes and [2] rotaxanes have been used to template the emergence of binary molecular memory.

\section{1}

\section{Molecular Switching}

Building on the early successes, a truly bistable [2]catenane $17 \mathbf{b}^{4+}$ was prepared $[91,262]$ that displays (Fig. 6) an "all-or-nothing" preference for one of the translational isomers until stimulated, whereupon the preference switches from the ground state to an excited translational state or even to the other translational isomer, a metastable one. In this example, the TTF unit of the aromatic cyclic polyether component is preferentially bound within the $\mathrm{CBPQT}^{4+}$ cyclophane's cavity with the DNP ring system on the outside. Solution phase studies reveal that upon two-electron oxidation of the TTF unit, the now-charged aromatic cyclic polyether circumrotates as a result of charge repulsion, thus relocating the DNP ring system inside the cavity of the $\mathrm{CBPQT}^{4+}$ cyclophane. This design is exemplary for controlling molecular motion because (a) one of the recognition units can be easily switched - in this case the redox active TTF unit - and (b) both of the recognition units can be selected to have vastly different binding affinities for the mechanically mobile cyclophane. 


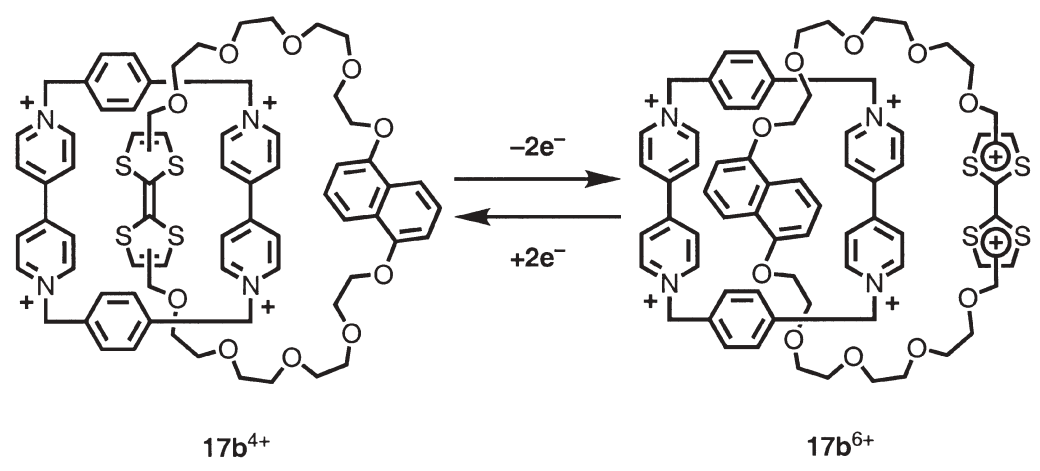

Fig. 6 Electrochemically stimulated circumrotational motion in the bistable [2]catenane $17 \mathrm{~b}^{4+}$ allows two distinct redox states to be reversibly accessed

A bistable light-driven switch [110] in the form of a [2] rotaxane 32 has been designed so that the hydrogen-bond accepting ability of a photoactive naphthalimide (Fig. 7) is "turned on" by a photochemical reaction with a secondary electron donor. In the electronic ground state, the benzylic amide macrocycle is located preferentially at the succinamide site $(\mathrm{MeCN}, 329 \mathrm{~K})$. Electrochemical reduction drives the translocation of the macrocycle to encircle the now-reduced naphthalimide unit. Consequently, the reduced form of the rotaxane can be considered a viable candidate for photo-induced electron transfer. In particular, the photo-excited $(355 \mathrm{~nm})$ naphthalimide unit of 32 accepts an electron from the

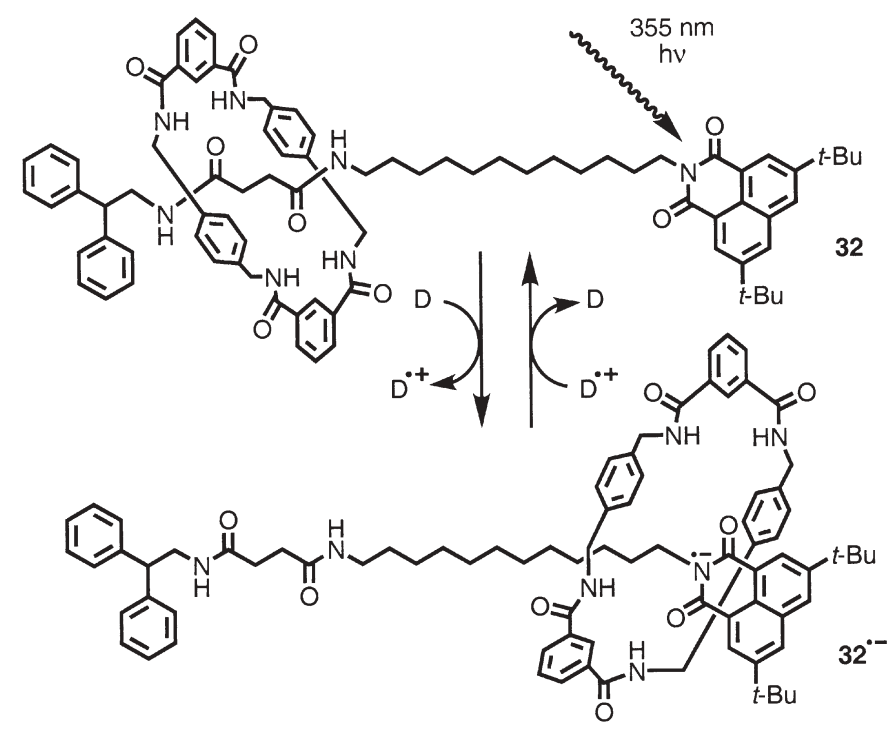

Fig. 7 Linear motions in the photoactive [2] rotaxane 32 can be driven by light in the presence of the secondary electron donor 1,4-diazabicyclo[2.2.2] octane $(D)$ 
triplet transfer agent 1,4-diazabicyclo[2.2.2] octane (D), generating the reduced state and thus turning on the unit's attraction for the macrocycle. In this manner, photo-induced translational motion is not only achieved but is also timeresolved to occur in $\sim 1 \mu \mathrm{s}$, with subsequent relaxation over a much longer $(\sim 100 \mu \mathrm{s})$ time-scale. The utilization of a secondary reagent has been employed in other instances [272], highlighting the fact that totally intramolecular photodriven motion is an ongoing challenge.

The design of the component parts of a machine is becoming increasingly dictated by the desired functional outcome. Unidirectional motion [279-280] has been demonstrated [105] recently by utilizing (Fig. 8) a switchable hydrogen-bonded [3] catenane 92, which is a by-product in the synthesis of the [2]catenane 30. In this instance, the second macrocycle acts as a blocking group that directs the movement of the other macrocycle. This example underscores the level of complexity that has been achieved and will continue to be demanded in the design of molecular machinery based on interlocked molecules.

Analogous bistable catenates and metallated rotaxanes, which can be electrochemically activated, have been developed that are based on the translocation of transition metal ions. In particular, Sauvage [281] has made effective use of the differences in coordination requirements between $\mathrm{Cu}(\mathrm{I})$ and $\mathrm{Cu}(\mathrm{II})$ redox centers. The former prefers a four-coordinate arrangement, whereas the latter likes a five-coordinate environment. For example, an electrochemically active copper [2] catenate $\mathbf{9 3}{ }^{+}$involves [282] one macrocycle that incorporates both a bidentate and tridentate polypyridyl ligand into its ring. In the presence of

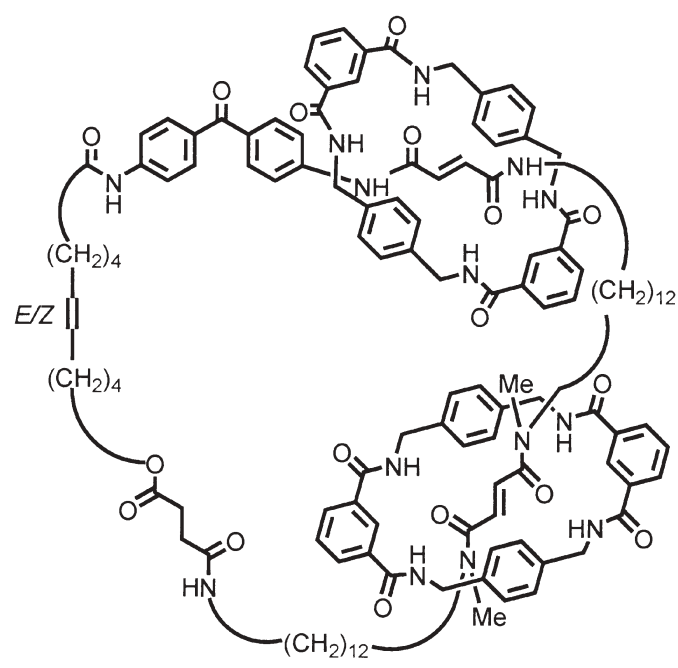

92

Fig. 8 Unidirectional circumrotational motion has been demonstrated from a [3]catenane 92 with four recognition units in which one of the two smaller rings acts as a blocking group 


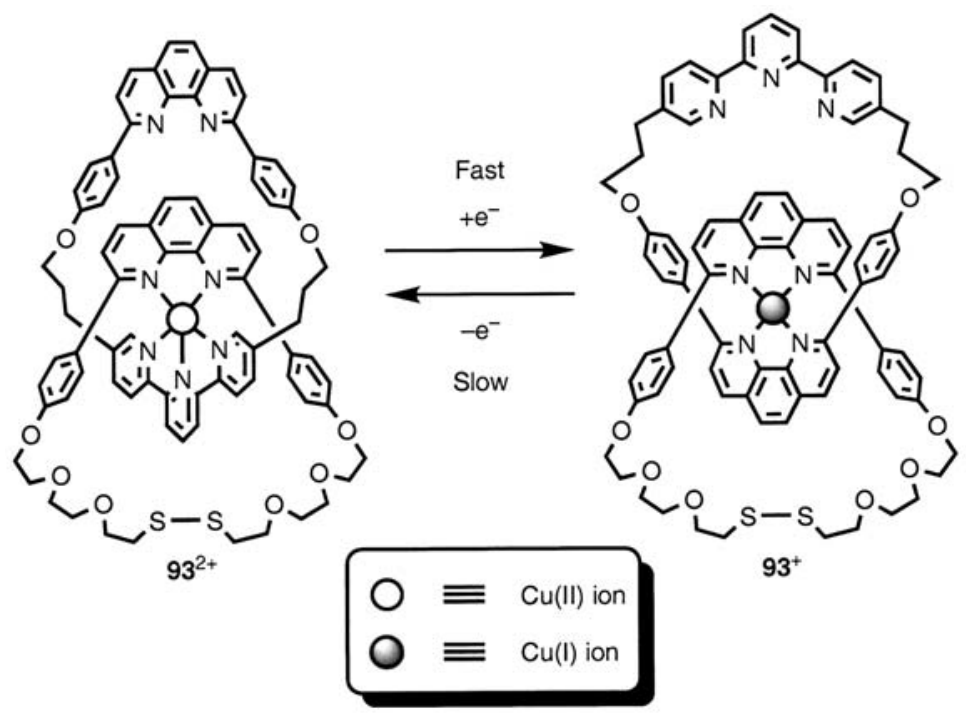

Fig.9 Circumrotational motion in a metallated copper [2] catenate $93^{2+/+}$ can be driven electrochemically in order to accommodate the 5- and 4-coordinate bonding preferences of $\mathrm{Cu}(\mathrm{II})$ and $\mathrm{Cu}(\mathrm{I})$, respectively

$\mathrm{Cu}(\mathrm{I})$, the two bidentate sites from the interlocked macrocycles are coordinated to the copper center. Oxidation to the $\mathrm{Cu}(\mathrm{II})$ state causes circumrotation and situates the tridentate ligand within the coordination sphere in order to accommodate the five-coordinate bonding requirement of the $\mathrm{Cu}$ center. This process (Fig. 9) can be stimulated electrochemically by beginning in the $\mathrm{Cu}$ (II) state. In addition to the circumrotational motions, the macrocycles can also be made to spin around the axles of rotaxanes $[76,265]$ and similarly, linear motion can be activated in rotaxanes [264].

\section{2}

\section{Surface Switching}

The linear motions of the moving components in a large number of controllable molecular machines distributed randomly in the solution state can be expressed coherently in a mechanical context by organizing them at interfaces [273, 282-283], either as Langmuir-Blodgett (LB) films [284-288] or as self-assembled monolayers (SAMs). Before any multi-scale and integrated devices based on molecular machines become viable for real technological applications, the conditions required to ensure that mechanical switching persists when the molecules are mounted onto solid supports are currently being investigated.

Molecular design motifs based on intramolecular disulfide bonding have been incorporated into a series of rotaxanes [289] and catenates [282] in order to facilitate their self-assembly onto gold surfaces. However, in both cases, the 


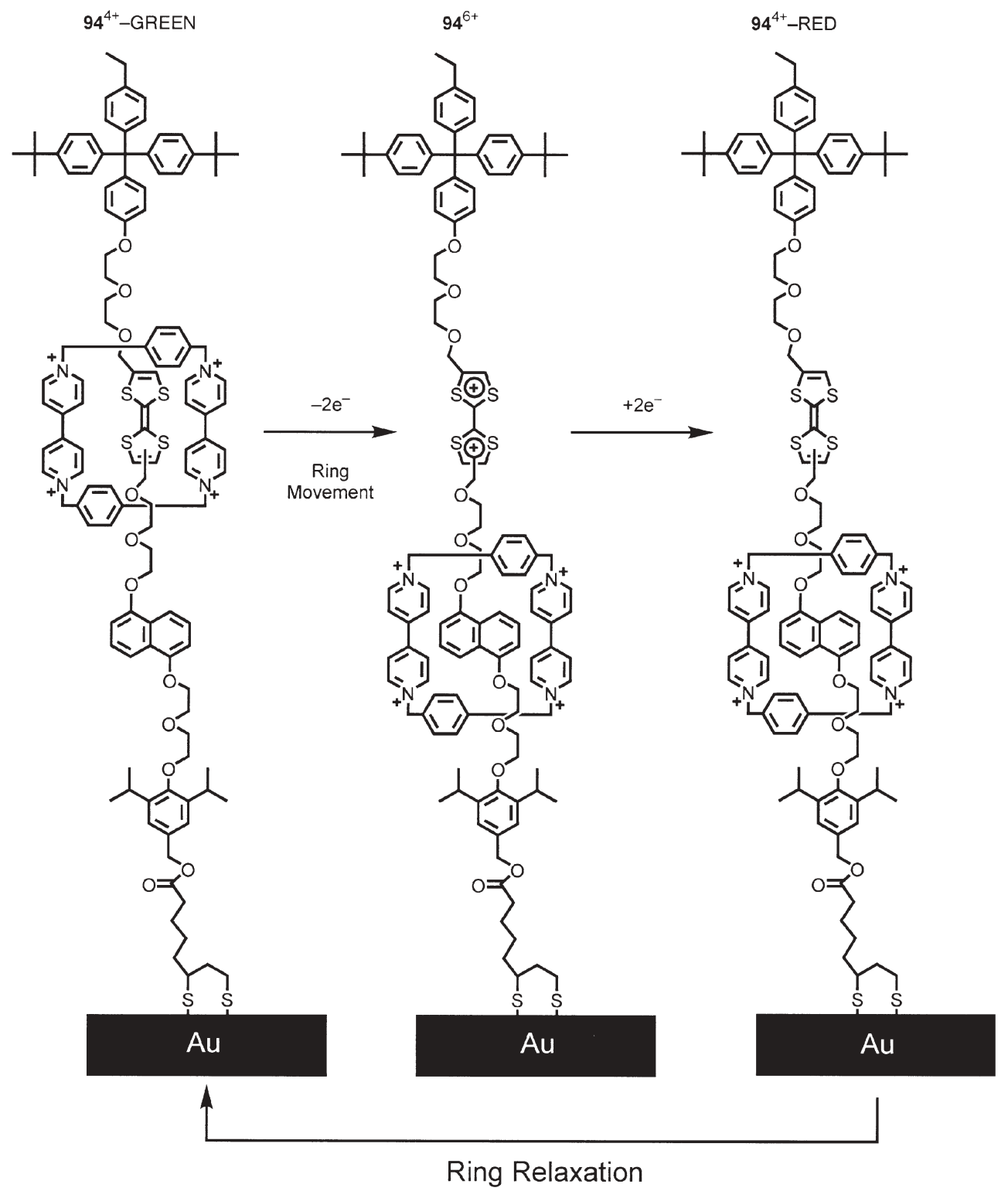

Fig. 10 The interlocked macrocycle of a surface-bound bistable [2] rotaxane 94 displays electrochemically driven linear motions between two recognition sites. The binding of the macrocycle to the weaker donor, 1,5-dioxynaphthalene, in the metastable state is sufficiently strong to forestall the reformation of the ground state, following electrochemical reset 
molecular movements were found to be highly hindered or quenched in comparison to the solution-phase behavior. For example, the circumrotation of the [2] catenate $\mathbf{9 3}^{+}$operates in solution following electrochemical stimulation according to the hysteresis observed in the $\mathrm{CV}$. However, when either the $\mathrm{Cu}$ (II) or $\mathrm{Cu}$ (I) form of the [2] catenate SAM were examined electrochemically, negligible hysteresis in the CV was observed.

A switchable [2] rotaxane, based on viologen recognition units, has been attached [278] to $6 \mathrm{~nm} \mathrm{TiO}_{2}$ nanoparticles by a rigid tripodal stopper with phosphonate tethers. In this instance, switching within the hetero[2] rotaxane is achieved by chemical or electrochemical reduction. Analysis of the CV reveals a complex sequence of mechanical movements that differ from the solution dynamics. This result illustrates how the dynamics of surface-bound species may not always behave exactly as those observed in solution. Consequently, the study of molecular machines in the context of surface-bound species is important in order to understand just how to optimize their molecular structure in order to elicit controllable molecular functions.

Taking advantage of the modularity of template-directed synthesis of mechanically interlocked molecules, a [2] rotaxane $94^{4+}$ was prepared with a disulfide tether attached to one of its two stoppers so that it can form a SAM on gold electrodes. These rotaxanes display redox-controlled motions (Fig. 10) of the $\mathrm{CBPQT}^{4+}$ cyclophane from the TTF unit to the DNP ring system. In an illuminating study using cyclic voltammetry (CV), fast redox switching at variable temperatures allowed the translational isomer with the $\mathrm{CBPQT}^{4+}$ cyclophane stationed at the DNP ring system to be identified and time-resolved. This translational isomer persists for a short period of time $(\sim s)$ even although the TTF unit has returned to its neutral and therefore more attractive redox state. This metastable state was found [283] to relax to the ground state in about $1 \mathrm{~s}$ at room temperature over a barrier of $18 \mathrm{kcal} \mathrm{mol}^{-1}$. Such DNP-based metastability had been observed in other systems [282] but had never been fully investigated. The presence of the metastable state, together with the barrier to motion, is consistent with the supramolecular history of these compounds from the perspective of the molecule's properties.

\section{3}

\section{Molecular Electronics}

Electrical crossbar devices (Fig. 11) built around the catenane $17 \mathrm{~b}^{4+}$, the amphiphilic bistable rotaxane $95^{4+}$, and others have been investigated [92-94, 290-291] for their ability to display binary switching. The general method for constructing such devices relies upon depositing a LB monolayer of closely packed molecular switches onto a highly doped polysilicon ( $p$-Si) electrode. A top electrode of $\mathrm{Ti}$, followed by $\mathrm{Al}$, is subsequently vapor-deposited on top of the monolayer.

The molecular devices display switching between high and low conductance states. Each device is interrogated and characterized by applying a "write" volt- 
age, $V$ and recording the "read" current, $I$. The ON state is accessed at $+2 \mathrm{~V}$, which is equivalent to net oxidizing conditions, whereas the OFF state is triggered at $-2 \mathrm{~V}$, or net reducing conditions. These data reveal that, in addition to the reversible voltage-gated switching of the device ON and OFF more than 30 times, the ON state is metastable, displaying a temperature-dependant resetting of the device back to the OFF state.

A molecule-based nano-electromechanical switching mechanism has been proposed to account for the device's observed experimental behavior. The OFF state corresponds to the translational isomer, with the cyclophane encircling the MPTTF unit. In the device, application of a $+2 \mathrm{~V}$ bias generates an oxidized form of the MPTTF unit in the rotaxane. Just as observed in solution, the

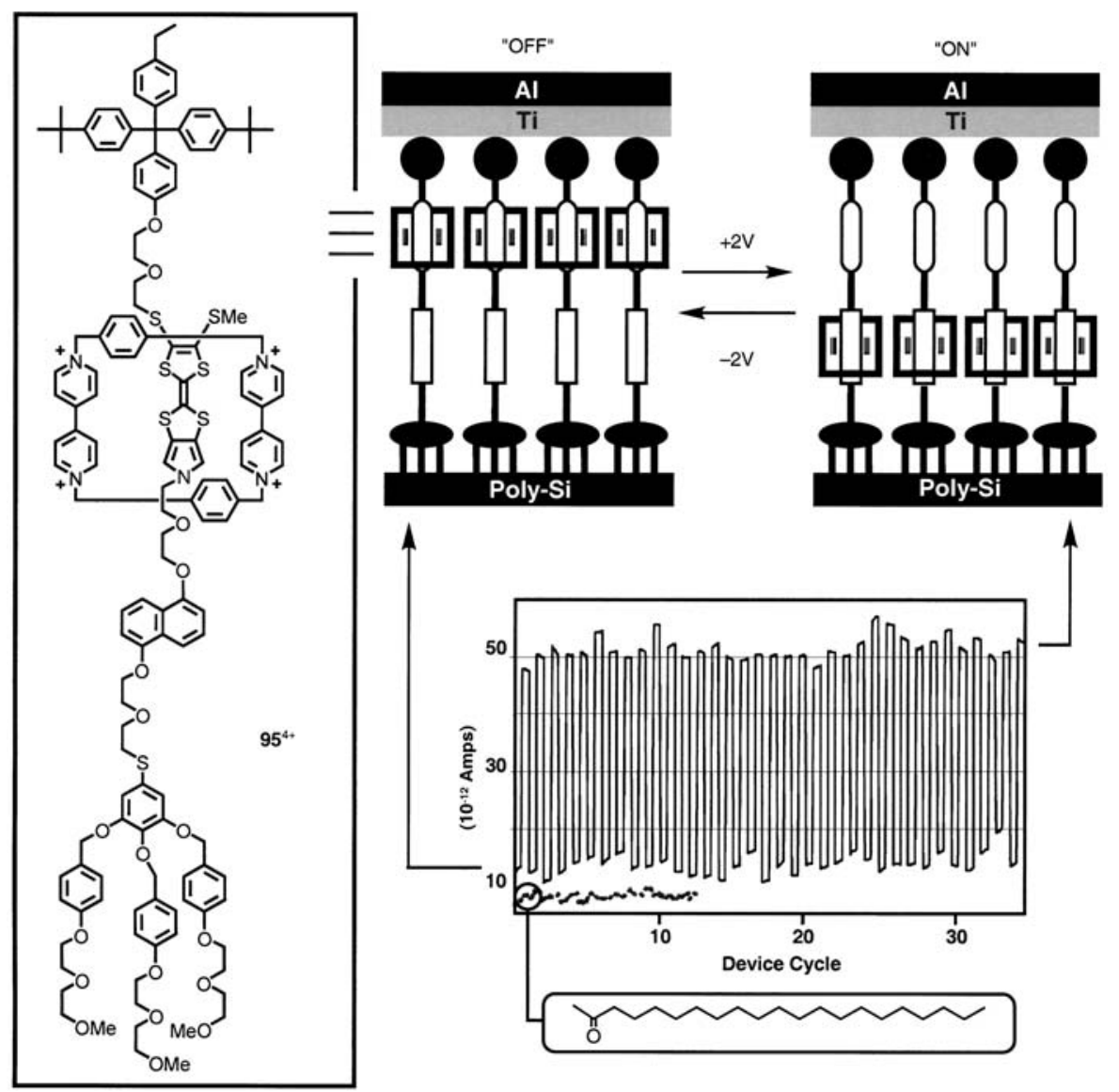

Fig. 11 The amphiphilic bistable [2] rotaxane $95^{4+}$ has been integrated into a crossbar device between two electrodes as a Langmuir-Blodgett monolayer. The ON and OFF states of the device are accessed at $+2 \mathrm{~V}$ and $-2 \mathrm{~V}$, respectively, and are assigned to two different translational isomers, the metastable and the ground states, respectively 
resulting charge-charge repulsive force drives a linear movement of the cyclophane along the dumbbell component to a position encircling the DNP ring system. When the bias is lowered to $+0.1 \mathrm{~V}$, for the purpose of reading the device, the charge on the MPTTF unit is neutralized and yet the cyclophane remains around the DNP ring system on account of the mutually attractive noncovalent interactions. This new metastable translational isomer is responsible for the high-conductance ON state. This metastable state of the device, and by inference the molecule, is observed to decay to the OFF state in a manner that is qualitatively similar [283] to the movements of the tetracationic cyclophane in rotaxanes that are self-assembled (vide supra) onto a gold electrode. Therefore, the decay rate is concomitant with the thermally activated linear movement of the cyclophane back along the dumbbell to the MPTTF unit. Alternatively, applying a reverse bias of $-2 \mathrm{~V}$ causes the electrochemical reduction of the tetracationic cyclophane, allowing the facile reformation of the most stable translational isomer.

The proposed switching mechanism, while based on the molecule's known mechanical movements in solution, is supported experimentally by the comparison to control devices. In particular, devices utilizing the dumbbell-only compounds and non-redox active molecules, such as eicosanoic acid (Fig. 11), do not display any switching behavior.

\section{4}

\section{Summary}

The tenet for the molecular sciences that structure follows function is equally apparent for mechanically interlocked molecules where their potential to be harnessed as molecular machines is becoming increasingly attractive both academically and technologically. Beyond synthesis, the template and its recognition partner(s) serve many other purposes. Selection of strong binding templates allows for sub-nanometer control over the mutual location of the interlocked components. Switchable templates open the door to controllable motion. Topological design allows for different types of motions, including unidirectional rotations. Integration of mechanically interlocked molecules into larger self-organized assemblies can be easily attained, although the mechanical movements become more challenging to identify. Consequently, structure-function analyses are required in order to elicit understanding, as much as they are essential to optimize the molecules' function for a desired technological application. Where an example is apparent in molecular electronics, there are likely more, as yet unexplored, areas of research and development for these classes of molecules that utilize purely the mechanical machinery paradigm to herald a new technology at the boundary between soft and hard matter. 


\section{6}

\section{Conclusions and Perspectives}

Mechanically interlocked molecules, such as catenanes and rotaxanes, can be synthesized at high efficiency by utilizing organic or inorganic templates under kinetic control. The efficiency of these templated syntheses relies upon a supramolecular approach that utilizes a combination of cooperative noncovalent bonding interactions (such as metal-ligand interactions, $\pi-\pi$ stacking and hydrogen bonding) to form a weakly bonded intermediate complex, leading to the irreversible formation of interlocked molecules on the formation of a strong chemical (covalent) bond.

The use of thermodynamically controlled approaches for the synthesis of wholly organic interlocked molecules is slowly growing in popularity. The use of olefin metathesis, imine formation/exchange, or disulfide exchange as the reversible covalent step - in addition to the exploitation of different molecular recognition motifs - demonstrates the generality of thermodynamically controlled approaches for the synthesis of interlocked molecules.

The dynamic interplay between molecular recognition and the reversible formation of covalent and mechanical bonds, using catalysts where appropriate, in combination with template-directed effects, can be used in the efficient production of intriguing and functional molecular assemblies and high molecular weight polymers with appealing materials properties. As the need for elaborate functional systems grows, the concepts of multivalency and cooperativity are likely to play significant roles in the areas of supramolecular, medicinal, and materials chemistry.

Beyond synthesis, the template and its recognition partner(s) serve many other purposes, such as control over the mutual location of the interlocked components. Switchable templates lead to controllable motion, and topological design affords the opportunity for different types of motions, including unidirectional rotations. The integration of mechanically interlocked molecules into larger self-organized assemblies, as revealed by structure function analyses, is beginning to show some technological promise in areas such as molecular electronics.

\section{References}

1. Schill G (1971) Catenanes, rotaxanes and knots. Academic, New York

2. Amabilino DB, Stoddart JF (1995) Chem Rev 95:2725

3. Vögtle F, Dünnwald T, Schmidt T (1996) Acc Chem Res 29:451

4. Sauvage J-P, Dietrich-Buchecker CO (1999) (eds) Molecular catenanes, rotaxanes and knots. Wiley-VCH, Weinheim

5. Hubin TJ, Busch DH (2000) Coord Chem Rev 200-202:5

6. Tauber SJ (1963) J Res Nat Bur Stand Sect A 67A:591

7. Wasserman E (1960) J Am Chem Soc 82:4433

8. Dietrich-Buchecker CO, Sauvage J-P, Kintzinger J-P (1983) Tetrahedron Lett 46:5095 
9. Johnson AG, Leigh DA, Pritchard RJ, Deegan MD (1995) Angew Chem Int Ed Engl 34:1209

10. Andrievsky A, Ahuis F, Sessler JL, Vögtle F, Gudat D, Moini M (1998) J Am Chem Soc 120:9712

11. Fujita M (1999) Acc Chem Res 32:53

12. Roh SG, Park KM, Park GJ, Sakamoto S, Yamaguchi K, Kim K (1999) Angew Chem Int Ed 38:638

13. McArdle CP, Vittal JJ, Puddenphatt RJ (2000) Angew Chem Int Ed 112:3819

14. Wiseman MR, Marsh PA, Bishop PT, Brisdon BJ, Mahon MF (2000) J Am Chem Soc 122:12598

15. Harrison IT, Harrison S (1967) J Am Chem Soc 89:5723

16. Kolchinski AG, Busch DH, Alcock NW (1995) J Chem Soc Chem Commun 1289

17. Ashton PR, Glink PT, Stoddart JF, Tasker PA, White AJP, Williams DJ (1996) Chem Eur J 2:729

18. Anderson S, Claridge TDW, Anderson HL (1997) Angew Chem Int Ed Engl 36:1310

19. Loeb SJ, Wisner JA (1998) Chem Commun 2757

20. Solladie N, Chambron H-C, Sauvage J-P (1999) J Am Chem Soc 121:3684

21. Kawaguchi Y, Harada A (2000) J Am Chem Soc 122:3797

22. Seel C, Vögtle F (2000) Chem Eur J 6:21

23. Brouwer AM, Frochot C, Gatti FG, Leigh DA, Mottier L, Paolucci F, Roffia S, Wurpel GWH (2001) Science 291:2124

24. Jeppesen JO, Perkins J, Becher J, Stoddart JF (2001) Angew Chem Int Ed 40:1216

25. Ng Y-F, Meillon J-C, Ryan T, Dominey AP, Davis AP, Sanders JKM (2001) Angew Chem Int Ed 40:1757

26. Tseng H-R, Vignon SA, Stoddart JF (2003) Angew Chem Int Ed 42:1492

27. Chichak KS, Cantrill SJ, Pease AR, Chiu S-H, Cave GWV, Atwood JL, Stoddart JF (2004) Science 304:1308

28. Balzani V, Credi A, Raymo FM, Stoddart JF (2000) Angew Chem Int Ed 39:3348

29. Balzani V,Venturi M, Credi A (2003) Molecular devices and machines - A journey into the nanoworld. Wiley-VCH, Weinheim

30. Cram DJ (1986) Angew Chem Int Ed Engl 25:1039

31. Lehn J-M (1995) Supramolecular chemistry: Concepts and perspectives. Wiley-VCH, Weiheim

32. Busch DH, Stephenson NA (1990) Coord Chem Rev 100:119

33. Lindsey JS (1991) New J Chem 15:153

34. Whitesides GM, Mathias JP, Seto CT (1991) Science 254:1312

35. Anderson S, Anderson HL, Sanders JKM (1993) Acc Chem Res 26:465

36. Hoss R, Vögtle F (1994) Angew Chem Int Ed Engl 33:375

37. Schneider JP, Kelly JW (1995) Chem Rev 95:2169

38. Philp D, Stoddart JF (1996) Angew Chem Int Ed Engl 35:1155

39. Fyfe MCT, Stoddart JF (1997) Acc Chem Res 30:393

40. Hubin TJ, Kolchinski AG, Vance AL, Busch DL (1999) Adv Supramol Chem 5:237

41. Diederich F, Stang PJ (2000) (eds) Templated organic synthesis. Wiley-VCH, Weinheim

42. Hunter CA (1994) Chem Soc Rev 23:101

43. Johnston AG, Leighton DA, Pritchard RJ, Deegan MD (1995) Angew Chem Int Ed Engl 34:1209

44. Glink PT, Schiavo C, Stoddart JF, Williams DJ (1996) Chem Commun 1483

45. Leigh DA, Moody K, Smart JP, Watson KJ, Slawin AMZ (1996) Angew Chem Int Ed Engl 35:306

46. Otteus-Hildebrand S, Meier S, Schmidt W, Vögtle F (1994) Angew Chem Int Ed Engl 33:1767 
47. Kolchinski AG, Alcock NW, Roesner RA, Busch DH (1998) Chem Commun 1437

48. Fyfe MCT, Stoddart JF (1999) Coord Chem Rev 183:139

49. Sauvage J-P (1990) Acc Chem Res 23:319

50. Bickelhaupt F (1994) J Organomet Chem 475:1

51. Chambron J-C, Dietrich-Buchecker CO, Sauvage J-P (1996) In: Atwood JL, Davies JED, MacNicol DD, Vögtle F (eds) Comprehensive supramolecular chemistry, vol 9. Pergamon, Oxford, p 43

52. Fujita M, Ogura K (1996) Chem Rev 148:249

53. Whang D, Park KM, Heo J, Ashton PR, Kim K (1998) J Am Chem Soc 120:4899

54. Amabilino DB, Stoddart JF (1993) Pure Appl Chem 65:2351

55. Pasini D, Raymo FM, Stoddart JF (1995) Gazz Chim Ital 125:431

56. Amabilino DB, Raymo FM, Stoddart JF (1996) In: Atwood JL, Davies JED, MacNicol DD, Vögtle F (eds) Comprehensive supramolecular chemistry, vol 9. Pergamon, Oxford, p 85

57. Hamilton DG, Davies JE, Prodi L, Sanders JKM (1998) Chem Eur J 4:608

58. Raymo FM, Stoddart JF (1998) Chemtracts 11:491

59. Try AC, Harding MM, Hamilton DG, Sanders JKM (1998) Chem Commun 723

60. Hamilton DG, Prodi L, Feeder N, Sanders JKM (1999) J Chem Soc Perkin Trans 1:1057

61. Stoddart JF (1992) Angew Chem Int Ed Engl 31:846

62. Isnin R, Kaifer AE (1993) Pure Appl Chem 65:495

63. Wenz G (1994) Angew Chem Int Ed Engl 33:802

64. Harada A (1996) Coord Chem Rev 148:115

65. Nepogodiev SA, Stoddart JF (1998) Chem Rev 98:1959

66. Gillard RE, Raymo FM, Stoddart JF (1997) Chem Eur J 3:1933

67. Thompson MC, Busch DH (1964) J Am Chem Soc 86:3651

68. Blinn EL, Busch DH (1968) Inorg Chem 7:820

69. Thompson MC, Busch DH (1962) J Am Chem Soc 84:1762

70. Curry JD, Busch DH (1964) J Am Chem Soc 86:592

71. Melson GA, Busch DH (1965) J Am Chem Soc 97:1706

72. Collin J-P, Dietrich-Buchecker CO, Gavina P, Jimeñez-Molero MC, Sauvage J-P (2001) Acc Chem Res 34:477

73. Sauvage J-P (1998) Acc Chem Res 31:611

74. Mobian P, Kern J-M, Sauvage J-P (2003) J Am Chem Soc 125:2016

75. Mobian P, Kern J-M, Sauvage J-P (2003) Inorg Chem 42:8633

76. Poleschak I, Kern J-M, Sauvage J-P (2004) Chem Commun 474

77. Odell B, Reddington MV, Slawin AMZ, Spencer N, Stoddart JF, Williams DJ (1988) Angew Chem Int Ed Engl 27:1547

78. Ashton PR, Goodnow TT, Kaifer AE, Reddington MV, Slawin AMZ, Spencer N, Stoddart JF, Vicent C, Williams DJ (1989) Angew Chem Int Ed Engl 28:1396

79. Stoddart JF, Tseng H-R (2002) Proc Natl Acad Sci USA 99:4797

80. Hernandez R, Tseng H-R, Wong JW, Stoddart JF, Zink JI (2004) J Am Chem Soc 126:3370

81. Hunter CA, Sanders JKM (1990) J Am Chem Soc 112:5525

82. Hunter CA (1993) Angew Chem Int Ed Engl 32:1584

83. Houk KN, Menzer S, Newton SP, Raymo FM, Stoddart JF, Williams DJ (1999) J Am Chem Soc 121:1479

84. Raymo FM, Barberger MD, Houk KN, Stoddart JF (2001) J Am Chem Soc 123:9264

85. Philp D, Slawin AMZ, Spencer N, Stoddart JF, Williams DJ (1991) J Chem Soc Chem Commun 1584

86. Nielsen MO, Jeppesen JO, Lau J, Lomholt C, Damgaard D, Jacobsen JP, Becher J, Stoddart JF (2001) J Org Chem 66:3559 
87. Amabilino DB, Ashon PR, Reder AS, Spencer N, Stoddart JF (1994) Angew Chem Int Ed Engl 33:1286

88. Asakawa M, Ashton PR, Balzani V, Boyd SE, Credi A, Mattersteig G, Menzer S, Montalti M, Raymo FM, Ruffilli C, Stoddart JF, Venturi M, Williams DJ (1999) Eur J Org Chem 985

89. Asakawa M, Ashton PR, Balzani V, Brown CL, Credi A, Matthews OA, Newton SP, Raymo FM, Shipway AN, Spencer N, Quick A, Stoddart JF, White AJP, Williams DJ (1999) Chem Eur J 3:860

90. Asakawa M, Ashton PR, Balzani V, Credi A, Hamers C, Mattersteig, Montalti M, Shipway AN, Spencer N, Stoddart JF, Tolley MS, Venturi M, White AJP, Williams DJ (1998) Angew Chem Int Ed 37:333

91. Balzani V, Credi A, Mattersteig G, Matthews OA, Raymo FM, Stoddart JF, Venturi M, White AJP, Williams DJ (2000) J Org Chem 65:1924

92. Collier CP, Mattersteig G, Wong EW, Luo Y, Beverly K, Sampaio J, Raymo FM, Stoddart JF, Heath JR (2000) Science 289:1172

93. Collier CP, Wong EW, Belohradsky M, Raymo FM, Stoddart JF, Kuekes PJ, Williams RS, Heath JR, (1999) Science 285:391

94. Collier CP, Jeppesen JO, Luo Y, Perkins J, Wong EW, Heath JR, Stoddart JF (2001) J Am Chem Soc 123:12632

95. Jeppesen JO, Nielsen KA, Perkins J, Vignon SA, Fabio AD, Ballardini R, Gandolfi MT, Venturi M, Balzani V, Becher J, Stoddart JF (2003) Chem Eur J 9:2982

96. Jeppesen JO, Vignon SA, Stoddart JF (2003) Chem Eur J 9:4611

97. Raehm L, Hamilton DG, Sanders JKM (2002) Synlett 11:1743

98. Hamilton DG, Lynch DE, Byriel KA, Kennard CHL (1997) Aust J Chem 50:439

99. Hamilton DG, Sanders JKM, Davies JE, Clegg W, Teat SJ (1997) Chem Commun 897

100. Hamilton DG, Montalti M, Prodi L, Fontani M, Zanello P, Sanders JKM (2000) Chem Eur J 6:608

101. Hansen JG, Feeder N, Hamilton DG, Gunter MJ, Becher J, Sanders JKM (2000) Org Lett 2:449

102. Hunter CA (1992) J Am Chem Soc 114:5303

103. Vögtle F, Meier S, Hoss R (1992) Angew Chem Int Ed Engl 31:1619

104. Adams H, Carver FJ, Hunter CA (1995) J Chem Soc Chem Commun 809

105. Leigh DA, Wong JKY, Dehez F, Zerbetto F (2003) Nature 424:174

106. Lane AS, Leigh DA, Murphy A (1997) J Am Chem Soc 119:11092

107. Gatti FG, Leigh DA, Nepogodiev SA, Slawin AMZ, Teat SJ, Wong JKY (2001) J Am Chem Soc 123:5983

108. Asakawa M, Brancato G, Fanti M, Leigh DA, Shimizuj T, Slawin AMZ, Wong JKY, Zerbetto F, Zhang S (2002) J Am Chem Soc 124:2939

109. Da Ros T, Guldi DM, Morales AF, Leigh DA, Prato M, Turco R (2003) Org Lett 5:689

110. Altieri A, Gatti FG, Kay ER, Leigh DA, Martel D, Paolucci F, Slawin AMZ, Wong JKY (2003) J Am Chem Soc 125:8644

111. Altieri A, Bottari G, Dehez F, Leigh DA, Wong JKY, Zerbetto F (2003) Angew Chem Int Ed 42:2296

112. Keaveney CM, Leigh DA (2004) Angew Chem Int Ed 43:1222

113. Jäger R, Vögtle F (1997) Angew Chem Int Ed Engl 36:930

114. Safarowsky O, Nieger M, Fröhlich R, Vögtle F (2000) Angew Chem Int Ed 39:1616

115. Li QY, Vogel E, Parham AH, Nieger M, Bolte M, Fröhlich R, Saarenketo P, Rissanen K, Vögtle F (2001) Eur J Org Chem 4041

116. Li XY, Illigen J, Nieger M, Michel S, Schalley CA (2003) Chem Eur J 9:1332

117. Seel C, Parham AH, Safarowsky O, Hübner GM, Vögtle F (1999) J Org Chem 64:7236 
118. Ashton PR, Chrystal EJT, Glink PT, Menzer S, Schiavo C, Spencer N, Stoddart JF, Tasker PA, White AJP, Williams DJ (1996) Chem Eur J 2:709 and references therein

119. Cantrill SJ, Pease AR, Stoddart JF (2000) J Chem Soc Dalton Trans 3715

120. Martínez-Díaz MV, Spencer N, Stoddart JF (1997) Angew Chem Int Ed Engl 36:1904

121. Rowan SJ, Cantrill SJ, Stoddart JF (1999) Org Lett 1:129

122. Rowan SJ, Stoddart JF (2000) J Am Chem Soc 122:164

123. Chiu S-H, Rowan SJ, Cantrill SJ, Stoddart JF, White AJP, Williams DJ (2002) Chem Eur J 8:5170

124. Hübner GM, Gläser J, Seel C, Vögtle F (1999) Angew Chem Int Ed 38:383

125. Reuter C, Wienand W, Hübner GM, Seel C, Vögtle F (1999) Chem Eur J 9:2692

126. Schmieder R, Hübner G, Seel C, Vögtle F (1999) Angew Chem Int Ed 38:3528

127. Mahoney JM, Shukla R, Marshall RA, Beatty AM, Zajicek J, Smith BD (2002) J Org Chem 67:1436

128. Ghosh P, Mermagen O, Schalley CA (2002) Chem Commun 2628

129. Linnartz P, Bitter S, Schalley CA (2003) Eur J Org Chem 4819

130. Loeb SJ, Wisner JA (1998) Angew Chem Int Ed 37:2838

131. Loeb SJ, Wisner JA (2000) Chem Commun 845

132. Loeb SJ, Wisner JA (2000) Chem Commun 1939

133. Hubbard AL, Davidson GJE, Patel RH, Wisner JA, Loeb SJ (2004) Chem Commun 138

134. Rowan SJ, Cantrill SJ, Cousins GRL, Sanders JKM, Stoddart JF (2002) Angew Chem Int Ed 41:898

135. Ashton PR, Belohradsky M, Philp D, Stoddart JF (1993) J Chem Soc Chem Commun 1269

136. Amabilino DB, Ashton PR, Belohradsky M, Raymo FM, Stoddart JF (1995) J Chem Soc Chem Commun 747

137. Ashton PR, Ballardini R, Balzani V, Belohradsky M, Gandolfi MT, Philp D, Prodi L, Raymo FM, Reddington MV, Spencer N, Stoddart JF, Venturi M, Williams DJ (1996) J Am Chem Soc 118:4931

138. Asakawa M, Ashton PR, Ballardini R, Balzani V, Belohradsky M, Gandolfi MT, Kocian O, Prodi L, Raymo FM, Stoddart JF, Venturi M (1997) J Am Chem Soc 119:302

139. Raymo FM, Stoddart JF (1997) Pure Appl Chem 69:1987

140. Amabilino DB, Ashton PR, Belohradsky M, Raymo FM, Stoddart JF (1995) J Chem Soc Chem Commun 751

141. Amabilino DB, Asakawa M, Ashton PR, Ballardini R, Balzani V, Belohradsky M, Credi A, Higuchi M, Raymo FM, Shimizu T, Stoddart JF (1998) New J Chem 959

142. Elizarov AM, Chang T, Chiu SH, Stoddart JF (2002) Org Lett 21:3565

143. Harrison IT (1972) J Chem Soc Chem Commun 231

144. Schill G, Beckmann W, Schweikert, Fritz H (1986) Chem Ber 119:2647

145. Raymo FM, Houk KN, Stoddart JF (1998) J Am Chem Soc 120:9318

146. Ashton PR, Baxter I, Fyfe, Raymo FM, Spencer N, Stoddart JF, White AJP, Williams DJ Venturi M (1998) J Am Chem Soc 120:2297

147. Macartney DH (1996) J Chem Soc Perkin Trans 22775

148. Händel M, Plevoets M, Gestermann S, Vögtle F (1997) Angew Chem Int Ed Engl 36: 1199

149. Hamilton DG, Feeder N, Teat SJ, Sanders JKM, (1998) New J Chem 1019

150. Fujita M, Ibukuro F, Hagihara H, Ogura K (1994) Nature 367:720

151. Dietrich-Buchecker CO, Geum N, Hori A, Fujita M, Sakamoto S, Yamaguchi K, Sauvage J-P (2001) Chem Commun 1182

152. Chichak K, Walsh MC, Branda NR (2000) Chem Commun 847

153. Gunter MJ, Bampos N, Johnstone KD, Sanders JKM (2001) New J Chem 25:166 
154. Hogg L, Leigh DA, Lusby PJ, Morelli A, Parsons S, Wong JKY (2004) Angew Chem Int Ed 43:1218

155. Mohr B, Weck M, Sauvage J-P, Grubbs RH (1997) Angew Chem Int Ed Engl 36:1308

156. Weck M, Mohr B, Sauvage J-P, Grubbs RH (1999) J Org Chem 64:5463

157. Arico F, Mobian P, Kern J-M, Sauvage J-P (2003) Org Lett 11:1887

158. Mobian P, Kern J-M, Sauvage J-P (2004) Angew Chem Int Ed 43:2392

159. Belfrekh N, Dietrich-Buchecker CO, Sauvage J-P (2000) Inorg Chem 38:5169

160. Dietrich-Buchecker CO, Rapenne GN, Sauvage J-P, (1997) Chem Commun 2053

161. Kidd TJ, Leigh DA, Wilson AJ (1999) J Am Chem Soc 121:1599

162. Hannam JS, Kidd JT, Leigh DA, Wilson AJ (2003) Org Lett 5:1907

163. Dayagi S, Degani Y (1970) In: Patai S (ed) The chemistry of the carbon-nitrogen double bond. Interscience, NewYork, p 64

164. Cantrill SJ, Rowan SJ, Stoddart JF (1999) Org Lett 1:1363

165. Amirsakis DG, Garcia-Garibay MA, Rowan SJ, Stoddart JF, White AJP, Williams DJ (2001) Angew Chem Int Ed 40:4256

166. Ashton PR, Becher J, Fyfe MCT, Nielsen MB, Stoddart JF, White AJP, Williams DJ (2001) Tetrahedron 57:947

167. Cantrill SJ, Youn GJ, Stoddart JF, Williams DJ (2001) J Org Chem 66:6857

168. Duggan SA, Fallon G, Langford SJ, Lau VL, Satchell JF, Paddon-Row MN (2001) J Org Chem 66:4419

169. Zehnder II DW, Smithrud DB (2001) Org Lett 3:2485

170. Clifford T, Abushamleh A, Busch DH (2002) Proc Natl Acad Sci USA 99:4830

171. Gibson HW, Yamaguchi N, Hamilton L, Jones JW (2002) J Am Chem Soc 124:4653

172. Tokunaga Y, Seo T (2002) Chem Commun 970

173. Tokunaga Y, Kakuchi S, Akasaka K, Nishikawa N, Shimomura Y, Isa K, Seo T (2002) Chem Lett 8:810

174. Furusho Y, Rajkumar GA, Oku T, Takata T (2002) Tetrahedron 58:6609

175. Chiu SH, Rowan SJ, Cantrill SJ, Ridvan L, Ashton PR, Garrell RL, Stoddart JF (2002) Tetrahedron 58:807

176. Elizarov AM, Chiu S-H, Glink PT, Stoddart JF (2002) Org Lett 4:679; (2000) Chem Eur J 6:2274

177. FujimoriiK, Yoshimoto H, Oae S (1980) Tetrahedron Lett 21:3385

178. Rowan SJ, Stoddart JF (1999) Org Lett 1:1913

179. Anelli PL, Ashton PR, Ballardini R, Balzani V, Delgado M, Gandolfi MT, Goodnow TT, Kaifer AE, Philp D, Pietraszkiewicz M, Prodi L, Reddington MV, Slawin AMZ, Spencer N, Stoddart JF, Vicent C, Williams DJ (1992) J Am Chem Soc 114:193

180. Ballardini R, Balzani V, Gandolfi MT, Gillard RE, Stoddart JF, Tabellini E (1998) Chem Eur J 4:449

181. Amabilino DB, Ashton PR, Stoddart JF, White AJP, Williams DJ (1998) Chem Eur J 4:460

182. Lyon AP, Macartney DH (1997) Inorg Chem 36:729

183. Fisher C, Nieger M, Mogck O, Bohmer V, Umgaro R, Vögtle F (1998) Eur J Org Chem 155

184. Benniston AC, Herrimen A, Lynch VM (1995) J Am Chem Soc 117:5275

185. Glink PT, Oliva AI, Stoddart JF, White AJP, Williams DJ (2001) Angew Chem Int Ed $10: 1870$

186. Kirby AJ (1996) Angew Chem Int Ed Engl 35:707

187. Nakash M, Clyde-Watson Z, Feeder N, Davies JE, Teat SJ, Sanders JKM (2000) J Am Chem Soc 122:5286

188. Horn M, Ihringer J, Glink PT, Stoddart JF (2003) Chem Eur J 9:4046

189. Cantrill SJ, Fyfe MCT, Heiss AM, Stoddart JF, White AJP, Williams DJ (2000) Org Lett 2:61

190. Luening U, Baumstark R, Peters K, von Schnering HG (1990) Liebigs Ann. 1990:129 
191. van Reijendam JW, Heeres GJ, Janssen MJ (1970) Tetrahedron 26:1291

192. Lewis KG, Mulquiney CE (1979) Aust J Chem 32:1079

193. Dominguez C, Escobar G, Plumet J, Gaset A, Rigal L (1986) An Quim Ser C 82:241

194. Kavallieratos K, Crabtree RH (1999) Chem Commun 2109

195. Youngman MA, Dax SL (2001) J Comb Chem 3:469

196. Yamaguchi N, Gibson HW (1998) Chem Commun 789

197. Ashton PR, Fyfe MCT, Hickingbottom SK, Stoddart JF, White AJP, Williams DJ (1998) J Chem Soc Perkin Trans 2:2117

198. Cantrill SJ, Fulton DA, Heiss AM, Pease AR, Stoddart JF, White AJP, Williams DJ (2000) Chem Eur J 6:2274

199. Chang T, Heiss AM, Cantrill SJ, Fyfe MCT, Pease AR, Rowan SJ, Stoddart JF, White AJP, Williams DJ (2000) Org Lett 2:2947

200. Kilbinger AFM, Cantrill SJ, Waltman AW, Day MW, Grubbs RH (2003) Angew Chem Int Ed 42:3281

201. Schwab P, Grubbs RH, Ziller JW (1996) J Am Chem Soc 118:100

202. Scholl M, Ding S, Lee CW, Grubbs RH (1999) Org Lett 1:953

203. Lee WJ, Whitesides GM (1993) J Org Chem 58:642

204. Raehm L, Hamann C, Kern J-M, Sauvage J-P (2000) Org Lett 2:1991

205. Kolchinski AG, Alcock NW, Roesner RA, Busch DH (1998) Chem Commun 1437

206. Furusho Y, Hasegawa T, Tsuboi A, Kihara N, Takata T (2000) Chem Lett 18

207. Furusho Y, Oku T, Hasegawa T, Tsuboi A, Kihara N, Takata T (2003) Chem Eur J 9:2895

208. Takata T, Kawasaki H, Kihara N, Furusho Y (2001) Macromolecules 34:5449

209. Furusho Y, Rajkumar GA, Oku T, Takata T (2002) Tetrahedron 58:6609

210. Field L, Oae S (eds) (1997) Organic chemistry of sulfur. Plenum, New York

211. Lee RT, Lee YC (1995) Acc Chem Res 28:321

212. Lundquist JL, Toone EJ (2002) Chem Rev 102:555

213. Kitov PI, Bundle DR (2003) J Am Chem Soc 125:16271

214. Ercolani G (2003) J Am Chem Soc 125:16097

215. Christensen T, Gooden DM, Kung JE, Toone EJ (2003) J Am Chem Soc 125:7357

216. Breslow R, Greenspoon N, Guo T, Zarzycki R (1989) J Am Chem Soc 111:8296

217. Zhang B, Breslow R (1993) J Am Chem Soc 113:9353

218. Drickamer K (1995) Struct Biol 2:437

219. Jayaraman N, Nepogodiev SA, Stoddart JF (1997) Chem Eur J 3:1193

220. Venema F, Nelissen HFM, Berthault P, Birlirakis N, Rowan AE, Feiters NC, Nolte RJM (1998) Chem Eur J 4:2237

221. Rockendorf N, Lindhorst TH (2001) Top Curr Chem 217:201

222. Turnbull WB, Stoddart JF (2002) Rev Mol Biotech 90:231

223. Gibson HW, Yamaguchi N, Hamilton L, Jones JW (2002) J Am Chem Soc 124:4653

224. Dubber M, Fréchet JMJ (2003) Bioconjugate Chem 14:239

225. Huang, F, Fronczek FR, Gibson HW (2003) J Am Chem Soc 125:9272

226. Mammen M, Choi S-K, Whitesides GM (1998) Angew Chem Int Ed 37:2754

227. Lee RT, Lee YC (2000) Glyconjugate J 17:543

228. Kiessling LL, Gestwicki JE, Strong LE (2000) Curr Opin Chem Biol 4:696

229. Arranz-Plaza E, Tracy AS, Siriwardena A, Pierce JM, Boons GJ (2002) J Am Chem Soc 124:13035

230. Rao J, Lahiri J, Isaacs L, Weiss RM, Whitesides GM (1998) Science 280:708

231. Kitov PI, Sadawska JM, Mulvey G, Armstrong GD, Ling H, Pannu NS, Read RJ, Bundle DR (2000) Nature 403:669

232. Rao J, Lahiri J, Weiss RM, Whitesides GM (2000) J Am Chem Soc 122:2698

233. Calama MC, Timmerman P, Reinhoudt DN (2000) Angew Chem Int Ed 39:755 
234. Gestwicki JE, Cairo CW, Strong LE, Oetjen KA, Kiessling LL (2002) J Am Chem Soc 124:14922

235. Woller EK, Walter ED, Morgan JR, Singel DJ, Cloninger MJ (2003) J Am Chem Soc 125:8820

236. Tobey SL, Anslyn EV (2003) J Am Chem Soc 125:10963

237. Ashton PR, Fyfe MCT, Glink PT, Stephan MJ, Stoddart JF, White AJP, Williams DJ (1997) J Am Chem Soc 119:12514

238. Chang T, Heiss AM, Cantrill SJ, Fyfe MCT, Pease AR, Rowan SJ, Stoddart JF, Williams DJ (2000) Org Lett 2:2943

239. Fulton DA, Cantrill SJ, Stoddart JF (2002) J Org Chem 67:7968

240. Lowe JN, Fulton DA, Chiu S-H, Elizarov AM, Cantrill SJ, Rowan SJ, Stoddart JF (2004) J Org Chem 69:4390

241. Fyfe MCT, Lowe JN, Stoddart JF, Williams DJ (2000) Org Lett 2:1221

242. Balzani V, Clemente-Leon M, Credi A, Lowe JN, Badjic JD, Stoddart JF, Williams DJ (2003) Chem Eur J 9:5348

243. Kolb HC, Finn MG, Sharpless KB (2001) Angew Chem Int Ed 40:2004

244. Badjic JD, Balzani V, Credi A, Lowe JN, Silvi S, Stoddart JF (2004) Chem Eur J 10:1926

245. Badjic JD, Cantrill SJ, Stoddart JF (2004) J Am Chem Soc 126:2288

246. Badjic JD, Balzani V, Credi A, Silvi S, Stoddart JF (2004) Science 303:1845

247. Ashton PR, Ballardini R, Balzani V, Baxter I, Credi A, Fyfe MCT, Gandolfi MT, GómezLópez M, Martínez-Díaz MV, Piersanti A, Spencer N, Stoddart JF, Venturi M, White AJP, Williams DJ (1998) J Am Chem Soc 120:11932

248. Wisner JA, Beer PD, Drew MGB, Sambrook MR (2002) J Am Chem Soc 124:12469

249. Coumans RGE, Elemans JAAW, Thordarson P, Nolte RJM, Rowan AE (2003) Angew Chem Int Ed 42:650

250. Badjic JD, Cantrill SJ, Grubbs RH, Guidry EN, Orenes R, Stoddart JF (2004) Angew Chem Int Ed 43:3273

251. Stoddart JF (1992) Chem Aust 59:576,581

252. Gómez-López M, Preece JA, Stoddart JF (1996) Nanotechnology 7:183

253. Balzani V, Gómez-López M, Stoddart JF (1998) Acc Chem Res 31:405

254. Tseng H-R, Stoddart JF (2002) In: Astruc D (ed) Modern arene chemistry. Wiley-VCH 574

255. Harada A (2001) Acc Chem Res 34:456

256. Schalley CA, Beizai K, Vögtle F (2001) Acc Chem Res 34:465

257. Ballardini R, Balzani V, Credi A, Gandolfi MT, Venturi M (2001) Struct Bonding 99:55

258. Stanier CA, Alderman SJ, Claridge TDW, Anderson HL (2002) Angew Chem Int Ed 41:1769

259. Balzani V, Credi A, Venturi M (2002) Chem Eur J 8:5524

260. Anelli PL, Spencer N, Stoddart JF (1991) J Am Chem Soc 113:5131

261. Bissell RA, Córdova E, Kaifer AE, Stoddart JF (1994) Nature 369:133

262. Flood AH, Ramirez RJA, Deng W-Q, Muller RP, Goddart III WA, Stoddart JF (2004) Aust J Chem 57:301

263. Livoreil A, Dietrich-Buchecker CO, Sauvage J-P (1994) J Am Chem Soc 116:9399

264. Collin J-P, Gaviña P, Sauvage J-P (1997) New J Chem 21:525

265. Raehm L, Kern J-M, Sauvage J-P (1999) Chem Eur J 5:3310

266. Martínez-Díaz M-V, Spencer N, Stoddart JF (1997) Angew Chem Int Ed Engl 36:1904

267. Kelly TR, De Silva H, Silva RA (1999) Nature 401:150

268. Elizarov AM, Chiu S-H, Stoddart JF (2002) J Org Chem 67:9175

269. Raehm L, Kern J-M, Sauvage J-P (1999) Chem Eur J 5:3310

270. Gaviña P, Sauvage J-P (1997) Tetrahedron Lett 38:3521 
271. Armaroli N, Balzani V, Collin J-P, Gaviña P, Sauvage J-P (1999) J Am Chem Soc 121:4397

272. Ashton PR, Ballardini R, Balzani V, Credi A, Dress KR, Ishow E, Kleverlaan CJ, Kocian O, Preece JA, Spencer N, Stoddart JF, Venturi M, Wenger S (2000) Chem Eur J 6:3558

273. Feringa BL, Koumara N, van Delden RA, Ter Wiel MKJ (2002) Appl Phys A 75:301

274. Blanco MJ, Jimenez MC, Chambron JC, Heitz V, Linke M, Sauvage J-P (1999) Chem Soc Rev 28:293

275. Mulder A, Jukovic A, Lucas LN, van Esch J, Feringa BL, Huskens J, Reinhoudt DN (2002) Chem Commun 2734

276. Preece JA, Stoddart JF (1994) Nanobiology 3:149

277. Colasson BX, Dietrich-Buchecker CO, Jimenez-Molero MC, Sauvage J-P (2002) J Phys Org Chem 15:476

278. Pease AR, Jeppesen JO, Stoddart JF, Luo Y, Collier CP, Heath JR (2001) Acc Chem Res 34:433

279. Hess H, Clemmens J, Qin D, Howard J, Vogel V (2001) Nano Lett 1:235

280. Yurke B, Turberfield AJ, Mills AP Jr, Simmel FC, Neumann JL (2000) Nature 406:605

281. Collin JP, Dietrich-Buchecker CO, Gaviña P, Jimenez-Molero MC, Sauvage J-P (2001) Acc Chem Res 34:477

282. Raehm L, Kern J-M, Sauvage J-P, Hamann C, Palacin S, Bourgoin J-P (2002) Chem Eur J 8:2153

283. Tseng H-R, Wu DM, Fang NXL, Zhang X, Stoddart JF (2004) Chem Phys Chem 5:111

284. Asakawa M, Higuchi M, Mattersteig G, Nakamura T, Pease AR, Raymo FM, Shimizu T, Stoddart JF (2000) Adv Mater 12:1099

285. Ahuja RC, Caruso PL, Mobius D, Wildburg G, Ringsdorf H, Philp D, Preece JA, Stoddart JF (1993) Langmuir 9:1534

286. Ahuja RC, Caruso PL, Mobius D, Philp D, Preece JA, Ringsdorf H, Stoddart JF, Wildburg G (1996) Thin Solid Films 285:671

287. Brown CL, Jonas U, Preece JA, Ringsdorf H, Seitz M, Stoddart JF (2000) Langmuir $16: 1924$

288. Long B, Nikitin K, Fitzmaurice D (2003) J Am Chem Soc 125:15490

289. Weber N, Hamann C, Kern J-M, Sauvage J-P (2003) Inorg Chem 42:6780

290. Luo Y, Collier CP, Jeppesen JO, Nielsen KA, Delonno E, Ho G, Perkins J, Tseng H-R, Yamamoto T, Stoddart JF, Heath JR (2002) Chem Phys Chem 3:519

291. Diehl MR, Steuerman DW, Tseng H-R, Vignon SA, Star A, Celestre PC, Stoddart JF, Heath JR (2003) Chem Phys Chem 4:1335 